\title{
Sound Coiled-Tubing Drilling Practices
}

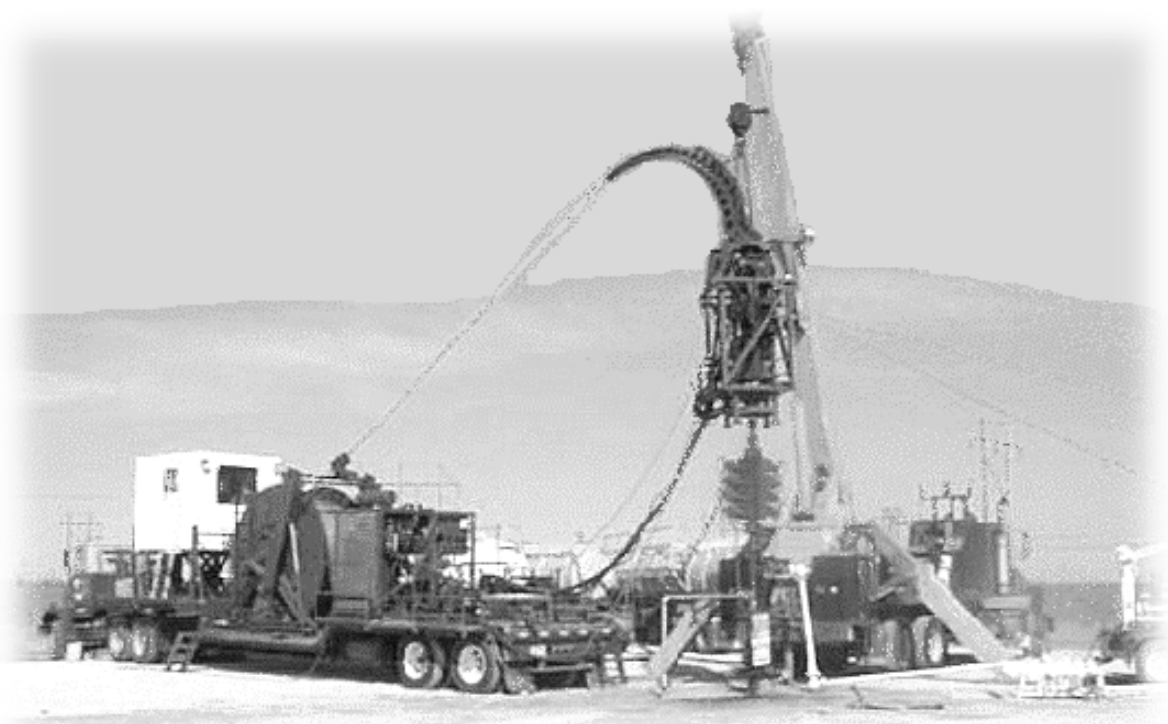

U.S. Department of Energy

National Energy Technology Laboratory

U.S. Department of the Interior

Minerals Management Service

DOE/NETL-2002/1170

September 2001

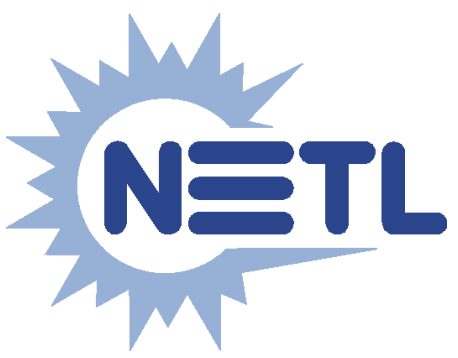




\section{Disclaimer}

This report was prepared as an account of work sponsored by agencies of the United States Government. Neither the United States Government nor any agency thereof, nor any of their employees, makes any warranty, express or implied, or assumes any legal liability or responsibility for the accuracy, completeness, or usefulness of any information, apparatus, product, or process disclosed, or represents that its use would not infringe privately owned rights. Reference herein to any specific commercial product, process, or service by trade name, trademark, manufacturer, or otherwise does not necessarily constitute or imply its endorsement, recommendation, or favoring by the United States Government or any agency thereof. The views and opinions of authors expressed herein do not necessarily state or reflect those of the United States Government or any agency thereof.

All applicable federal, state and local governmental rules, regulations or restrictions, now in effect or which my be promulgated, take precedence over the suggestions in this manual. No suggested method, practice, precaution or program set forth in this guide shall be deemed to establish a legal standard of conduct or a legal duty, the violation of which would constitute negligence of any degree in any legal proceeding. 


\section{Sound Coiled-Tubing Drilling Practices}

Final Report

(February - August 2001)

Prepared for:

U.S. Department of Energy

National Energy Technology Laboratory

U.S. Department of the Interior

Minerals Management Service

Prepared by:

Mr. Thomas Williams and Mr. Greg Deskins

Maurer Technology Inc.

2916 West T.C. Jester

Houston, Texas

Mr. Stephen L. Ward

Advantage Energy Services Ltd.

Mr. Mel Hightower

Consulting Engineer

DOE/NETL-2002/1170

September 2001

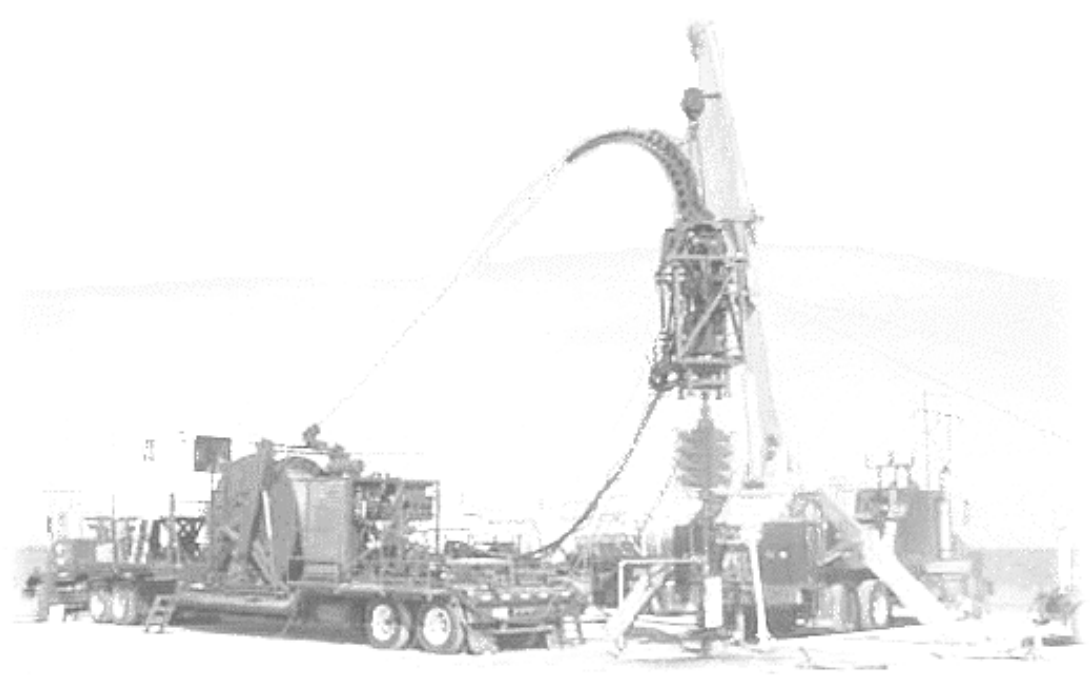




\section{Acknowledgements}

We gratefully acknowledge the support and contributions of the project managers from the Minerals Management Service (Bill Hauser) and the Department of Energy (Roy Long).

A significant volume of technical data was contributed to this manual by Maurer Technology from technical reports and other deliverables of the DEA-67 joint-industry project on coiledtubing and slim-hole operations.

The authors also appreciate the contributions of John Misselbrook of BJ Services, who reviewed the draft manual and provided a variety of very useful comments. 


\section{Table of Contents}

1. INTRODUCTION

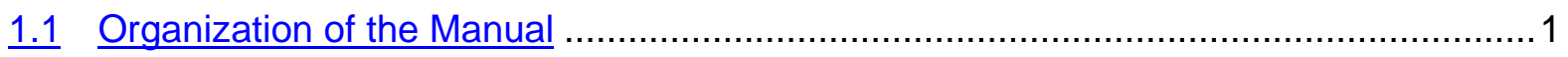

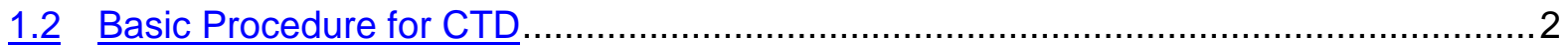

2. PRE-JOB PLANNING - ENGINEERING ............................................................ 5

2.1 Overview of Engineering Analysis ......................................................................

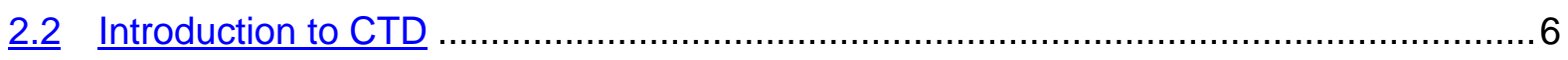

2.3 Initial Well Research and Planning ..................................................................

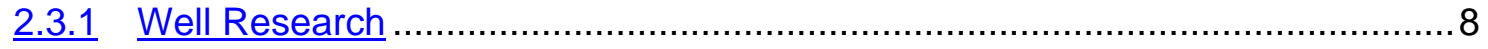

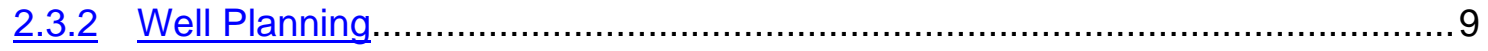

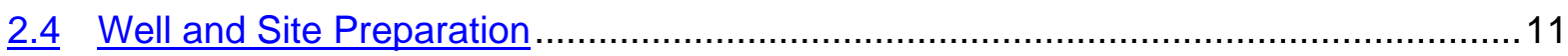

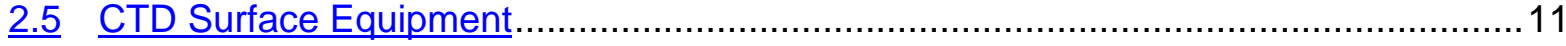

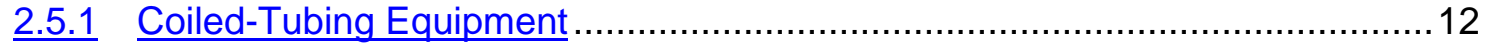

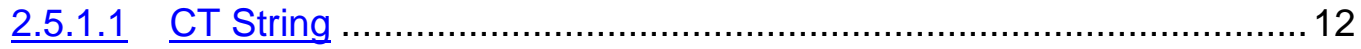

2.5.1.2 CT Injector Head .................................................................. 15

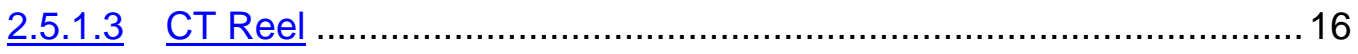

2.5.1.4 CT Power Pack.......................................................................... 17

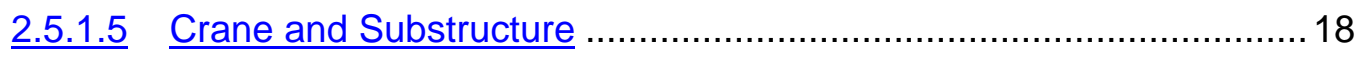

2.5.1.6 Pipe-Handling Equipment................................................................. 19

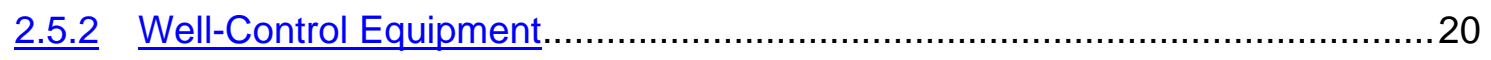

2.5.2.1 Well-Control Equipment Testing ....................................................2

2.5.2.2 Well-Control Procedures and Responsibilities ……………............2 23

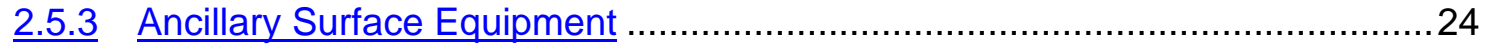

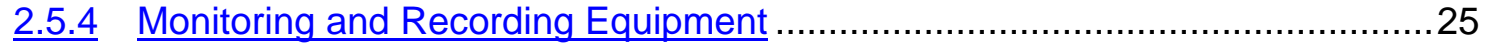

2.5.4.1 CTU Monitoring Equipment ……................................................. 25

2.5.4.2 Drilling Fluid Monitoring Equipment..............................................26

2.5.4.3 Wellbore Steering and Navigation ...................................................26

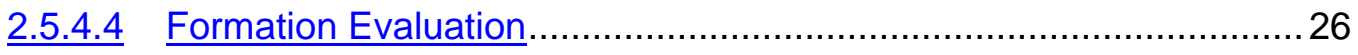

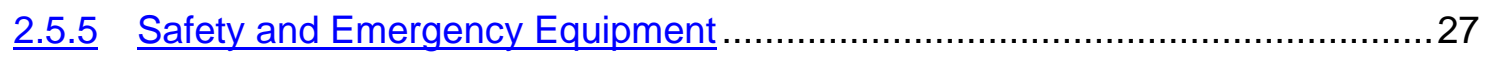




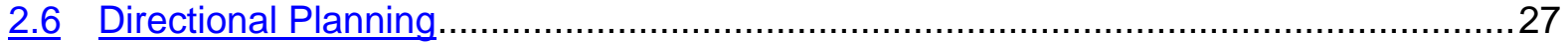

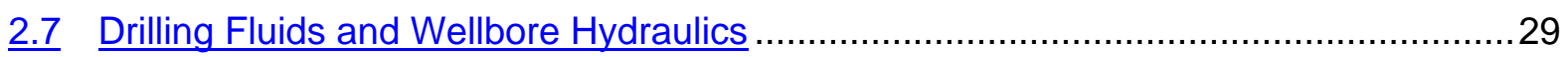

2.7.1 Hole Cleaning and Annular Velocity ..........................................................33

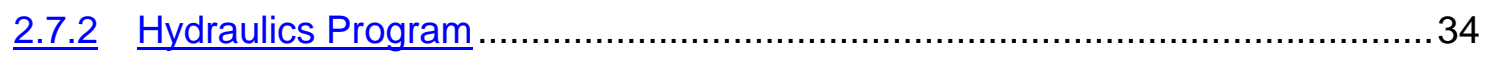

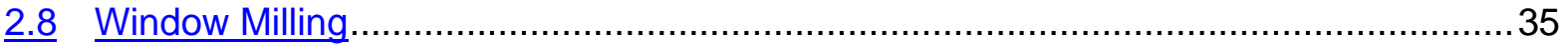

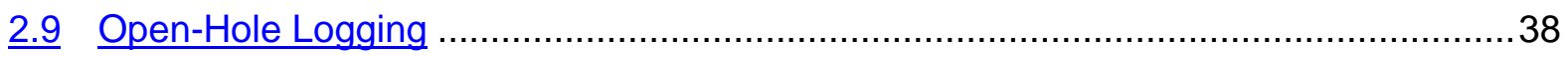

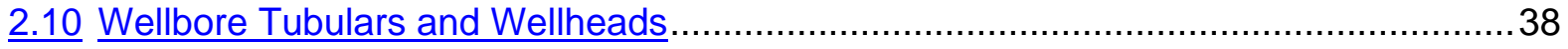

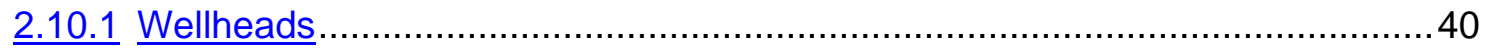

2.10.1.1 New Well.................................................................................... 40

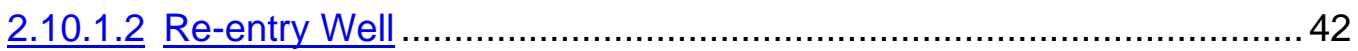

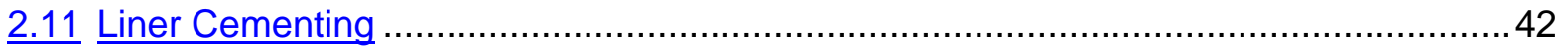

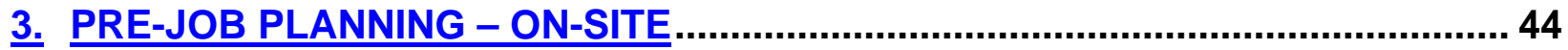

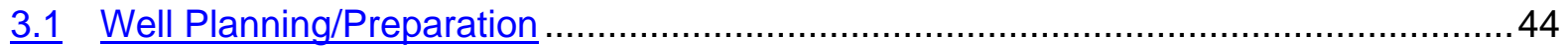

3.2 CT Management and Safe Operations .................................................................. 48

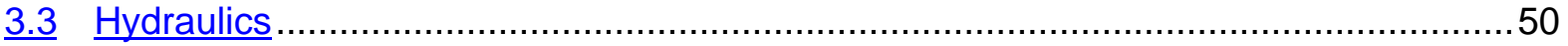

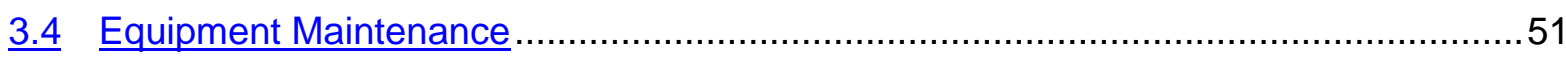

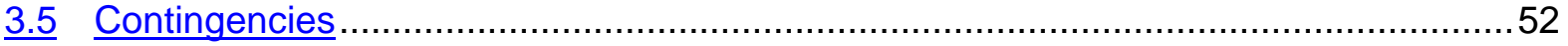

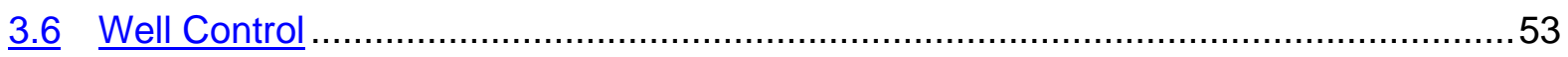

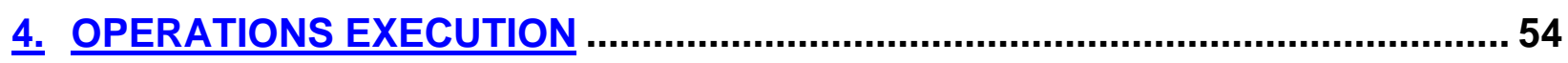

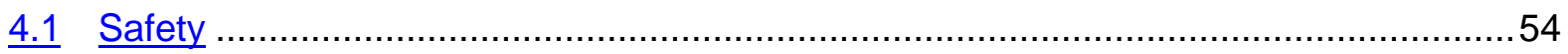

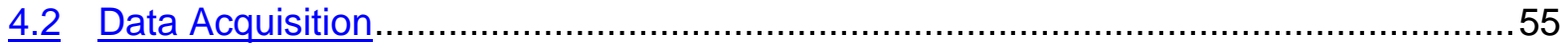

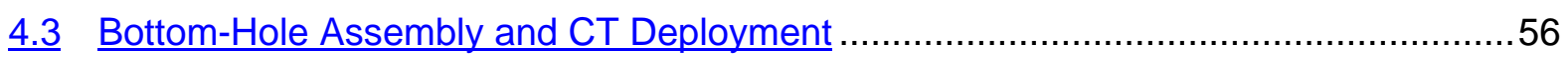

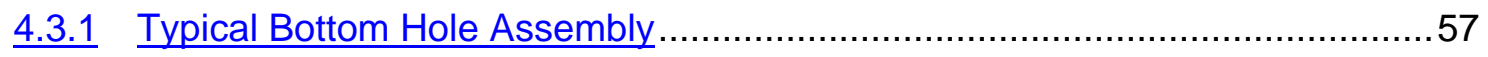

4.3.1.1 CT Connector (CTC) ………................................................

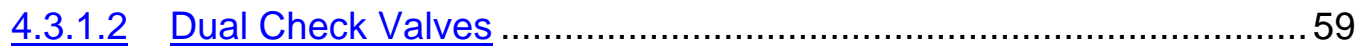

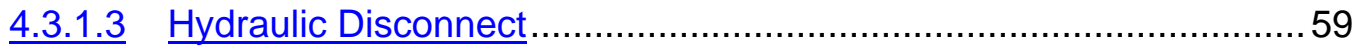

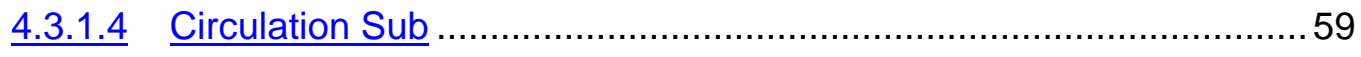

4.3.1.5 Non-Rotating Joint ..................................................................... 59

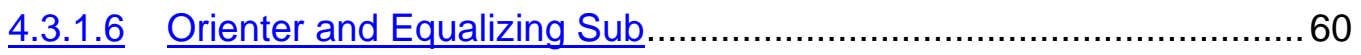

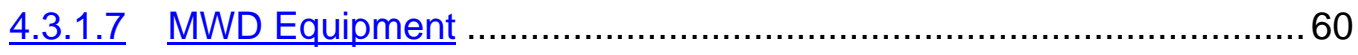


4.3.1.8 Downhole Mud Motors...................................................................61

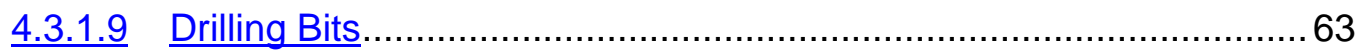

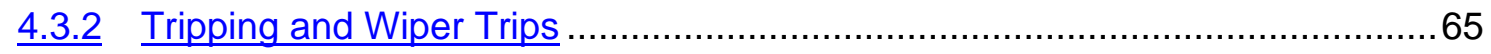

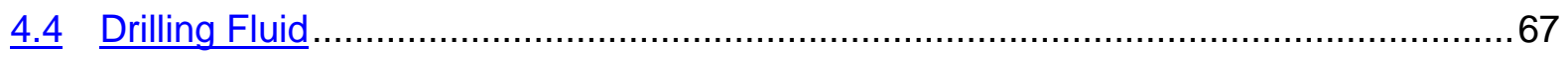

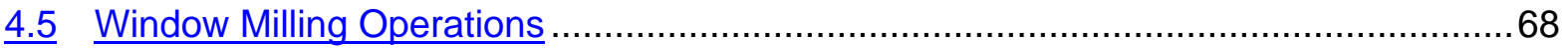

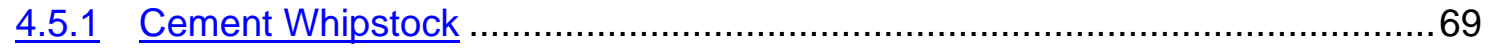

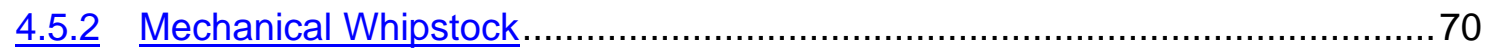

4.6 Production Liner: Running and Cementing........................................................... 72

4.6.1 Liner Running: Blank Liner ................................................................. 73

4.6.2 Liner Cementing ...........................................................................

4.6.3 Liner Running: Pre-Perforated or Slotted Liner ….....................................76

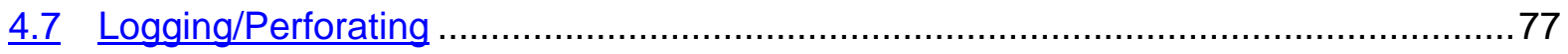

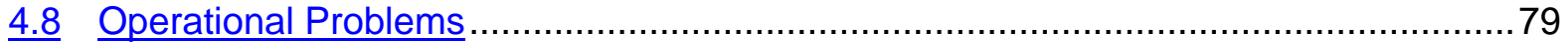

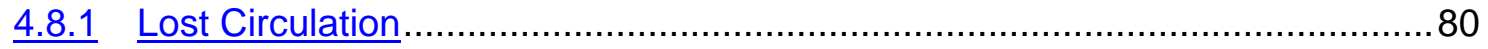

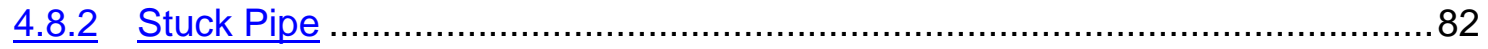

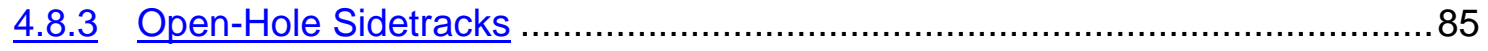

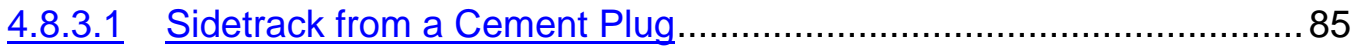

4.8.3.2 Sidetrack from a Mechanical Plug ............................................... 87

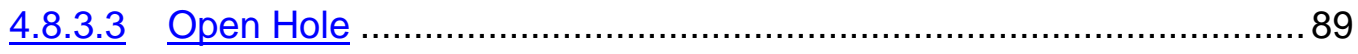

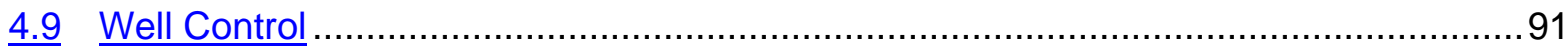

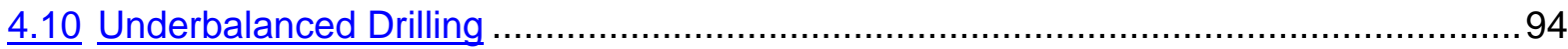

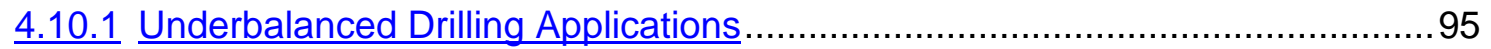

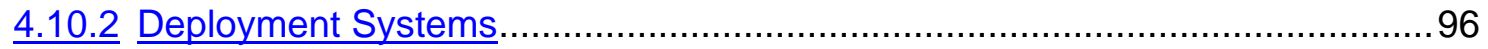

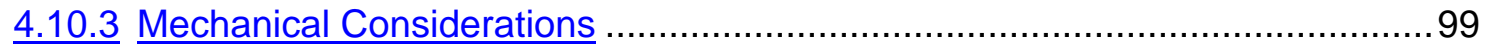

4.10.3.1 Hydraulically Operated BHA Components.........................................99

4.10.3.2 Tubing Collapse Pressure ………............................................. 100

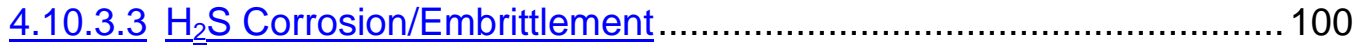

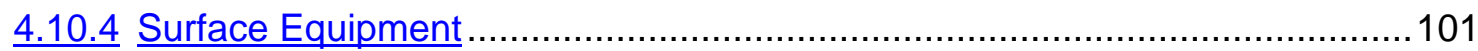

4.10.5 Well Control ........................................................................................... 102

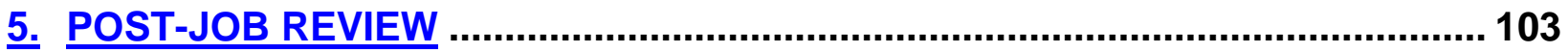

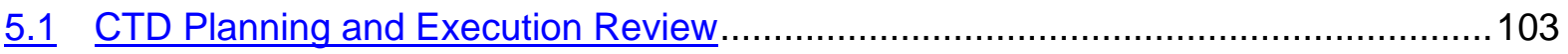




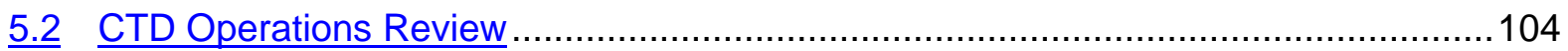

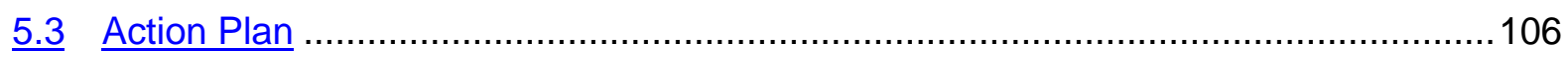

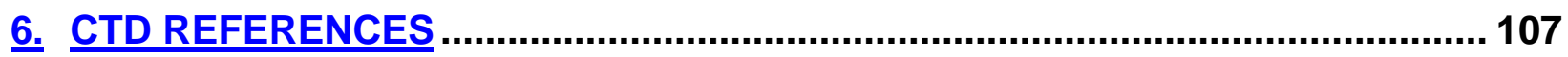

\section{ATTACHMENTS}

Attachment 1: Example CTD Check Lists............................................................... A-1

Attachment 2: Example CTD Sidetrack Well Summary .............................................. A-7

Attachment 3: Example CTD Wellbore Diagram ....................................................... A-9

Attachment 4: Example CTD BOP Design ............................................................... A-11 


\section{Introduction}

\subsection{ORGANIZATION OF THE MANUAL}

This Coiled-Tubing Drilling (CTD) Sound Practices Manual provides tools needed by CTD engineers and supervisors to plan, design and perform safe, successful CTD operations. As emphasized throughout, both careful planning and attention to detail are mandatory for success. A bibliography of many useful CTD references is presented in Chapter 6 .

This manual is organized according to three processes: 1) Pre-Job Planning Process, 2) Operations Execution Process, and 3) Post-Job Review Process. Each is discussed in a logical and sequential format.

\section{PRE-JOB PLANNING (Chapters 2 and 3)}

The purpose of the pre-job planning process is to interpret the proposed wellbore configuration and objectives of the well. This process involves input from all parties participating in the project with emphasis on engineering planning and on-site preparation. Objectives of this process are:

- Clearly define objectives of the CTD job

- Data acquisition and review as well as analysis of feasibility

- Develop a detailed project scheduling chart outlining critical tasks and milestones

- Initial design of the wellbore along with procedures and approvals

- Estimated cost and equipment procurement

- Safe overall operational plan

\section{OPERATIONS EXECUTION (Chapter 4)}

Safe and successful completion of wellbore drilling operations is the primary purpose of the operations execution process. Effective monitoring, recording and correct interpretation of the data acquired during operations are crucial to the success of the project and future CTD projects. This process provides the following outcomes:

- Data acquisition and quality assurance of data

- A cost-effective wellbore drilled to meet objectives as set forth in Pre-Job Planning Process

- Safe overall operation 


\section{POST-JOB REVIEW (Chapter 5)}

A comprehensive review of the execution, process, data and results of the CTD Operation is the ultimate purpose of the post-job review process. This process is designed to validate the data acquired and transform it into information that can be used to modify and improve operations for subsequent CTD jobs. If an operator undergoes the extra effort required for collecting highquality data, then those data should be used to derive all possible benefits. This information needs to be distributed to all parties for edification for future CTD projects. The following outcomes are provided from this process:

- An assessment of the CTD operations and modifications to the planning and execution processes

- A review of the data/information for input into CTD operations

- A review of the results of the well (i.e., were the objectives for the well met?)

- More efficient operations on future CTD jobs

- CTD data base for monitoring operational efficiency and cost reduction

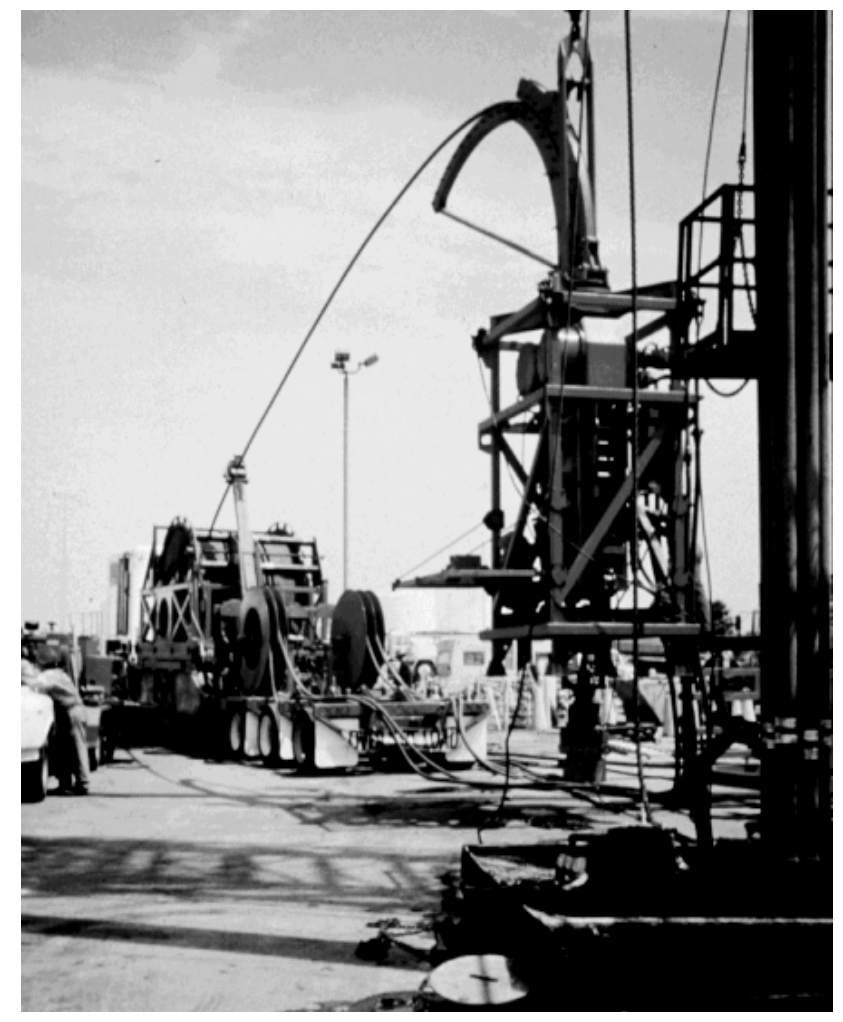

Figure 1. CTD Operation

\subsection{BASIC PROCEDURE FOR CTD}

As a general rule, these steps should be followed to drill a well using CT:

1. Clearly define the objectives of the well. Why use CT for this well? Re-entry or new? Underbalanced, balanced, or over-balanced fluid? Hole size? Cuttings transport? Liner or open-hole completion?

2. Review the well history and mechanical condition of an existing well. If a new well, review offset well data. Well should be screened in the three main areas of mechanical condition, reservoir quality and issues, and directional considerations for reaching the target.

3. Perform feasibility study and identify drilling hazards, risks and controls. Determine what workover operations are required prior to the CTD rig coming to location and write procedures for this work. 
4. Design and prepare a preliminary directional plan.

5. Obtain regulatory approval for pre-rig work and CTD operation. Perform preCTD rig work.

6. Begin site preparation review with the CT contractor.

7. Review CT equipment needed for the project and determine what equipment meets the requirements of this particular project.

8. Determine auxiliary equipment required and its position in relation to the CTD rig.

9. Determine required well-control equipment and determine proper configuration for the proposed well and anticipated conditions.

10. Review and finalize the directional plan for the well. Discuss with the directional driller and determine the bottom-hole assembly (BHA) that will be needed to accomplish this plan.

11. Choose a drilling fluid based on formation information provided and run wellbore hydraulics calculations to determine if fluid and system are appropriate for the well conditions.

12. Determine type of window-milling operation required for the well.

13. Decide if any open-hole logging is required and if the well will be perforated.

14. Evaluate need for a liner in the open hole. If a liner is needed, choose size and type of liner to be run and if cementing is required.

15. Write final drilling procedure. Set up and conduct a pre-spud meeting.

16. Make changes/additions to the procedure. Write any contingency procedures.

17. Prepare site for the rig and move in rig.

18. Ensure all equipment is inspected and maintenance records are available.

19. Confirm that all procedures are written and in place.

20. Call regulatory agency, directional tool personnel, directional driller and BHA supplier as well as any specialty tools, liner and liner equipment.

21. If window was not milled during pre-rig work, mill window in existing well.

22. Swap out milling fluid for drilling fluid and drill well according to directional plan.

23. Record and report all required data during the drilling operation.

24. Run open-hole logs as required. 
25. Run liner in open hole, if required. If cementing is necessary, cement liner according to procedure.

26. Log and perforate as necessary.

27. Rig down CT unit and move off of well.

28. Accumulate and assimilate all data from the CTD project.

29. Review with the CTD team the results from the project. Perform vendor review with each vendor.

30. Enter all data into the database. Make changes and document for future wells. 


\section{Pre-Job Planning - Engineering}

\section{Summary}

The Pre-Job Planning Process is a primary key to a successful CTD project and meeting the desired objectives. There are two essential elements to this process 1) Preliminary Engineering (see Chapter 2) and 2) On-Site Preparation (see Chapter 3).

Preliminary engineering requires several steps to ensure the well is ready for CTD operations. Through thorough research and planning, the well is screened for suitability as well as feasibility, and all reasonable alternative remedial operations are considered. About half of CTD projects are sidetracks from existing wells and half are new wells. Sidetracking operations involve understanding the extent of remaining reserves and the planned wellbore position in relation to the existing wellbore. A preliminary directional plan is determined and then generated. Also, if applicable, CT simulation studies are performed to determine if the proposed well can be re-entered and worked over with smaller diameter CT for later operations. Plans are made for performing all of the needed preparatory work (i.e., P\&A existing well, run caliper survey, set whipstock, etc.) before the CTD unit is set up over the well or the work is performed due to timing or other issues.

\subsection{OVERVIEW OF ENGINEERING ANALYSIS}

Screening of the candidates for CTD is a core priority for the engineering team. As part of the screening process, the geologist, reservoir engineer, and CTD engineer provisionally agree on the target polygon. For re-entries, the kick-off point is determined by the CTD engineer and is generally located in the production casing/liner and below the intermediate casing shoe. Every attempt should be made to avoid milling a window in areas of difficult formations, especially known sloughing shales. Also, if feasible, the kick-off point should be located deep enough to allow future CTD sidetracks. The cement bond log, if available, is reviewed and good cement coverage behind the casing where the window is to be milled is recommended. The open-hole caliper, if available, should be reviewed as well to determine if any washouts exist in the vicinity of the proposed kick-off point.

After the kick-off point is determined, the first directional plan is developed and approved by the reservoir engineer and the geologist before proceeding. The condition of the casing/liner and tubing (if applicable) is determined. A review of well records is undertaken to check that there are no unusual restrictions in the wellbore that might inhibit setting the whipstock or running the CT drilling assembly. Casing damage or restrictions (such as scale, cement nodes or fill) will affect the P\&A procedures or the final choice of whipstock setting depth/cement kick-off plug top. Any required tubing/casing pressure tests, caliper surveys and drift runs should be requested at this time. 
The CTD engineer should review the equipment to be used on the project to ensure that it meets the requirements of the job. Fluids to be used for the operation are determined and hydraulics checked to ensure the system will handle the required rates and pressures. Wellcontrol equipment is inspected, checked, and tested to ensure that all regulatory as well as additional job requirements are met. Final preparation of the procedure is completed and approved prior to informing on-site personnel about the job. The pre-spud meeting is scheduled, during which the job is fully reviewed, as well as ascertaining that all personnel involved understand the objectives of the well.

\subsection{INTRODUCTION TO CTD}

Coiled Tubing Drilling (CTD) as performed today is generally considered to have begun in 1991 with a horizontal sidetrack re-entry drilled by Oryx Energy in the Austin Chalk of Texas. From that time to the present, the technology advanced rapidly, with on the order of 4000 CTD operations completed (Figure 2). Currently, about 900-1000 CTD wells are completed a year, including about 120 directional re-entries and 800 new shallow vertical wells (many of these vertical wells are in Canada). Several key factors have contributed to the rapid rise in activity:

- The CT service industry has achieved a level of maturity capable of providing necessary equipment and basic techniques with the required degree of reliability.

- Technical advantages exist for CTD that enable it to compete in and sometimes dominate certain "niche" markets.

- Technical advances have occurred in directional-drilling technology and underbalanced drilling techniques.
CT Drilling Jobs

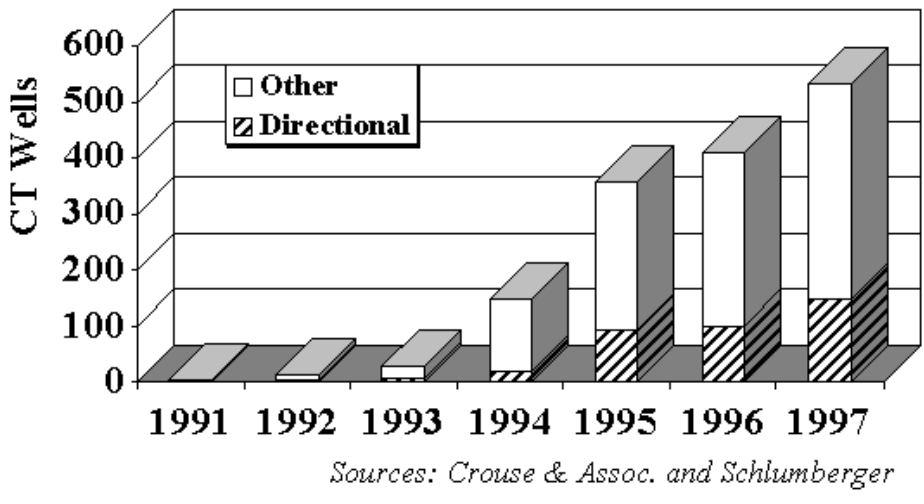

Figure 2. Early Growth of CTD

- The industry has gained greater understanding of the capabilities and limitations of CTD, enabling better candidate selection and ultimately a higher success rate.

Understanding the criteria for selection of appropriate CTD candidates is possibly the most influential factor for ensuring the success of any CTD project. This requires a thorough knowledge and understanding of the capabilities and limitations of the equipment and techniques in use. Preparation for a CTD project typically involves a considerable amount of pre-planning and research, as well as coordinating the input of several specialist disciplines. These disciplines and their responsibilities are as follows (note: not all disciplines will be required for every CTD project): 
1. CTD Project Manager - in charge of overall management of the CTD project. In most cases, this will be an employee from the operator (if desired).

2. CTD Engineer - responsible for the technical aspects of the CTD project. Prepares all procedures and obtains regulatory approvals.

3. CTD Supervisor - responsible for coordination and implementation of all wellsite activities.

4. CT Tool Pusher - responsible for operations and personnel in the execution of the drilling program.

5. CT Driller - responsible for operation of the CT equipment for safe and efficient drilling of the well.

6. Reservoir Engineer - responsible for determining well placement and reserves.

7. Geologist - responsible for well placement in targeted sand and for determining any formation problems that may be encountered (i.e. faults, high-permeability streaks, changes in rock properties, etc.).

8. Directional Driller - responsible for on-site execution of well placement. Ensures all directional equipment is functioning and properly assembled.

\subsection{INITIAL WELL RESEARCH AND PLANNING}

Sound CTD operations require careful and complete pre-planning and exhaustive research. The first task for the CTD project manager is to interpret the well proposal and objectives using the following criteria:

Define ultimate objectives. The project objectives must be clearly defined and benchmarks established for measuring achievements. Is the objective to expand CTD research, or to provide a commercially viable product, or to drill for appraisal, production, delineation or exploration purposes? Will this wellbore be utilized again for another sidetrack? If so, how should the completion be set up to accommodate future sidetracks?

Acquire accurate data. The complete well history including a mechanical history and reservoir considerations is generated. An annotated production plot of the well highlighting fluctuations in production is needed. An updated wellbore sketch with all tubular dimensions noted as well as any problems such as tight spots, holes in tubing/casing, plugs, fill and fish left in hole should be validated by the mechanical history. Formation description of each horizon to be encountered including but not limited to bottom-hole temperature and pressure, rock properties, formation dip angle, lost-circulation zones, faults and/or high permeability streaks, and any offset well data available are supplied by the Reservoir Engineer and/or Geologist. 
What is the primary reason for using CTD? Does the condition of the well and the equipment to be used indicate a reasonable chance of success? The fewer variables introduced to the project, the greater the chance for success.

Give careful attention to details concerning equipment procurement, personnel assignment, and timing of start up. A detailed project scheduling chart to reflect critical tasks is needed. Is the time frame acceptable for obtaining personnel and equipment, and conducting any pre-testing or trial?

Pre-test whenever uncertain and wherever possible. It is advisable to conduct tests/trials on operations that are technically complex, or which utilize new concepts.

\subsubsection{Well Research}

It is essential that all information concerning the well be freely communicated to the parties involved. The Reservoir Engineer (RE) should confer with the Geologists and ensure that the placement of the well will be optimal as well as feasible. It is imperative that the field map, reservoir isopach, and formation cross-section be reviewed in detail prior to proposing the well to the CTD Engineer. Research and discussion of the type of well needed to accomplish the objective should be fully resolved (e.g., will this be a deepening of the well, a sidetrack or a well drilled from the surface?). There are three major areas of criteria that must be considered for candidate selection:

1. Mechanical

- minimum restrictions

- competent tubing, caliper history

- true vertical depth (TVD) distance from packer to target zone to incorporate the kick-off point and landing horizontal

- well inclination: vertical, high angle (inclination $50-90^{\circ}$ ) or horizontal

- two-string kick out due to low packer or damaged straddle completion

- amount and/or cost of preparatory work for CT rig

- $\quad$ what is the future utilization for this wellbore? (set up completion to allow for future through tubing work)

- indications of potential lost circulation in target sands: injection well, fraced, or losses noted in drilling original hole 
2. Reservoir

- Will proposed target cross faults or sands with differential pressures too high to handle (i.e., will high pressures cause excessive losses to lower pressure zone)?

- Existing reserves value of current completion - too high to risk?

- Existing production rates and sand quality in target zone - too poor for even horizontal to provide sufficient rate?

- Net pay with knowledge of water/oil contact and gas/oil contact

- Object of sidetrack?

- Horizontal for productivity

- Extend or convert to horizontal to reach infill target

- Replace damaged production liner with new twin well

- Do sand quality/formation damage issues dictate running a slotted liner versus a cemented/perforated liner?

- Reservoir description: rock type, faulting, geological changes in zone, formation dip

3. Directional

- KOP in optimal direction and preferably not in shale zone. Is there good cement behind casing at this point?

- Horizontal length needed - can CT reach target with acceptable WOB?

- Azimuth changes - will coil lose too much weight transfer while steering toward target?

4. Other

- Can the formations to be encountered be drilled with CT? If rock types dictate the use of roller-cone bits, is sufficient bit weight available?

\subsubsection{Well Planning}

An information package including the research and discussion of location and target for the well should be sent to the CTD Engineer for review and preliminary study. The CTD engineer should review in extensive detail the information package, well history and wellbore sketch for any possible problems that might change the risk of the well. Once it is determined that the well 
is a viable candidate for CTD, a preliminary directional plan should be developed by the CTD engineer and the Directional Planner. A step-by-step procedure should be followed to

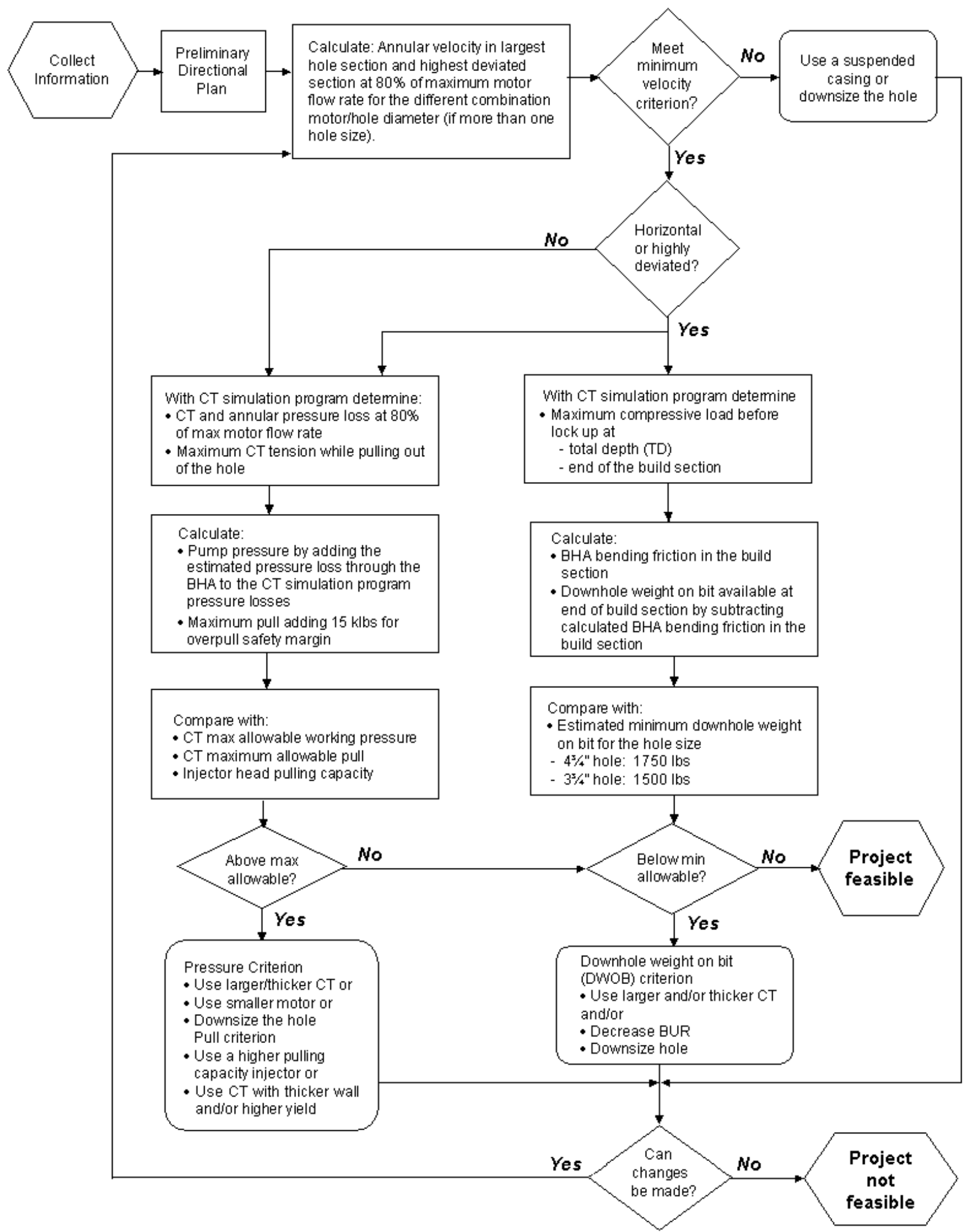

Figure 3: Example Procedure for Determining Feasibility of CTD 
determine the feasibility of the well and to identify the drilling hazards, risks and controls. Figure 3 illustrates the type of logical procedure that should be used in this initial analysis stage. (This is provided as an example only.)

After feasibility has been determined and drilling risks and hazards assessed, personnel and equipment requirements are established by the CTD engineer. Due to the complexity of these projects, use of a suitable project planning program is highly recommended. A contract for the project operations is set up with the CTD contractor and the planned objectives presented, as well as personnel and equipment requirements. The CTD contractor should be provided with as much information as possible that allows for planning personnel and equipment usage and also any input the contractor may have on the project. Cost of the project can now be generated with all aspects of the operation in mind, and the necessary permits and approvals applied for from governing agencies. As discussed in the following sections, drilling and contingency procedures are written with each section tied into the objectives of the well.

\subsection{WELL AND SITE PREPARATION}

Well data gathered earlier should be reviewed again to determine the status of the existing well. No CTD work should begin until the wellbore condition is fully understood. Any recent well work performed should be documented and all files updated. The CTD engineer will then plan the workover operations required prior to the CTD rig coming to location. Some of the operations that may be required are (but are not limited to) well kill, removal of any restrictions in the wellbore (i.e., mill nipple, clean out fill), drift tubing and tag TD, change out live gas-lift valves to dummies, pull or lock open the subsurface safety valve, run a thru-tubing whipstock, and $P \& A$ existing perforations.

Site preparation for the project is an important initial consideration whether the well is onshore or offshore. The engineer plans for transportation to the site, as well as plans rig position on the well-site pad or platform. Consideration should be made for heavy equipment use for leveling the pad onshore or the possible need for an additional crane and skid beams for offshore. The equipment layout is vital to a successful operation and a detailed drawing should be provided as part of the procedure for moving and rigging up the CTD unit and equipment. To make this effective, the CTD contractor needs to be highly involved in this portion of the preparation. For offshore operations, a seabed survey should be reviewed and supplied to the contractor.

\subsection{CTD SURFACE EQUIPMENT}

\section{Overview of Surface Equipment}

Many CTD applications can be undertaken using the same CT equipment as used for conventional CT well-intervention work. However, as CTD experience has been gained and the 
complexity of CTD operations increases, there is an increasing trend toward the manufacture of CT equipment specifically for CTD operations.

The type of application, location and complexity of the operation will determine which items of surface equipment are required. Principal components required to complete most CTD projects are reviewed below:

- Basic CT equipment

- CTD substructure or rig

- Drilling fluid mixing, storage and treatment

- Drilling fluid pumping equipment

- Monitoring and recording equipment
- Pressure control equipment

- Ancillary surface equipment

- Pipe handling equipment

- Safety and emergency equipment

- Rig camp and well-site facilities.

\subsubsection{Coiled-Tubing Equipment}

Basic CT equipment used for the majority of CTD operations is very similar to that used for CT well intervention services (Figure 4). In some cases, individual items may be modified or altered to suit a specific application, but generally the equipment is interchangeable between applications. The trend toward larger CT sizes in CTD often results in equipment of a size that is not easily compatible with well-intervention operations.

For example, 2 -in. or $23 / 8$-in. CT strings are not commonly used for wellintervention operations. A brief overview of key components (CT string, injector, reel, power pack, crane, and substructure) is provided below.

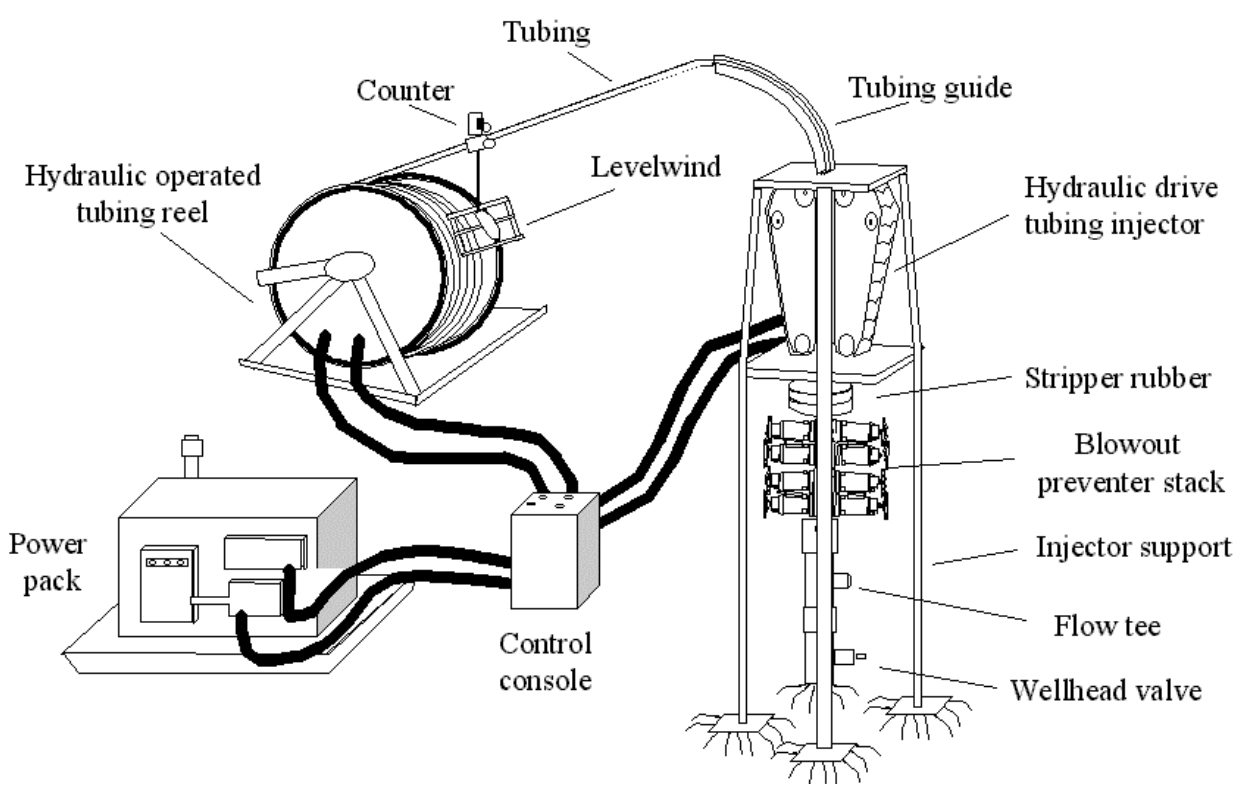

Figure 4. Basic CT Equipment Subsystems

\subsubsection{CT String}

Even "basic" CTD operations can require high performance from the CT string. For example, if drilling operations require multiple passes over the same hole section (wiper trips), string fatigue can quickly accumulate. In addition, the likelihood of stuck pipe is greater during CTD than in 
most conventional well-intervention applications. This not only means that the performance characteristics of the CT string must be optimum, but that operating limits of CT strings for CTD must be known at all times.

For new and directional wells, CT sizes of $23 / 8$ or $2 \frac{7}{8}$ in. are typically required. However, for some simple well deepenings using a BHA with limited hydraulic requirements, a 2 -in. CT string may be sufficient. Currently, most vertical deepenings are done with 2-in. CT and most vertical new wells are done with $27 / 8$-in CT. In almost all applications, CT strings with wall thickness of at least 0.156-in. manufactured from 70,000 - or $80,000-p s i$ yield strength material are recommended. However, for deeper vertical wells or longer step-out horizontal wells, a 100,000 - or 110,000-psi yield strength material may be required. The well configuration might

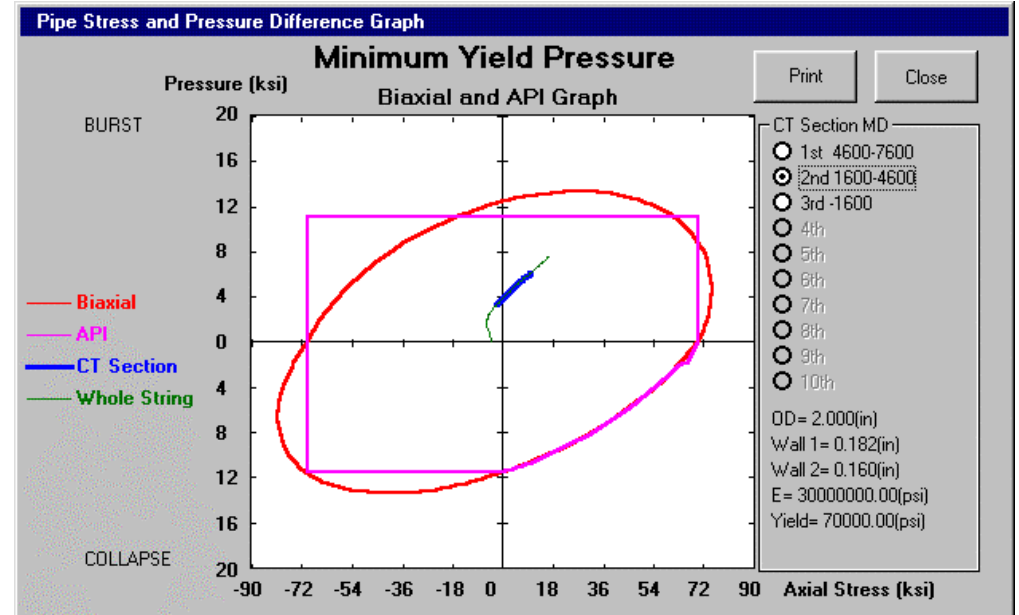

Figure 5. Modeling CT Stresses for Planned Field Operations (from MTI's CTPRO Model) require the use of a tapered string with wall thickness varying from $0.190-$ to 0.125 -in. to reach the required objective.

During the design phase of most applications, the optimum size, wall thickness and yield strength are determined using CT modeling software (Figures 5 and 6) and design data from the intended application. The CTD Engineer must determine the parameters of the project and provide the CTD contractor with the design data for modeling runs. Some of the design data required are, but not limited to,

- $\quad$ the well path

- open-hole diameter

- drilling fluid weight and viscosity

- length and diameter of existing tubulars if drilled through tubing

- length and diameter of the BHA

- maximum overpull allowed

- required weight on bit (WOB) at total depth (TD) 
In general, the size of CT selected for a given drilling job will be a compromise based on tubing life (smaller sizes have a longer cycle-life, but lower strength and limited flow rates) and flow area (larger sizes have greater strength and flow area, but shorter cycle life). Consequently, CTD is usually done with $23 / 8^{-}$or $2 \frac{7}{8-i n}$. CT. However, recent developmental work has been performed using "odd" sizes of CT to optimize performance. For example, $25 \%$-in. CT has been used to drill $33 / 4$ - to $4 \frac{1}{8}$-in. hole size because it exhibited the optimal combination of cycle-life (due to lower surface pressures), annular area and flow rates for increased annular velocities and additional WOB. Another consideration is the amount of CT that can be reeled onto a given spool to achieve the desired depth or the maximum weight the crane can support.

After modeling runs are completed, a thorough review and comparison of the runs is made to determine the best case for the project. Friction factors used especially in a deviated and/or horizontal hole are checked to ensure validity of the data. Availability and delivery of the CT string must be verified with the CT manufacturer.

In the event that a computer model is not available, the following longstanding recommendations may be

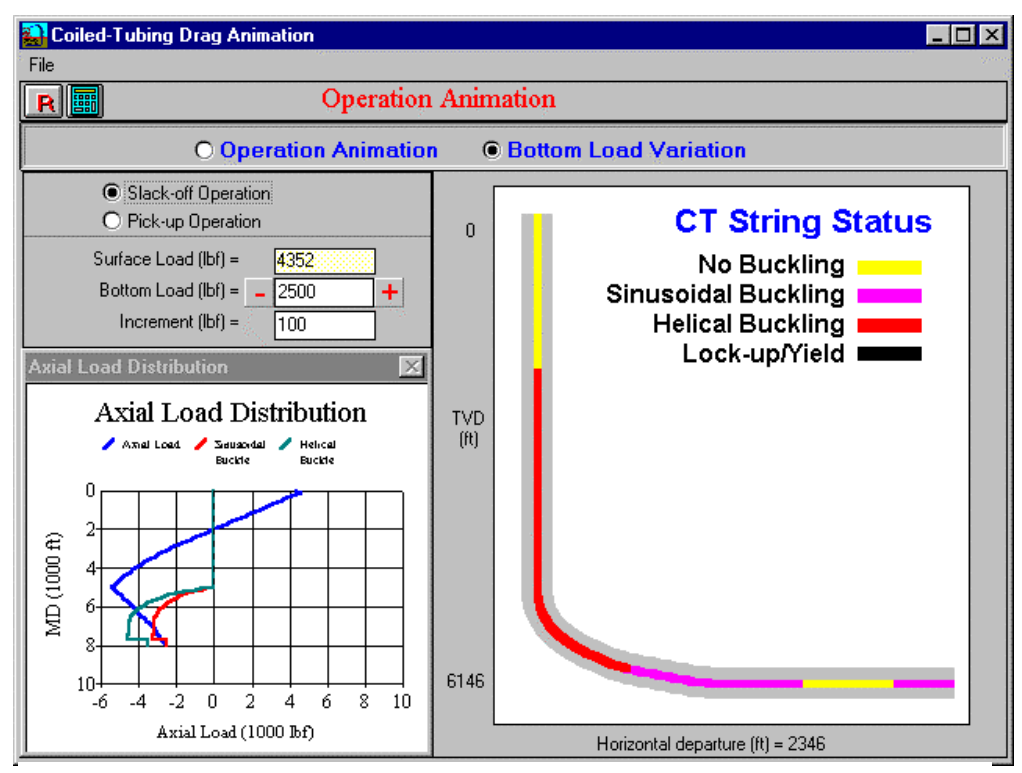

Figure 6. Modeling CT Buckling for Planned Wellpath (from MTI's CTDRAG Model) considered:

- Internal pressure limits:

․ Maximum pump pressure while running tubing -4000 psi

a Maximum pump pressure while tubing stationary -5000 psi

- Maximum collapse differential: 1500 psi

- Maximum recommended wellhead pressure: 3500 psi

- Maximum CT tension limit: $80 \%$ of manufacturer's published yield strength

- Maximum CT diameter and ovality:

a Maximum OD - $106 \%$ of nominal CT diameter

a Minimum OD - 96\% of nominal CT diameter 


\subsubsection{CT Injector Head}

The CT injector head (Figure 7) provides the power and traction necessary to run and retrieve the CT string into and out of the wellbore. Several hydraulic systems are used to enable the CT unit (CTU) operator to exercise a high degree of control over any CT string movement - an important feature in delicate CTD operations where WOB must be carefully controlled. A thorough understanding of the injector control and monitoring systems is essential to ensure the equipment is operated efficiently, safely and without risk of damage to the well equipment, pressure control equipment, CT

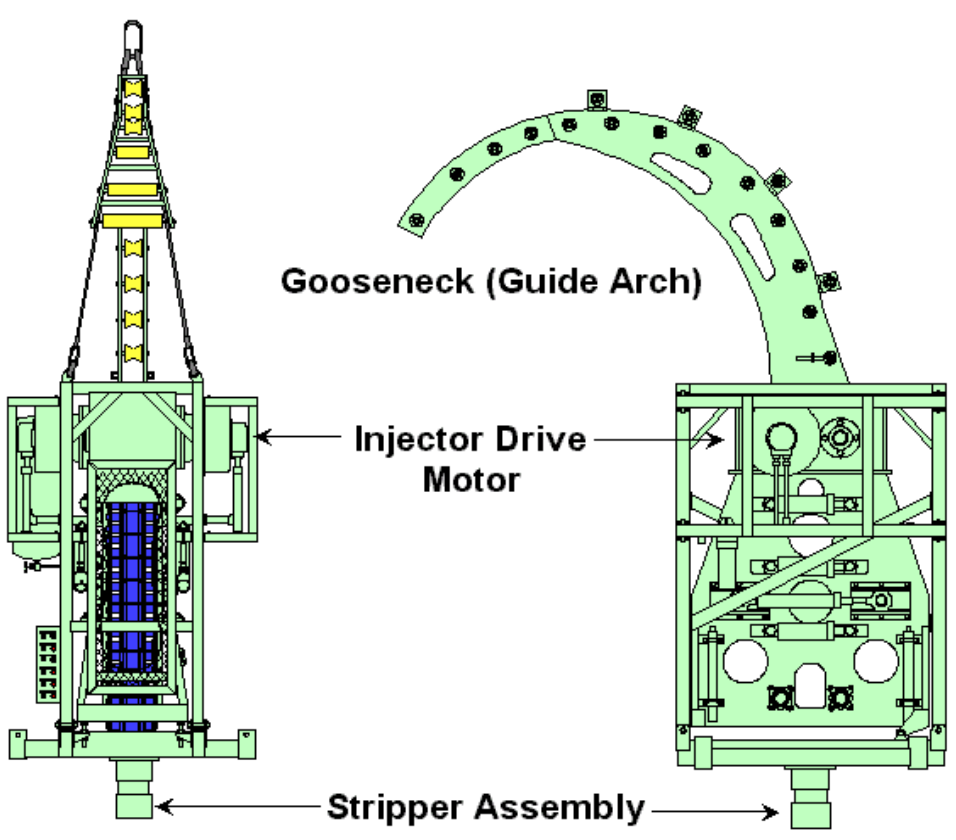

Figure 7. Typical CT Injector string or CTU.

For new and directional wells, an injector head with at least a 60,000-lbf pull capacity is recommended. For well deepening, a 40,000-lbf capacity injector head may be adequate if conditions allow. A minimum gooseneck radius of $72 \mathrm{in}$. is required for $13 / 4$-in. and larger CT strings. While the majority of drilling is done with standard CT injector heads, special hybrid units have been developed which allow running both continuous CT and jointed pipe. These units allow the CTU to do more of the tasks associated with drilling, such as running and pulling completion tubing. Key performance data and specifications of common injector head models are listed in Table 1; recommended guide arch radii are shown in Table 2.

Table 1. Injector Head Specifications

\begin{tabular}{|l|c|c|c|c|c|c|c|}
\hline Injector Model & Height & Width & Depth & Weight & Snub & Pull & CT Sizes \\
\cline { 6 - 9 } & (in.) & (in.) & (Ib) & (x1000 lb) & (in.) \\
\hline HR440 & 80 & 52 & 55 & 6750 & 20 & 60 & 1 to $23 / 8$ \\
\hline HR480 & 109 & 60 & 60 & 11200 & 40 & 100 & $11 / 4$ to $3 \frac{1}{2} 2$ \\
\hline SS 400 & 82 & 42 & 58 & 5700 & 20 & 40 & $3 / 4$ to $23 / 8$ \\
\hline SS 800 & 82 & 42 & 58 & 6125 & 20 & 80 & $3 / 4$ to $23 / 8$ \\
\hline
\end{tabular}


Table 2. Typical Guide Arch Radii

\begin{tabular}{|c|c|c|}
\hline $\begin{array}{c}\text { CT OD } \\
\text { (in) }\end{array}$ & $\begin{array}{c}\text { Reel Core } \\
\text { Radit (in.) }\end{array}$ & $\begin{array}{c}\text { Tubing Guide } \\
\text { Arch Radii (in.) }\end{array}$ \\
\hline $3 / 4$ & 24 & 48 \\
\hline 1 & $20-30$ & $48-54$ \\
\hline $1 \frac{1}{4} 4$ & $25-36$ & $48-72$ \\
\hline $1 \frac{1}{2} 2$ & $30-40$ & $48-72$ \\
\hline $13 / 4$ & $35-48$ & $72-96$ \\
\hline 2 & $40-48$ & $72-96$ \\
\hline $23 / 8$ & $48-54$ & $90-120$ \\
\hline $2 \frac{3}{7} / 8$ & $54-58$ & $90-120$ \\
\hline $31 / 2$ & $65-70$ & $90-120$ \\
\hline
\end{tabular}

\subsubsection{CT Reel}

The primary function of a CT reel (Figure 9) is to safely store and protect the CT string. This should be achieved while avoiding excessive damage to the string through fatigue (bending) or mechanical damage from spooling. The reel typically incorporates a swivel assembly which enables fluids to be pumped through the tubing string while the reel drum rotates. For CTD applications incorporating a CT string with wireline installed, a bulkhead and collector assembly is required to enable the electrical conductors to pass from within the CT string (pressure seal) and out of the rotating reel drum (electrical swivel/collector). In addition to the hydraulic connections required to operate the drive, braking and spooling guide (level-wind) systems, reels used in CTD operations are typically fitted with additional monitoring equipment and connections

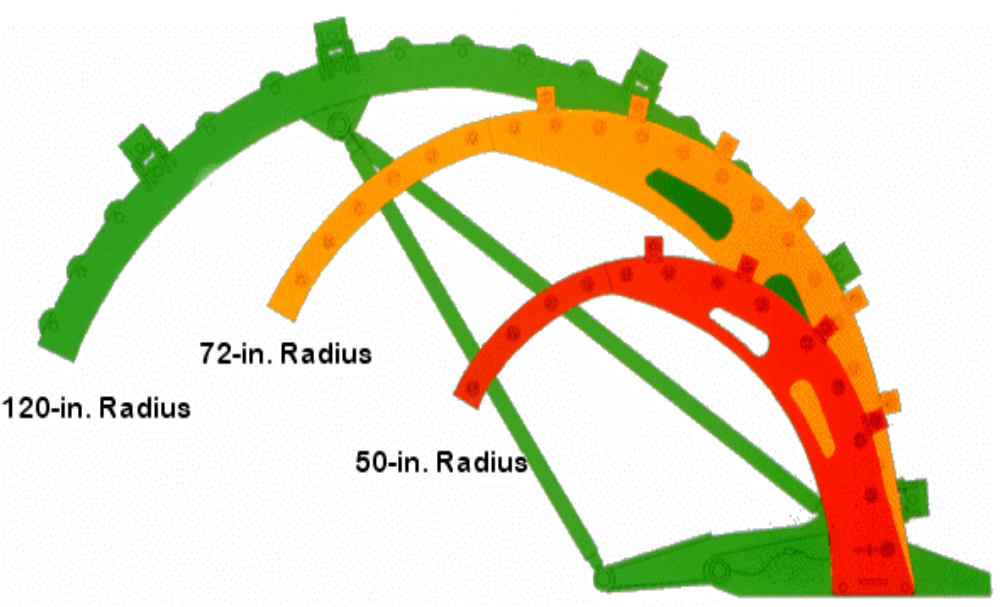

Figure 8. CT Guide Arches

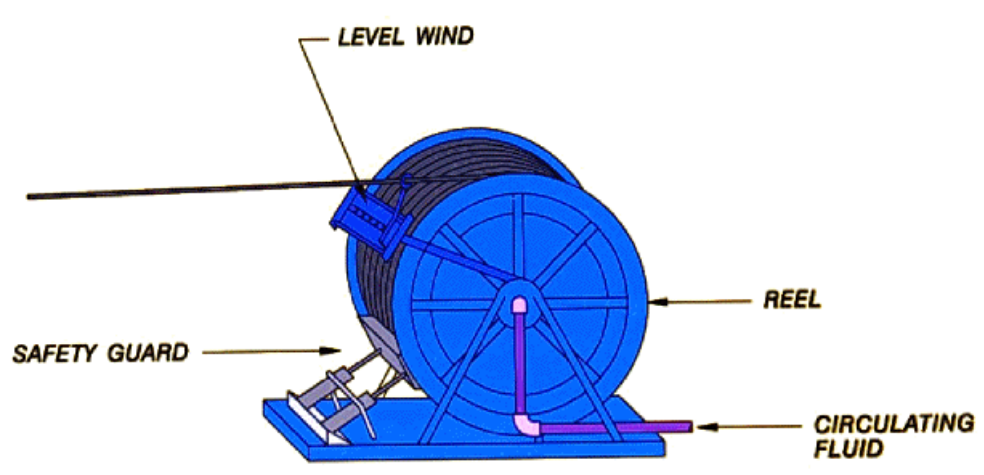

Figure 9. CT Reel 
(for example, pressure monitoring sensors used with MWD mud-pulse technology, or CT string monitoring equipment such as a diameter and ovality monitoring device).

The theoretical tubing capacity of a reel (Figure 10) can be calculated using the formula below. This assumes perfect spooling across the width of the reel. Because this condition is difficult to achieve in practice, an allowance must be made to maintain reel capacity within its practical limitations.

$$
L=(A+C) A B K
$$

where:

$$
\begin{aligned}
& \mathrm{L}=\text { tubing capacity }(\mathrm{ft}) \\
& \mathrm{A}=\text { tubing stack height }(\mathrm{in} .) \\
& \mathrm{B}=\text { width between flanges }(\mathrm{in} .) \\
& \mathrm{C}=\text { reel drum core diameter }(\mathrm{in} .) \\
& \mathrm{K}=\mathrm{K} \text { value for different tubing sizes }\left(\mathrm{ft} / \mathrm{in}^{3}\right) \text { (see below) }
\end{aligned}
$$

$\mathrm{K}$ values for different tubing sizes are:

\begin{tabular}{|cc|}
\hline Tubing OD (in.) & K value $\left(\mathbf{f t} / \mathbf{i n}^{3}\right)$ \\
1 & 0.262 \\
$1 \frac{1}{4} 4$ & 0.168 \\
$1 \frac{1}{2}$ & 0.116 \\
$13 / 4$ & 0.086 \\
2 & 0.066 \\
$23 / 8$ & 0.046 \\
$27 / 8$ & 0.032 \\
$31 / 2$ & 0.021 \\
\hline
\end{tabular}

\subsubsection{CT Power Pack}

The function of the power pack is to provide the hydraulic power to operate the CTU and

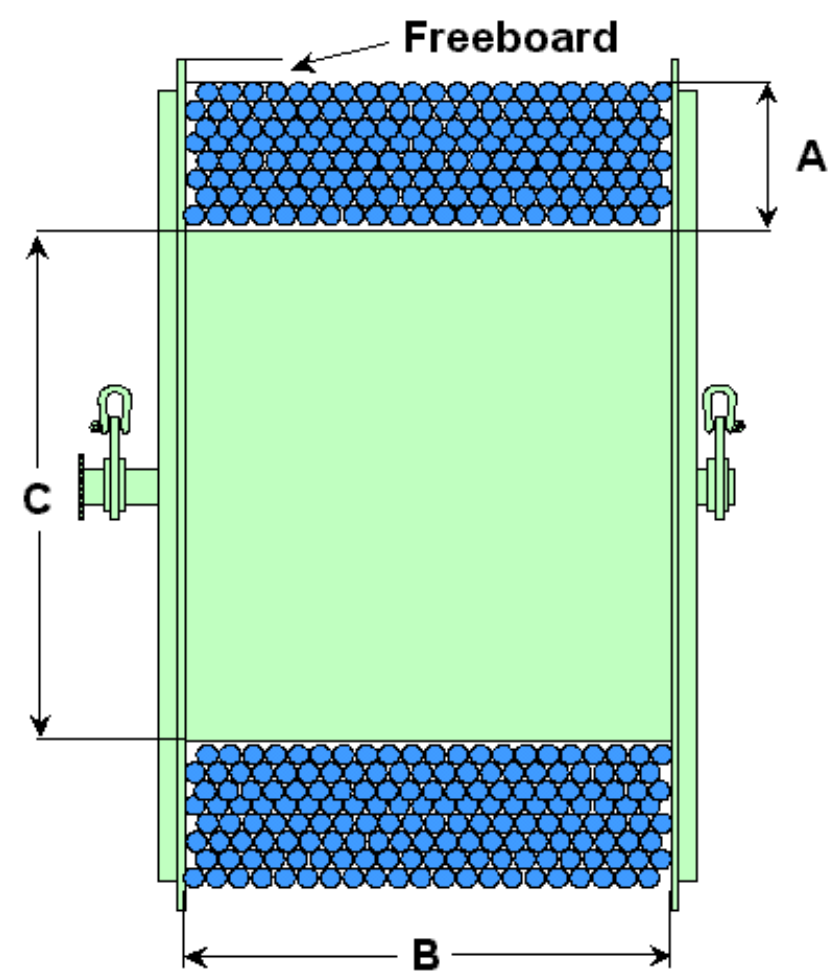

Figure 10. CT Reel Capacity primary/secondary pressure-control systems (e.g., stripper and BOP systems). In addition to the hydraulic power supplied when running, the power pack incorporates an accumulator facility to allow limited operation of pressure-control equipment following engine shut-down. The CTD engineer should verify certification of this 
equipment and the maintenance schedule with the contractor. If nonstandard equipment or auxiliary equipment is to be powered by the CTU power pack during drilling operations, it should be confirmed that the output of the power pack is adequate and that the pressures and flow rates are compatible. The extended duration of most CTD operations requires that provision be made for adequate inspection and maintenance during the operation, e.g., refueling and lubrication checks.

\subsubsection{Crane and Substructure}

All CTD operations will require some lifting, moving and placing of equipment of tools (BHA). These requirements must be determined during this planning stage. Local conditions and configuration of the equipment will determine the size (height) and capacity of the crane. The crane is often used to place the injector on top of the BOP and then to hold the injector in place. This effectively ties up and limits the crane. Typically, the crane's boom length should be sufficient to handle a $40-\mathrm{ft}$ $\mathrm{BHA}$ (straight drilling/milling) or a $65-\mathrm{ft}$ BHA (directional drilling) over the substructure. The CTD engineer must determine if a substructure is needed and then the size and type required for the given project parameters.

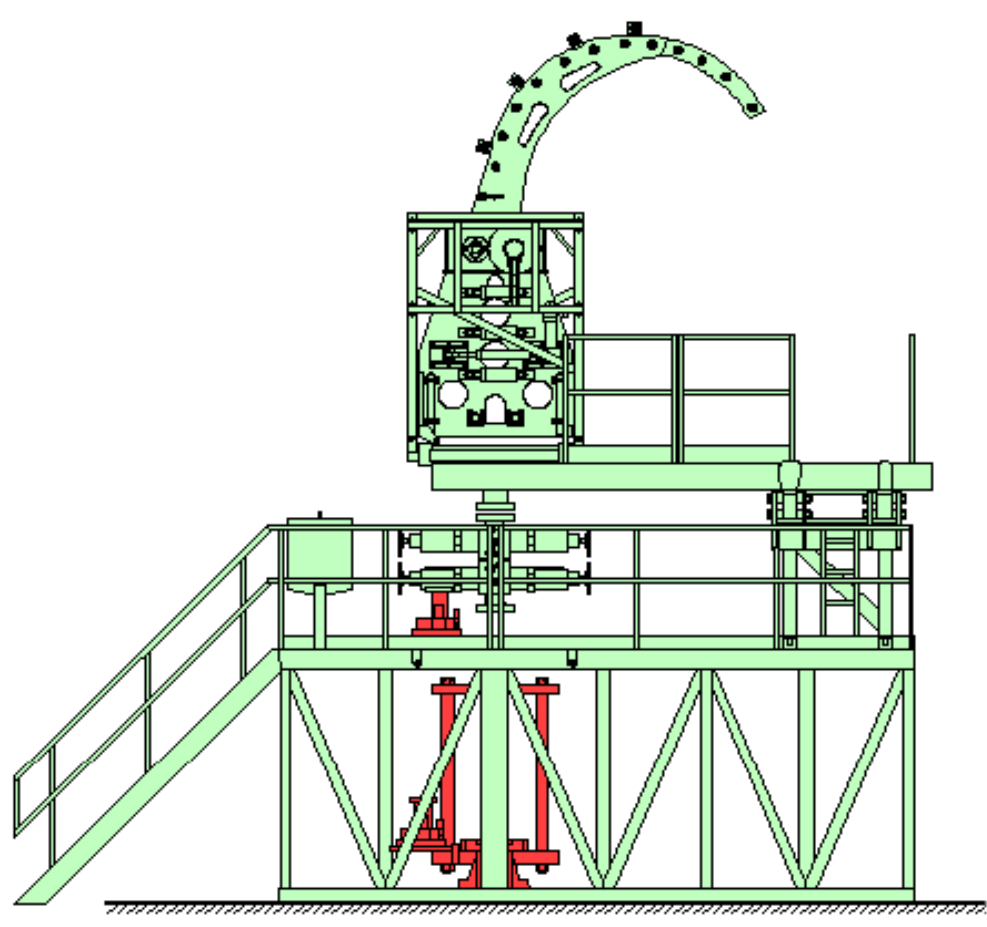

Figure 11. Multipurpose CT Support Structure

The substructure (Figure 11) provides stability to the wellhead equipment and can include additional features ranging from a simple platform to a complex jacking frame capable of running and pulling wellbore tubulars. The key features of a drilling substructure are:

- Elevates the working area above the wellhead for easier access to the wellbore

- Allows supporting the injector head without the crane and provides a means for raising/lowering the injector for make-up. Also, allows skidding the injector on/off the wellhead when rigging BHAs.

- Provides a safe working platform for personnel while handling the BHA and injector hook-up 
- Provides a means for supporting the BHA/tubulars during make-up using a "false rotary" opening and use of spider and slips

Substructures are designed for use within a limited range of vertical adjustment, enabling the substructure to be adjusted to suit the specific wellhead and surrounding conditions. Typically, sub-structure legs are adjusted to an appropriate height and fixed (pinned) in place.

A more complex version of the CTD drilling substructure is the hybrid unit, or jacking frame. This structure is equipped with an upper platform mounted on hydraulic rams that can be raised and lowered from the lower substructure base. By using power slips on the upper and lower platform openings, tubulars can be run or pulled from the well by raising/lowering the upper platform. Advantages of this type of substructure are flexibility in position adjustment, and a reduced dependence on high-capacity cranes or derricks for running or pulling well tubulars.

\subsubsection{Pipe-Handling Equipment}

Pipe-handling equipment is used to help ensure safe and correct handling and make-up/breakout of jointed tubulars and tools, e.g., drill collars, tubing joints, casing joints, etc. Although several pipe-handling components are considered standard items commonly used on conventional drilling rigs, their use on CTD operations may require minor modifications or a reduction in size to operate efficiently.

The requirement for pipe-handling equipment is dependent on the size and nature of the equipment to be made-up/broken-out, and the configuration of CT and pressure-control equipment. The following items of equipment are commonly used to increase the safety and efficiency of CTD operations.

1. C plate - Slotted plate that allows passage of tubulars into the wellbore and can be removed/installed with tubulars in place. This plate supports the slip bowls.

2. Tubing spider slips - used to hold the BHA or jointed tubing when making up or breaking two joints.

3. Elevators - used to handle single joints of drill collars, tubing, casing.

4. Safety clamps - used as a safety device to prevent the string from falling into the hole (if the slips do not hold and the string slides).

5. Power tong - used to make up or break the BHA, casing or tubing connections under controlled torque conditions.

6. Crane - used to handle single joints of BHA, casing or tubing. If necessary, it may be used to handle/run the whole BHA or casing string if within the crane capacity. Boom length must be sufficient to handle a $40-\mathrm{ft}$ pipe/BHA over the substructure. 


\subsubsection{Well-Control Equipment}

The configuration of BOP equipment required for any CTD operation largely depends on the type of application and the anticipated "worst case" conditions that may be encountered. Depending on the application, the configuration may change as work progresses; i.e., as the likelihood of higher pressures increases, so must the operating capacity of equipment increase. There are several categories of "BOP systems" which require significantly different approaches to equipment configuration. One or more of the following scenarios will apply to the majority of CTD operations:

1. Low-pressure diverter system - Used for drilling surface hole on new wells where shallow gas is a potential hazard

2. Bit size less than quad $C T$ BOP ID - Bit sizes less than 4 in. can pass through the quad BOP (Figure 12). If the well is deviated, the bend in the motor housing will further limit bit OD. In general, maximum bit OD is $3 \frac{7}{8}$ in. for directional wells.

3. Bit size greater than quad CT BOPID - Bit sizes greater than 4 in. cannot pass through the quad BOP

4. Hybrid pulling/running operations - Requires BOPs to suit the size of tubing/ casing handled

5. Underbalanced BHA deployment - Requires special BOP configuration to accommodate live well conditions and allow pressure deployment.

Basic well-control equipment requirements can be summarized as shown below. Priority or importance assigned to each factor may vary with application and specific conditions. However, each will have some bearing on the configuration and operation of the necessary pressurecontrol equipment:

- Contain wellbore pressure and fluids, e.g., provide a primary barrier (stripper)

- Enable controlled circulation, e.g., through the drilling or choke manifold

- Divert or route wellbore returns or separated products to safe area for storage or disposal

- Continually monitor drilling fluid levels, flow rates and pressures

For most CTD applications, a 5000-psi pressure rating is adequate. However, the operating pressure rating must exceed the expected bottom-hole pressure. BOP size (or bore) depends on the hole or planned completion size. CT BOP systems are commonly available in 4-in. (ID) quad configurations. Larger BOP sizes (e.g., $5 \frac{1}{8}$-in. up to $7 \frac{1}{16}$-in.) are less common but generally available in single or dual-ram configurations. If bit/hole sizes greater than $71 / 16^{1}$-in. are desired, then conventional drilling BOPs may be required (e.g., 11 in.). In most cases, a pipe 
ram shear/blind ram configuration is required as a minimum. In such cases an annular BOP is frequently included to provide flexibility and contingency in operation. In ram-type BOPs, the tool or CT-string diameter that can be closed on is determined by the fixed size of the rams (although variable-bore rams are available that allow closing on a limited range of diameters). The annular-type BOP can be closed on any diameter, ranging from full open to full closed.

CT well-control equipment used for the majority of CTD operations is very similar to that used for CT well-intervention services. In some cases the individual items may be modified or altered to suit a specific application, but generally the equipment is interchangeable between applications. A brief overview of key components is provided below.

\section{Stripper}

Side-door strippers are the most common configuration used on CTD operations. General availability combined with easy serviceability while in operation (with the necessary precautions implemented) make this a popular choice.

\section{Quad BOP}

If the size (ID) allows, a standard 4in. quad BOP (Figure 12) provides

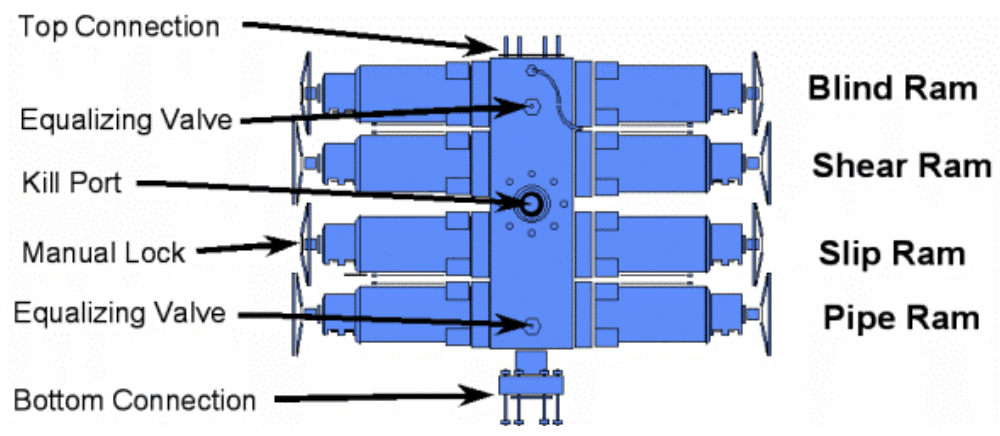

Figure 12. Quad BOP adequate functionality with convenient rig-up and operation. Larger hole sizes typically require use of $7 \frac{1}{16}$-in. BOPs.

\section{Single/Dual BOP}

For applications requiring through-bore access greater than $5 \frac{1}{8}$ in., the BOP stack, or part thereof, may be assembled for single or dual-ram BOPs in $6 \frac{1}{8^{-}}$or $7 \frac{1}{16}$-in. sizes.

\section{Annular BOP}

The annular BOP is an extremely flexible component enabling a wide variety of contingency options over a range of tool/BHA sizes.

\section{Additional BOP Equipment}

Additional equipment typically required to connect, monitor or operate the pressure-control equipment package includes the following:

- Kill line - runs between the well-control stack and the high-pressure pump manifold and can be used as a contingency facility to kill the well by pumping down the annulus 
- Choke line - runs from the well-control stack to the choke manifold providing a high-pressure conduit necessary when operating the choke manifold

- Choke manifold - the choke manifold must be configured for drilling applications with two manual chokes and one pressure gauge (some applications may require a remotely operated choke). The choke manifold is an important item of pressure control equipment since it is used to control wellbore pressures during critical phases of a drilling operation, e.g., as contingency well control or maintaining well control during underbalanced drilling.

- Mud return line - A remotely operated valve may be installed on the outlet of the mud return line, but typically a manual valve is used as this is simply to shut off the mud flow. If desired, this mud return outlet can be configured as a highpressure line to enable the use of the CT stripper as a functional well-control device. This requires that the spool, riser and outlet be rated to full pressure and the line from the spool be fitted with remote valves as required by regulations or prudent practices to permit total isolation for use of the stripper under full pressure conditions.

- BOP controls and instruments - all BOP equipment should be controlled from the CTU operator's console (Figure 13) or control cabin area. In some cases, it may also be desirable or necessary to include a repeat/remote control located in a safe area for emergency operation, e.g., remote operation of shear/seal tertiary pressure control equipment.

- Mud spool/riser - Typically, the injector is connected to the actual wellhead BOPs by way of a spool and/or riser. This represents what is termed the "bellnipple" on a conventional drilling rig. The function of this piece of equipment is to provide an outlet for the mud return to the pits, and to provide a means of connecting the CT injector physically to the riser. This physical connection is often termed the quick disconnect or quick connect.

For $7 \frac{1}{16}$-in. BOPs and remotely operated valves on the mud return or choke lines, the control position is located on the accumulator or Koomey unit that must be positioned next to the CTU cabin. Remote controls between the Koomey unit and the CTU BOP command panel can be adapted if necessary.

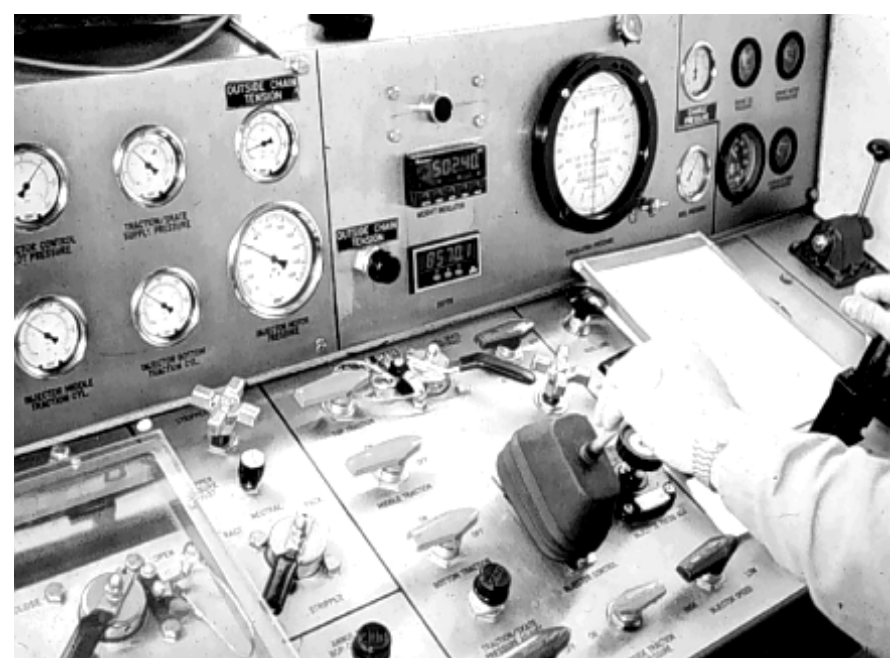

Figure 13. CTU Operator's Console 


\subsubsection{Well-Control Equipment Testing}

Testing of the well-control equipment is required for CTD operation. In this initial planning stage, a full-body test or stump test of the well-control equipment should be performed to the required working pressure of the equipment using an incompressible fluid prior to bringing the equipment to location, except that an annular type preventer need not be tested to more than $50 \%$ of its rated working pressure. The CTD Supervisor should witness this testing and the results recorded as part of the daily well log record.

\subsubsection{Well-Control Procedures and Responsibilities}

The preparation phase of every CTD operation should include procedures that are developed to suit specific conditions and requirements of each well. The following well control issues relating to job responsibilities and procedures are provided as a guide in preparation for specific CTD operations.

- It is the CTD operator's responsibility to close in the well if a kick is indicated or suspected. It is better to shut in the well as a precautionary measure than to hesitate when conditions may require closure of the BOP equipment.

- The hole must be kept full of fluid at all times. (This is core to the philosophy of overbalanced drilling, but may not be such a requirement in some underbalanced operations.)

- $\quad$ Flow checks should be performed coinciding with all drilling breaks.

- When tripping pipe, a trip sheet should be completed and a flow check performed:

a at the lowest casing shoe

a prior to pulling BHA through the BOP

- Slow circulation rate check should be taken:

a $\quad$ at the beginning of every tour/prior to every $\mathrm{RIH}$

a any time the drilling fluid density is changed

- When lost circulation occurs and cannot be regained by circulation through the CT string, the annulus should be filled with the lightest fluid available (typically water) and volumes recorded. CT has no tolerance for differential sticking. If circulation is lost, then you are probably stuck!

- Tripping out of the hole without full returns is potentially dangerous and should only be permitted under known conditions with permission of the CTD superintendent. 
- Drillers should be provided with procedures detailing the actions to be taken if a well kicks while drilling surface hole.

- Unless the following materials are available for use at the rig site, drilling operations should be reviewed and, if necessary, suspended:

1. enough salt $(\mathrm{KCl}$ or $\mathrm{NaCl})$ to raise the fluid weight in the active mud system at least $120 \mathrm{~kg} / \mathrm{m}^{3}$ or $1 \mathrm{ppg}$

2. enough cement to place at least a $120-\mathrm{m}$ or $400-\mathrm{ft}$ plug in open hole

- Kick drills should be held on a weekly basis or more often if the rig superintendent considers it necessary. Details and results of any drills should be logged in the drilling report.

- BOP and related equipment should be pressure and function tested at least every 14 days.

- Check valves should be run while drilling and opening hole.

- An appropriate safety valve (TIW) to fit the top of any BHA left hanging in the slips should be kept on the rig floor.

- Casing/liner strings will be completely filled from the top at least every five joints, irrespective of the type of float equipment in use.

- Wells should be shut in following the procedures designated by the operating company. The relevant step-by-step procedures for shutting the well in should be posted near the driller's panel.

- The driller should check and confirm all choke manifold, kill and choke lines for correct positioning at the beginning of each tour.

- The driller should know true vertical depth (TVD) measurements at all times.

- Prior to spudding, it is the responsibility of the CTD Supervisor to review the well plan and ensure that all primary well-control/pressure-control issues have been addressed.

- If the well cannot be closed in with the BOP, the well should be properly secured and tested by setting a plug.

- A well-control report should be completed by the CT driller and CT Supervisor after all well-control operations.

\subsubsection{Ancillary Surface Equipment}

Ancillary surface equipment required for any CTD operation will depend on many factors, such as: 1) location, 2) expected duration and 3) availability of well-site utilities/facilities. The 
following items are commonly required in support of CTD operations and are not generally considered as "CT equipment."

1. Generator - provides electricity to the portacabins/offices, floodlights, centrifuge, monitoring equipment, Koomey unit, mud pits (agitators, shakers, circulating pumps), etc.

2. Electrical distribution panel - provides electrical connection between the generator and various electrical devices, with all necessary breakers and safety features

3. Flood lights - provide light for safe and efficient operations at night

4. Air compressor - provides air to start the CTU engine, or provide compressed air as required for air winches and power tools. Air is also required (approximately 100 to 115 psi) to run the air-powered pumps on the Koomey unit.

5. Miscellaneous items - tools and equipment necessary to maintain the CTU and supporting equipment (almost certainly including a cutting torch and welding machine)

\subsubsection{Monitoring and Recording Equipment}

Monitoring and recording key parameters of a drilling operation is generally required, regardless of the technique involved, i.e., conventional rotary or CTD. Well established reporting formats are used to enable key information and statistics to be retrieved for the well report or for use in selection of equipment and techniques for offset wells. Although many of the systems in use will be integrated to some degree, there are several distinct areas to be considered.

1. CTU based systems, e.g., CT string monitoring

2. Drilling fluid parameters

3. Wellbore steering and navigation

4. Formation evaluation

\subsubsection{CTU Monitoring Equipment}

The majority of CTUs engaged in CTD operations will be equipped with recording and monitoring systems designed to provide a high degree of reliability to the CTU and associated equipment. Typical monitoring and recording parameters include the following:

- $\quad$ CT depth and movement - required for CT string cycle fatigue monitoring and ROP assessment 
- CT string circulation pressure and flow rate - required for CT string cycle fatigue monitoring and well-control purposes

- Wellhead pressure - required for well control

- $\quad$ CT string weight - monitors CT string and BHA forces, e.g., WOB

- $\quad$ Tubing monitor - required to confirm CT string integrity and geometry

\subsubsection{Drilling Fluid Monitoring Equipment}

Key drilling fluid parameters (e.g., pressure rate and density) are typically displayed and recorded in real time in the CTU control cabin. Additional parameters may be monitored and processed continually, with alarms providing notice of unusual conditions (e.g., flow in/out comparison alarm if losses/gains are detected). Typical monitoring and recording parameters include the following:

1. Pump pressure and wellhead pressure

2. Pump rate

3. Flow in/out of well - comparison for kick detection

4. Drilling fluid density

5. Circulating tank volumes - detection of gain/loss for kick detection

\subsubsection{Wellbore Steering and Navigation}

Monitoring and recording equipment typically used in CTD directional measurement are directly adapted conventional directional drilling or wellbore survey technology. Directional data on the following parameters are typically monitored and recorded:

1. Wellbore inclination

2. Tool face angle

3. Azimuth

\subsubsection{Formation Evaluation}

1. Gamma ray

2. Resistivity

3. Annular pressure 


\subsubsection{Safety and Emergency Equipment}

Several items of safety and emergency equipment are generally required in support of CTD operations. For many of these items, the place of storage and "readiness for action" are key issues. For example, it is not sufficient to simply provide/supply $\mathrm{H}_{2} \mathrm{~S}$ protective equipment; such equipment must be in operating condition and placed at key locations around the well site.

Safety and emergency equipment inspections should be conducted regularly during any drilling operation and a note of status made on relevant daily reports (or similar). Typical items of safety and emergency equipment used in support of CTD operations include the following:

1. Emergency engine kill systems - often required on CTU engine and pump engines located within the designated hazardous zone surrounding the wellhead

2. Fire-fighting equipment - general guidelines, as a minimum, should provide for $\mathrm{CO}_{2}$ fire extinguishers on the CTU power pack, pumping unit power pack, near any port-a-cabins or office accommodations and in the vicinity of the fuel tank

3. $\mathrm{H}_{2} \mathrm{~S}$ protective equipment and gas detection equipment - type, quantity and placement of $\mathrm{H}_{2} \mathrm{~S}$ protective equipment may be subject to legislation or corporate policy

4. Eye wash station - typically located adjacent to the drilling fluid mixing facility

5. Personal protective equipment - often required for safe preparation of drilling fluids, e.g., apron, goggles and long-sleeved gloves for chemical handling. A chemical shower may also be required if corrosive chemicals are to be prepared.

\subsection{DIRECTIONAL PLANNING}

The amount of directional planning required for a CTD project will vary depending on the target to be reached and the wellbore configuration. Directional drilling companies have a wide range of directional programs and tools for planning the proposed wellbore. Hole size to be drilled as well as the location of the well will help in determining which directional company to use. The CTD Engineer should work closely with the directional planner (DP) and the Reservoir Engineer to ensure any changes from the preliminary plan are instituted in this final plan. If the well is a sidetrack, the position and depth of the window will play an important role in the smoothness of the build section and any turn required. This will also be a factor in the ability to drill with WOB at TD. Careful attention to the changes in inclination and azimuth in this design will save drilling time and cost.

The DP needs information such as the planned kick-off point (depth and direction); if a sidetrack, the original wellbore survey, surface coordinates, planned well inclination, target location (coordinates and approximate depth), target zone height in TVD ft, planned landing point for horizontal well (TVD ft), and any zonal boundaries (faults, dip angle, bottom and top of 
zone). These data are provided by the CTD and confirmed with the Reservoir Engineer for the project. Planning of this wellbore is to optimize the placement of the well for production/injection. Any questions about the planned wellbore should be addressed here and re-iterated in the pre-spud meeting prior to drilling the well. Once the directional plan is completed, the CTD Engineer, the Reservoir Engineer and the Geologist should review it and ensure that all landing and target points are correct and the well design meets the planned objectives.

\section{BHA Design and Selection}

For any drilling BHA, the downhole tools and equipment required largely depend on the type and complexity of the drilling operation and the conditions under which it is to be conducted. The preferred BHA will typically be selected considering technical requirements, local availability and (perhaps most importantly) the experience of personnel, history and reputation of the various tool components.

The drilling BHA comprises several components fulfilling many functions in a relatively aggressive environment. The operation, limits and reliability of each component or tool affects the overall performance of the drilling BHA. As with many other BHA selection processes, there is frequently a compromise between sophistication (flexibility) and simplicity (reliability). Typically, BHAs are configured according to the type of drilling being done. Currently, for new vertical wells, BHA sizes are generally 3 to $43 / 4$ in. OD, depending on the size of the downhole motor. Concurrently, for directional drilling, $23 / 4$ to 3 in. seem to be the standard sizes for directional tools and assemblies. (Note: the actual dimension may vary from $2 \frac{7}{8}$ to $3 \frac{1}{8}$ in. with the motor being $3 \frac{3}{8}$ in., but these are considered as 3 in. nominal size. In slim-hole BHAs, actual dimensions may vary from $2 \frac{1 / 4}{4}$ to 3 in. with a $23 / 8$ in. motor.) For underbalanced drilling of directional and vertical wells, a $3 \frac{3}{4}$-in. motor is most often used. Plans are still moving forward for future drilling of hole sizes ranging from 6 to $63 / 4$ in. Several projects have been performed at shallow depths with these larger hole sizes. However, more testing and CT development is required before deeper wells can be drilled in this range.

Basic CTD applications commonly performed are:

- Vertical applications

- New wells

\Well deepenings

- Directional applications

- high angle wells

a horizontal wells 
Each application varies in the requirements of, or functions included in, the drilling BHA. Therefore, the components and configuration of the BHA designed, for each application will be different. The key components and functions of the relevant tool strings are

- Bit

- Downhole motor

- Drilling head
a connector
a check valve assembly
ㄱelease joint
a circulating sub

- Drill collars (typically for vertical wells; non-magnetic collars for directional tools)

- Directional drilling tools

- Special application tools

An important part of the well-planning process relates to determining the optimum drilling parameters. The objective is to identify (estimate) the combination of bit design, weight-on-bit, and rate of penetration that will produce the most cost-efficient drilling performance (i.e., typically the lowest cost per foot drilled).

In its simplest form, achieving optimal performance is a compromise of two extremes:

1. Drill at the highest possible ROP for as long as the bit lasts (priority given to ROP), or

2. Maximize bit life and minimize "non-drilling" time, e.g., tripping to change out bits (priority given to bit life).

During the well planning phase, the task is to determine the point within these two extremes that produces the lowest cost per foot drilled. The cost per foot is a function of: 1) bit costs, 2) trip time costs, and 3) rig operating costs (for the time required to drill a given footage).

\subsection{DRILLING FLUIDS AND WELLBORE HYDRAULICS}

\section{Overview}

Drilling fluid, or mud, can have a major influence in the success of any drilling operation. Optimization of the drilling fluid and associated hydraulics is very important. In CTD operations, 
the geometry of the CT string and the configuration of wellbores typically drilled present many challenges to drilling fluid performance. However, the unique features associated with CT equipment and related pressure-control equipment simplify many of the requirements of the drilling fluid and the circulation system. CTD is challenged by an inability to rotate the string, small annular clearances in the open hole, low annular velocities inside casing, high fluid friction losses in the long CT reel, low initial weight on bit (WOB), and diminishing weight transfer while drilling. In this section the following will be discussed:

1. Drilling fluid design

2. Hole cleaning and annular velocity

3. System hydraulics program

The drilling fluid selection process is principally based on the lithology and pore pressures anticipated over the wellbore section to be drilled. Significant changes in either of these parameters may require that the operation be completed in distinct sections (casing points) including the necessary changes in drilling fluid characteristics. Drilling fluid density is generally specified for each wellbore section and typically represents a compromise between anticipated pore pressure and the fracture gradient of the formation being drilled. Such a delicate balance is necessary to avoid too little wellbore hydrostatic pressure - risking a fluid inflow or kick - or too much hydrostatic pressure - resulting in formation breakdown, drilling fluid losses and possible permeability impairment of reservoir sections. Fracture gradients predicted during the well design phase are generally confirmed during the drilling operation by performing leak-off tests. In CTD operations, fluid selection must also take account of high friction losses encountered in the CT string and the difficulties of cuttings transport at relatively low annular velocities.

In reviewing drilling fluids, it is important also to consider the circulating system. It is only through successfully combining the equipment and practices of the circulating system with an appropriate drilling fluid that an optimized performance will be achieved. Selecting the appropriate drilling fluid incorporates the basic functions of the fluid as listed below:

- Cuttings transport. Removing cuttings and drilling debris from the wellbore, including horizontal open-hole sections with small annuli and vertical cased hole sections of relatively large diameter, is critical to success. An efficient cuttings removal process also requires that the carrier fluid and cuttings be easily separated at surface.

- Cool and lubricate. The bit and motor will quickly overheat and prematurely

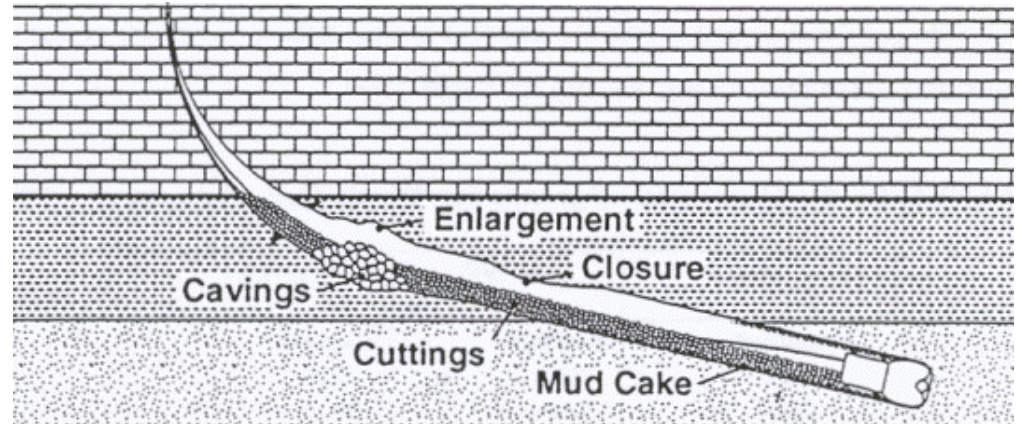

Figure 14. Hole Cleaning Problems 
fail if not adequately cooled and lubricated by an appropriate drilling fluid. An additional lubricating function important to the non-rotating CT string enables the smooth and controlled application of downhole force, i.e., in long horizontal intervals where sliding the CT string results in a slip-stick motion.

- Well control. In conventional rotary drilling, the drilling fluid column exerts sufficient hydrostatic pressure to maintain a safe overbalance pressure on reservoir fluids. This is less critical with CT because the pipe can be moved while containing the pressure at the surface.

- Wellbore stability. Maintaining a stable wellbore requires that the following conditions are controlled or prevented.

a washing out formation while drilling, e.g., unconsolidated formations

a sloughing or caving of unstable formations, e.g., sloughing shales

a reaction of sensitive formations to drilling fluid, e.g., swelling clays

口 isolating drilling fluids from the formation, e.g., create filter cake

- Buoyancy. Significant buoyancy forces affect the drill string, which can either help or hinder progress depending of the application and wellbore conditions.

- Protecting the drill string and casing. In some CTD applications there may be a tendency for localized wear of the string at contact points with the casing or wellbore tubulars.

- Transmitting hydraulic power. The downhole motor (and some tools) used in CTD applications are powered by the drilling fluid. Characteristics of the fluid must be compatible with the operation of the motor or tool, e.g., solids content.

- Corrosion control. The CT string, tubing or casing and drilling equipment may require protection from corrosive formation or reservoir fluids. Similarly, the selected fluid should be compatible with the component materials present in the string, BHA and circulation system.

- Optimizing penetration rate. There are many variables that contribute toward an optimized rate of penetration (ROP). Drilling fluid parameters can be relatively easily changed. Consequently, changing drilling fluid parameters might be viewed as a convenient means of optimizing ROP. On the other hand, hole cleaning may be the dominant issue, and dictate fluid design (regardless of ROP).

- Compatibility. Although not strictly a fluid function, it is essential that drilling fluids (including additives) be compatible with BHA, wellbore and pumping equipment materials, e.g., elastomers such as seals and motor stators.

While the functions summarized above apply to most drilling techniques, there are operating principles or practices that influence fluid performance and require a different approach to drilling fluid design for CTD applications. 
- There is the tendency for cuttings to settle on the low side of the hole. In conventional drilling, rotation of the drill string and annular velocity of the fluid causes cuttings to stay suspended and be carried to the surface. The absence of tubing rotation in CTD means that cutting beds will almost always be present in horizontal and highly deviated wellbores. The procedure should recommend frequent short trips over the drilled section while circulating to help keep these beds moving along the hole and avoid severe build-up. Alternatively, use a circulating valve and controlled velocity pumping.

- In CTD operations, the distance the drilling fluid travels through the drilling tubular remains constant, regardless of depth, i.e., the length of the CT string. Therefore as part of the design the CTD Engineer needs to be aware of the shear in the CT and BHA causing breakdown of the long polymer chains and affecting the carrying capacity of the fluid.

- The relatively low WOB and high rate of rotation associated with CTD applications creates small cuttings.

- When drilling underbalanced, produced fluid will supplement the drilling fluid flow rate to assist with cuttings transport and hole cleaning.

Drilling fluids for overbalanced operations are typically sophisticated products that are engineered and carefully prepared for specific wellbore and formation/reservoir conditions. Therefore the CTD Engineer should work closely with the fluid supplier to ensure all fluid characteristics of the project are met. Drilling fluids (not including foams or two-phase fluids) typically are comprised of four principal ingredients:

1. Base component - water or oil forming the bulk fluid volume

2. Active solids - colloidal solids used to increase the fluid viscosity, e.g., clays (bentonite)

3. Inactive solids - inert solids added to increase the fluid density, e.g., barite (typically not used in CTD because of the small clearances in the BHA equipment)

4. Lubricants and Chemical additives - a wide range of chemical additives are commonly used to impart the appropriate drilling fluid properties for the specific application, e.g., dispersant, $\mathrm{pH}$ control, corrosion inhibitors. Drilling fluid chemicals are commonly categorized as organic or inorganic. Lubricants are used to aid in lowering friction between the open hole and the CT for better sliding and weight transfer.

The formulation and proportion of these components determine the properties of the drilling fluid, the principal characteristics of which can be summarized as follows.

- Density. Fluid density is tailored to provide the required hydrostatic pressure, under downhole conditions, to prevent (or control) influx of formation fluids into the wellbore. 
- Rheology. Rheology is the study of the flow and deformation of fluids. The ease with which a drilling fluid can be pumped (fluid friction) and the ability of the fluid to transport solids (cuttings) are key characteristics determined by controlling fluid rheology.

- Filtrate. In overbalanced conditions, drilling fluids are designed to deposit a controlled filter cake on the permeable wellbore surface. Once in place, this sheath prevents further influx of drilling fluid or filtrate to the formation.

- Chemical inhibition. The drilling fluid should be chemically stable and should not react unfavorably with wellbore materials, formation fluids or formation solids. A wide range of chemicals are available to control or prevent undesirable drilling fluid reactions.

- Solids content. The action of drilling creates small particulates which, if not controlled, may adversely affect drilling-fluid performance (density and rheology) or operation of pumps and motors (abrasion of key components).

\subsubsection{Hole Cleaning and Annular Velocity}

Efficient hole cleaning is especially important in CTD applications since problems can be exacerbated due to the smaller clearances between the drilling BHA and wellbore. In general terms, turbulent flow provides more efficient cleaning and particle-carrying characteristics but occurs at higher fluid velocities than laminar flow. Geometries and fluid properties commonly encountered in CTD operations mean it is often difficult, and frequently impossible, to achieve turbulent flow. Maximum flow rate in CTD operations is typically constrained by the downhole motor specification and limitations on surface pressure (related to efforts to minimize CT string fatigue (Figure 15)).

Historical rule-of-thumb guidelines for minimum CTD annular velocities with nonviscosified fluids are $120 \mathrm{ft} / \mathrm{min}$ in vertical

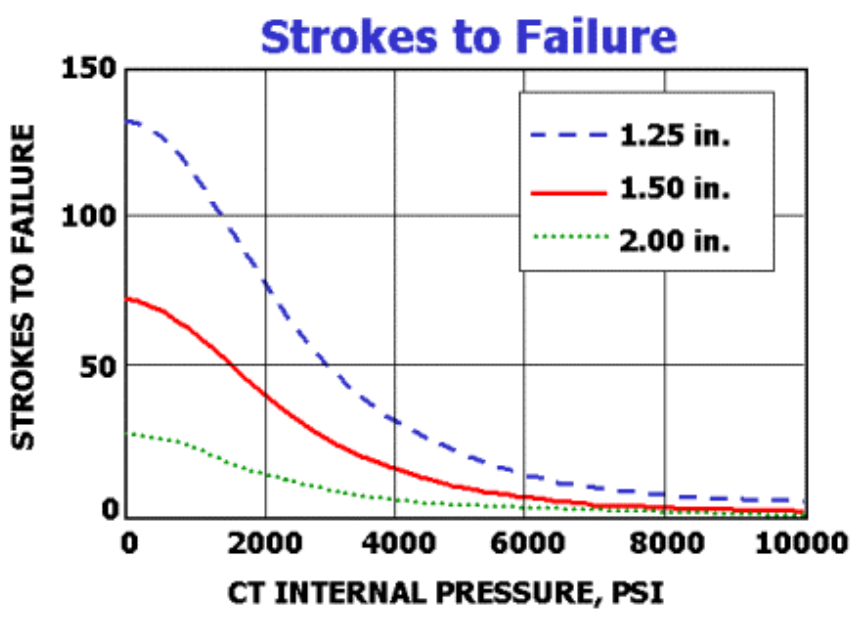

Figure 15. CT Life with Internal Pressure wellbores and $240 \mathrm{ft} / \mathrm{min}$ in horizontal wellbores. These values may be reduced for viscosified fluids. However, the scouring action of non-viscosified fluids in turbulent flow can be advantageous, especially in horizontal wellbores. A similar rule of thumb, often applied in preliminary feasibility studies, recommends that annular velocity should be at least twice the fall velocity of a particle in the fluid under review. A general formula for calculating annular velocity is as follows: 


$$
V=\frac{24.5 Q}{d_{1}^{2}-d_{2}^{2}}
$$

where

$$
\begin{aligned}
& V=\text { annular velocity (ft/min) } \\
& Q=\text { flow rate }(\mathrm{gal} / \mathrm{min}) \\
& \mathrm{d}_{1}=\text { diameter of hole }(\mathrm{in}) \\
& \mathrm{d}_{2}=\text { diameter of drillstring (in) }
\end{aligned}
$$

Given the number of potential variables in any fluid/particle/wellbore study, computer models are typically used to design fluid performance and the hydraulics program (Figure 16).

\subsubsection{Hydraulics Program}

The primary purpose of a hydraulics program is to ensure the drilling operation is conducted in an efficient manner and within the limits determined during the design phase. The "program" may vary in form from a simple, relatively informal check list and pumping schedule to a computer-based system providing continuous monitoring, recording and real-time modeling. In advanced monitoring systems, the real-time parameters may be displayed alongside the modeled results to enable design values to be closely followed. The common objective of hydraulics programs is that all components, elements or parameters influencing, or influenced by, the circulating system are considered and that circulation of an appropriate fluid at the desired rate and pressure can achieve the necessary results.

The requirement for a formal hydraulics program increases as the complexity of the wellbore, tool string or drilling operation increases. For example, the effect of pumping high viscosity fluid slugs on the operation of motors or hydraulically operated equipment should be understood. Similarly, the effect or implications of changing fluid parameters on pump rate and pressure should also be assessed. Ultimately, it is the impact that any variable may have on hole- 
cleaning efficiency that must be assessed and understood. Key parameters which should be known or considered for most operating conditions include the following.

1. Fluid flow rate - pump rate (in), wellbore returns rate (out)

2. System pressure - circulating pressure (pump), bottomhole pressure (available at the tool string), wellhead pressure

Factors which directly or indirectly influence hydraulic performance and, therefore, the hydraulic program include:

1. Fluid flow - CT string (ID and length), geometry of tool-string components, rheology of drilling fluid(s)

2. Fluid system pressures - separator or process equipment back pressure, solids (cuttings) loading

3. Pump capacity - operating (and maximum peak operating) pressure, rate and horsepower of the pump system

4. Fluid capacity and handling - ability to safely prepare, store and deliver varying quantities of different drilling fluids at the desired rate, e.g., if high-viscosity slugs are to be pumped

5. Fluid processing - on a recirculating system, the ability to process fluids at an adequate rate to maintain the desired solids, gas or reservoir fluid content is important. Subsequent fluid conditioning or treatment may also require a minimum "residence time" before the fluid is recirculated.

\subsection{WINDOW MILLING}

One of the operations in the CTD project that requires significant planning is window milling. The use of CTD for through-tubing casing exits provides an economical means of accessing marginal or bypassed pockets of oil, by avoiding the need to remove existing completions and eliminating expensive workovers. Sidetrack re-

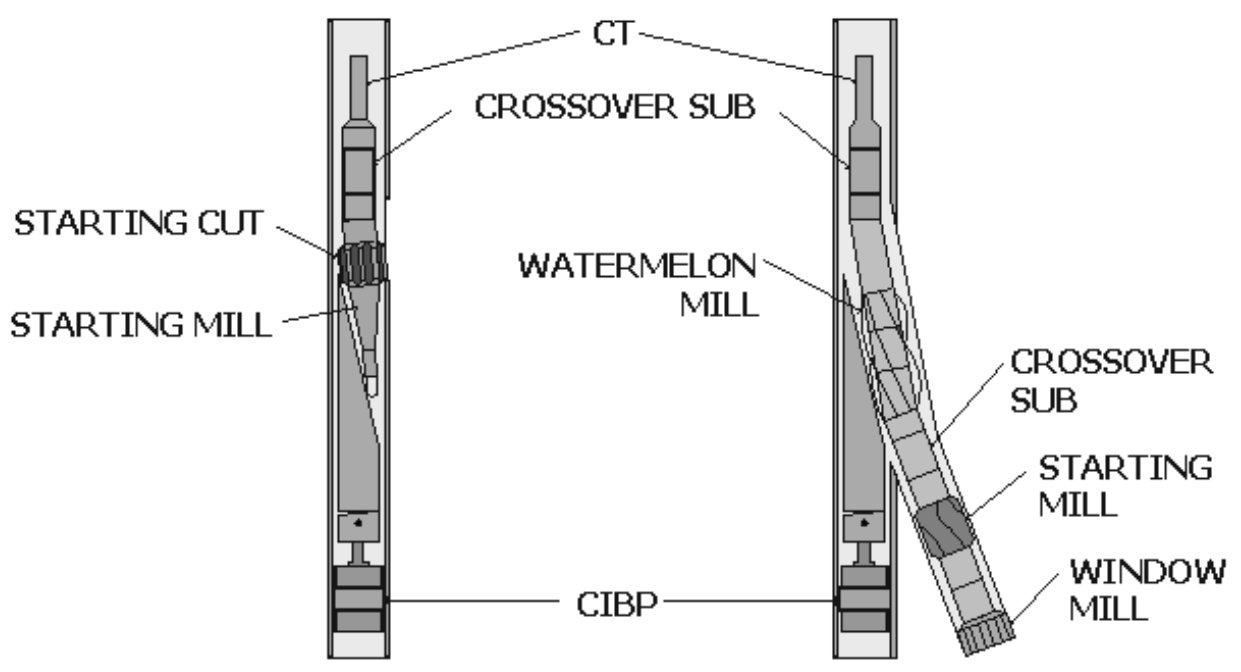

STARTING MILL

WATERMELON MILL

Figure 17. CT Window Milling with Whipstock 
entry applications currently completed with CTD techniques include the following:

1. Through-tubing re-entry with completion left in place and side-track below the tailpipe

2. Through-tubing re-entry with completion left in place and side-track from inside the tubing

3. Conventional re-entry with completion pulled and sidetrack from existing wellbore

Initial well research performed on the project will indicate whether through-tubing tech-niques can be used or if conventional techniques are required. Through-tubing re-entries can only be undertaken using mill and bit assemblies compatible with the minimum ID (restriction) in the tubing string or completion. In some cases, tubing restrictions can be milled out or cut to allow access for larger mills and bits. Directional and non-directional deepenings and sidetracks may generally be undertaken through completion strings of $3 \frac{1}{2}$ in. or greater. The resulting drain hole is generally 3 in. for the $23 / 4$-in. tools and $4 \frac{1}{8}$ in. for the 3 -in. directional tools, depending on the minimum restriction.

Through-tubing re-entry techniques have special significance in applications where completion removal is uneconomical or impractical. The constraints associated with working within the completion tubulars generally preclude conventional rigs and equipment from this type of operation. There are three basic techniques that can be used to kick off and mill a casing or liner window:

1. Cement kick-off

2. Conventional whipstock

3. Through-tubing whipstock

Merits and shortcomings of each should be weighed, along with the specific circumstances of the well to determine which method is best suited. Some circumstances to be considered are:

- Is this a cement kick off below a tubing tail?

- Is there a nipple or restriction in the tubing tail that must be milled out or removed?

- How much rat hole is available?

- How much distance is there between the tubing tail and the top perforation?

- Is the area for the window in a high build portion of the wellbore?

- What is the history of work done in the perforated zone? Will it require additional cement or additives to bridge off the perforations? 
Where is the window in relation to the gas cap?

- Will this window be milled through two different tubular sizes (i.e., tubing and casing or two overlapping casing strings)?

- Will this be a low side or high side window?

- What are future plans? Can I leave enough room for another sidetrack?

- Is this a through-tubing whipstock window?

- Do perforations need to be squeezed before setting the whipstock or can they be squeezed afterwards or at all?

․ Will the whipstock be set in or below the perforations?

- What is the condition of the liner or casing to be set in?

- Is there a nipple or restriction in the tubing tail that must be milled out?

- Can this whipstock be set on wireline or does CT need to set?

a Can the whipstock be oriented in the desired direction?

- Is a whipstock available that will pass the required restriction and set in the casing?

- Is the whipstock the right one for the weight casing in this well and has casing weight been verified?

- Can this window be milled in one step or is two-step method required?

- Is this a conventional whipstock window?

- Do perforations need to be squeezed before setting the whipstock or can they be squeezed afterwards or at all?

- Will the whipstock be set in or below the perforations?

- What is the condition of the liner or casing to be set in?

a Can this whipstock be set on wireline or does CT need to set?

- What fluids will be required to kill the well?

a Can the whipstock be oriented in the desired direction?

- Has a CBL been run in the area of the window?

- Is there sufficient cement bond behind the casing string to be milled?

- Is a block squeeze required prior to milling the window? 
- Is the well vertical, deviated or horizontal at the depth of the window?

\subsection{OPEN-HOLE LOGGING}

Due to the small clearances between logging tools and the open-hole diameter, open-hole logging has been kept to a minimum. However, tools have been and are continuing to be developed for logging in these smaller diameters and used while drilling (mainly in a measurement-after-drilling (MAD) pass mode). The Reservoir Engineer, Geologist and CTD Engineer should discuss in detail the logs needed versus the logs requested. Different wellbore circumstances will dictate the logs required or feasible for a particular project. Availability of the tools when required is a question that needs attention up front.

Objectives of the well must be kept in mind particularly while discussing logging operations. Generally, an agreement is reached, based on the hole conditions, to go (or not go) forward with logging. Also, depending on logging tool length and hole conditions, it may be decided to perform one or multiple logging runs. Most logging operations in CTD require a gamma-ray and neutron log which can be obtained through the liner before perforating, thereby avoiding any need for open-hole logs. A resistivity log, if required, will have to be run in the open hole. Any precautions necessary for particular tools should be discussed while planning the log runs (e.g., if differential sticking is possible, be aware of the weak point in the logging string so as not to leave a fish in the hole; when radioactive source is in the riser, precautions must be made for emergency situations where personnel must pass the source while evacuating).

\subsection{WELLBORE TUBULARS AND WELLHEADS}

Casing strings are run to prevent collapse of the wellbore and to act with the cement sheath to isolate and separate producing formations. Size and specification of the casing string are optimized based on expected productivity and must be designed to withstand internal and external forces associated with completion, corrosive environments and forces associated with running the casing. The casing string is typically designed from "the inside out," i.e., a design that is based on providing a stable wellbore of a size which optimizes the total fluid production over the life of the well (including the possibility of artificial lift later in the life of the well).

The design process is typically comprised of four principal steps or phases:

1. Determine the length and size of all casing strings that are needed to produce the well to its maximum potential

2. Calculate the pressure and loads from predicted production and operations such as stimulation, thermal application and secondary recovery

3. Identify any corrosive fluids or environments to which the casing string will be exposed and select appropriate alloys or protection systems 
4. Determine the weight and grade of casing that will satisfactorily resist all mechanical, hydraulic and chemical forces applied

Table 3 shows common casing/bit-size combinations.

Table 3. Typical Casing/Liner and Bit Combinations (inches)

\begin{tabular}{|c|c|c|c|c|c|c|c|c|c|c|c|c|c|c|c|c|}
\hline \multirow[b]{2}{*}{ Bit Size } & \multicolumn{16}{|c|}{ Casing/Liner } \\
\hline & $23 / 8$ & $27 / 8$ & $31 / 2$ & 4 & $41 / 2$ & 5 & $51 / 2$ & $65 / 8$ & $\begin{array}{l}75 / 8 \\
73 / 4\end{array}$ & $85 / 8$ & $95 / 8$ & $10^{3} / 4$ & $\begin{array}{l}113 / 4 \\
117 / 8\end{array}$ & $\begin{array}{l}133 / 8 \\
14\end{array}$ & 16 & 20 \\
\hline $23 / 4$ & $x$ & & & & & & & & & & & & & & & \\
\hline $27 / 8$ & $x$ & & & & & & & & & & & & & & & \\
\hline 3 & $x$ & & & & & & & & & & & & & & & \\
\hline $3 \frac{3}{4}$ & $x$ & $x$ & & & & & & & & & & & & & & \\
\hline $37 / 8$ & $x$ & $x$ & & & & & & & & & & & & & & \\
\hline $41 / 4$ & & $x$ & & & & & & & & & & & & & & \\
\hline $41 / 2$ & & $x$ & $x$ & & & & & & & & & & & & & \\
\hline $4 \% 8$ & & & $x$ & & & & & & & & & & & & & \\
\hline $43 / 4$ & & & $x$ & $x$ & & & & & & & & & & & & \\
\hline $57 / 8$ & & & & $x$ & $x$ & & & & & & & & & & & \\
\hline $61 / 8$ & & & & & $x$ & $x$ & & & & & & & & & & \\
\hline $61 / 2$ & & & & & & $x$ & $x$ & & & & & & & & & \\
\hline $77 / 8$ & & & & & & & $x$ & $x$ & & & & & & & & \\
\hline $81 / 2$ & & & & & & & & $x$ & $x$ & & & & & & & \\
\hline $83 / 4$ & & & & & & & & & $x$ & & & & & & & \\
\hline $91 / 2$ & & & & & & & & & $x$ & $x$ & & & & & & \\
\hline $105 / 8$ & & & & & & & & & & & $x$ & & & & & \\
\hline $12 \frac{1}{4}$ & & & & & & & & & & & $x$ & $x$ & & & & \\
\hline $14 \frac{3}{4}$ & & & & & & & & & & & & $x$ & $x$ & $\mathrm{x}$ & & \\
\hline $171 / 2$ & & & & & & & & & & & & & & $x$ & $x$ & \\
\hline 20 & & & & & & & & & & & & & & & $x$ & \\
\hline 26 & & & & & & & & & & & & & & & $x$ & $x$ \\
\hline
\end{tabular}

If a casing string is not hung from the surface, but is hung from a point downhole, it is called a liner. Production liners are permanent liners run through the productive interval. On a new completion, these liners will typically be hung from a liner hanger with approximately $300 \mathrm{ft}$ of overlap into the casing string through which it is run and cemented in place. On CTD throughtubing sidetracked wells, the liner is typically brought back up to above the production tubing tail and cemented in place (no liner hanger is used). The top of the liner needs to be designed such that it is away from any downhole restrictions and is at a point where it can be retrieved/fished if necessary. In the through-tubing application, a flush-joint type connection is utilized on the liner to facilitate passage of the restrictions in the wellbore, the window, and the open-hole doglegs. 
Because of this string design, the use of centralizers/turbolizers is needed to help with stand-off from the open-hole wall and provide for good circulation of cement around the pipe. A good rule of thumb for the designed spacing of the centralizers in the liner is one every joint in the horizontal section and one every other joint in the build section to $200 \mathrm{ft}$ above the window.

\subsubsection{Wellheads}

The wellhead is a generic term used to describe the surface equipment from which the well is constructed during drilling operations. The Xmas tree or valve array used to control the well during production is mounted above the wellhead and is typically obtained from the same manufacturer to ensure compatibility. The primary functions of most wellheads include:

- $\quad$ Suspend and secure wellbore tubulars (casing and tubing)

- Provide a hydraulic seal between casing strings

- Provide access port(s) to casing or tubing annuli

- Provide a secure and pressure-tight mounting for the Xmas tree or surface flow control devices

Wellhead specification and configuration can be an issue when designing and executing CTD operations in two principal areas:

1. Design and configuration for new well applications

2. Ensuring compatibility of existing wellheads (flanges and connections) for rig-up of pressure control equipment for re-entry applications

Components of a typical wellhead include the following:

- Casing head

- Casing hanger

- Tubing head

- Xmas tree
- Casing spool

- Crossover flange

- Tubing hanger

Following are examples of casing/wellhead configurations for a CTD new well and a re-entry.

\subsubsection{New Well}

The largest feasible hole size for CTD techniques is generally $12 \frac{1}{4}$ inches. The most common hole size for new drills is $61 / 2$ in. A new well might begin with a joint of $13 \% 3$-in. casing set at surface, pile driven or surface drilled by a water-well rig depending on wellsite conditions and local equipment availability. 
An example of new well casing/wellhead configurations are as follows:

\section{Example 1}

Step 1:

a $135 \%$-in. flange welded on $13 \frac{3}{8}$-in. casing stub

- 135/8-in. casing spool (or a 135/8-in. casing head can be attached directly to the top of the casing stub by screwing or welding. This would serve as the casing spool).

a $135 / 8$ - by $13 \frac{5}{8}$-in. drilling spool with two outlets

- BOP (either $13 \frac{5}{8}$-in. ram or single annular, depending on setup)

a CTD riser with bottom and top adaptors to suit

With the $12^{1 / 4}$-in. hole section drilled, the next casing string $\left(9 \frac{5}{8} \mathrm{in}\right.$.) is hung off from the $135 \%$-in. casing spool. The configuration is as follows:

Step 2:

135/8-in. flange on $13 \%$-in. casing

a $13 \%$-in. casing spool

प 11-in. casing spool

a 11-in. drilling spool with two outlets

- 11-in. BOPs (ram or annular)

- CTD riser with bottom and top adaptors to suit

The $81 / 2$-in. hole section is drilled and 7 -in. casing run to provide the following configuration.

Step 3:

a $13 \%$-in. flange on $13 \%$-in. casing

$13 \%$-in. casing spool

11-in. casing spool

a 7-in. casing spool

a 7-in. drilling spool with two outlets

- 7-in. BOPs (either ram-type or annular) 


\section{CTD riser with bottom and top adaptors to suit}

The well is now ready for the final drilling phase and completion process, i.e., tubing hanger and Xmas tree installation.

\subsubsection{Re-entry Well}

Re-entry CTD operations are typically performed on wellbores having an existing wellhead. This requires that the CTD pressure-control equipment be installed on the production tree (as in conventional CT service applications). If the existing wellhead configuration causes the BOP stack to be too tall for the substructure the tree can be removed and the pressure-control equipment installed on the lower master valve. Typical spool size/tubing combinations are:

- $\quad$ 7-in. spool for 31/2-in. production tubing or smaller

- $\quad 9$-in. spool for $4 \frac{1}{2}$ - to $5 \frac{1}{2}$-in. production tubing, or

- $\quad$ 11-in. spool for larger sizes such as 7 - or $95 / 8$-in. production tubing

Standard drilling spools, casing spools, and crossover spools are available in a wide range of sizes and pressure ratings. The CTD riser assembly will be configured to suit the equipment in use, i.e., size, rating and functionality.

\subsection{LINER CEMENTING}

Running and cementing liners with $\mathrm{CT}$ is a relatively new operation in the petroleum industry. Cementing liners with CT combines aspects of conventional liner cementing, slim-hole cementing, and deviated wellbore cementing. Liner sizes are generally small, ranging between $23 / 8$ - and 51/2-in. OD. Liner lengths are typically about 500 to $2000 \mathrm{ft}$. Annular clearances are generally between 0.3125 - and 0.625 -in. Some common annular clearances are: $23 / 8$-in. liner inside a 3 -in. hole gives an annular clearance of 0.3125 -in.; 27/8-in. liner inside a $4 \frac{1}{8}$-in. hole gives a 0.625 -in. annular clearance. Maximizing this clearance in the design of the well is crucial to the cement slurry design.

The cement slurry design for a CT liner operation includes some special properties. These properties allow it to be mixed and pumped at the rates needed to ensure good displacement of the drilling fluid; allow for adequate fluid-loss control; and in many cases, control gas migration. The following design parameters are particularly important to CT liner cementing, and are provided, along with recommended ranges of values, as general guidelines. Specific situations may require specialized testing and design parameters.

- Thickening time - mixing time (generally 1-2 hr) + pumping time for cement placement + static time (releasing from liner) + safety factor (generally 1-2 hr). Total time in general is 4-6 hr. 
- Fluid loss - industry standard requirement for liners is to design the slurry with a fluid loss less than $50 \mathrm{cc} / 30 \mathrm{~min}$. This guideline applies for CT liners as well. If annular gas migration is likely, lower the designed fluid loss to approximately 20 to $30 \mathrm{cc} / 30 \mathrm{~min}$.

Table 4. API Fluid-Loss Guidelines for CT Liner Cementing

\begin{tabular}{|l|c|}
\hline CT Liner Operation Conditions & $\begin{array}{c}\text { API Fluid Loss } \\
\text { (cc/30 min) }\end{array}$ \\
\hline No gas migration potential & 50 to 80 \\
\hline Low gas migration potential & 30 to 50 \\
\hline Moderate to high gas migration potential & 20 to 30 \\
\hline
\end{tabular}

- Rheological properties - recommendations for rheological properties for CT liners are:

a plastic viscosity less than 50 at BHCT

a yield point - maximum: 20lbm/100 $\mathrm{ft}^{2}$ at $\mathrm{BHCT}$; minimum: 5 to 6 $\mathrm{lbm} / 100 \mathrm{ft}^{2}$ at BHCT

- Compressive strength recommendations are as follows:

a final strength: 2000 to $3000 \mathrm{psi}$

a minimum compressive strength: 500 psi in 12 hours

- $\quad$ Free water and settling required parameters are 0 .

Once these parameters are determined for the particular project, it is imperative that both a laboratory design and computer design be performed. Simulation

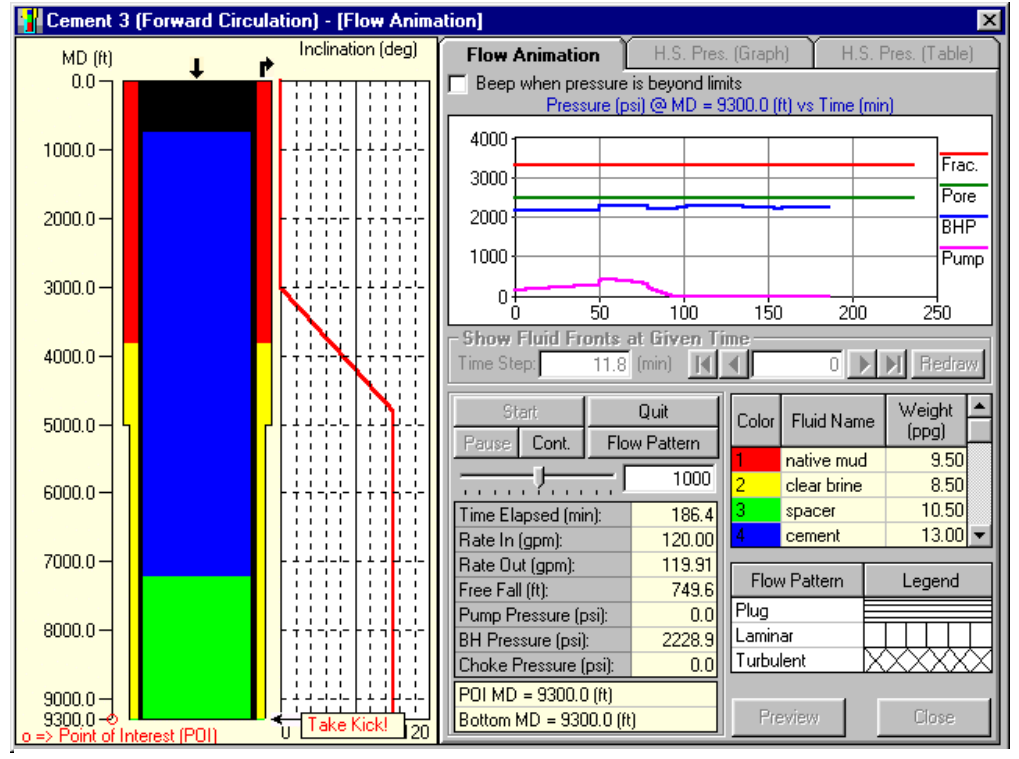

Figure 18. Modeling Pressures for Pumping Cement Stages (from MTI's CEMENT Model)

will determine the appropriate flow rates that can be pumped during the cementing process and ensure that the displacement process is optimized. A simulator must be used to calculate the hydraulic pressure schedule that will occur during the job (Figure 18). 


\section{Pre-Job Planning - On-Site}

\section{Overview}

On-site preparation and planning is the point in the operation where field personnel become involved and provide input to the project to ensure a complete understanding of the well objectives. This understanding is reached by performing several tasks which include review of the procedure and well data, pre-spud meeting, pre-rig work, rig move in and set up, review of equipment and maintenance records, and review of contingencies and procedures. The prespud meeting is where any special needs for the upcoming well are noted, such as special bits or equipment requiring shipment. Any problems or questions about the well and/or objectives should be discussed and answered at this meeting. After the procedures and well are fully discussed, the CTD Supervisor should be prepared to begin the preparation work and ensure the location is prepared for the rig.

The CTD Supervisor should make all necessary notifications to the regulatory representative and any equipment vendors or suppliers when the rig begins its rig-up process. Besides procuring the proper equipment, the CTD Supervisor ensures the maintenance, inspection, and testing of the equipment are performed and completed. All of the equipment should have updated maintenance records, inspection records, insurance verification and certification of rating for conditions in which it will be used. In particular, a record of the history of the usage and storage of the CT must be reviewed.

As a further precaution, any contingency plan needs are discussed and procedures written to be included with the main procedure. Responsibilities for coordinating and conducting the contingency plans are determined prior to the starting of the CTD operation. Also, assurance of availability of adequate material and equipment to implement contingency measures is made and documented.

\subsection{WELL PLANNING/PREPARATION}

The on-site planning and preparation of the well is the major point at which the CTD Supervisor needs to ensure that, from the field point of view, there is a complete understanding of the well objectives. The CTD Supervisor needs to review the procedure in detail, making note of any questions or problems foreseen from the procedure to reaching the stated objectives.

A discussion of the proposed wellbore preparation with the CTD Engineer/procedure author must take place prior to any activity on the well. During this discussion, any special needs should be noted for the upcoming well such as special bits or equipment that will require

shipment. As a follow-up to this discussion, the CTD Supervisor should review the following well data: 
- Well history file for important items such as

- PBTD tags (soft or solid? were the last three consistent? sample taken?)

a Tubing or liner obstructions

․ Fish left in hole

- Subsurface safety valve removed; open or closed status if tubing retrievable

๑ Profile modifications

- How perforations react to fluid injection

- Gas-lift valves (live or dummies)

Shut-in tubing pressures

- Are perforations plugged and abandoned? Do they need to be?

- Well schematic for key items such as

a Maximum hole angle

Tubing and liner internal dimensions

\ Minimum internal dimensions

- Gas-lift mandrels

- Type of subsurface safety valve

․ Tubing tail detail

口 Profile modifications

a Pack-off gas-lift mandrels (POGLM's), tubing patch, or straddle

A pre-spud meeting should be planned between the CTD Engineer and the CTD Supervisor to include all involved parties in a review of the planned work and objectives. This meeting should include the CTD contractor, the directional driller, reservoir engineer, geologist, bit company representative, and fluid company representative. All aspects of the well should be discussed in detail from the geology to the completion of the well. Any concerns or changes stemming from this meeting should be assigned to the appropriate individual and a date for assigned for reporting back to the CTD Engineer.

The CTD Supervisor should coordinate any downhole preparation work that is needed with the CTD Engineer and ensure that all work is performed, reported and recorded. Copies of all work performed and the records of that work should be sent to the CTD Supervisor. He needs to 
check for a recent corrected PBTD tag by slick line or E-line, and review tag depths with previous tags for consistency. Dummy gas-lift valves are preferred in the gas-lift mandrels, but are not always necessary.

The following tasks need to be performed prior to moving the rig to location:

1. Verify that a recent mechanical integrity tubing analysis (MITA) has been performed and passed.

2. Ensure the well is dead and all downhole pre-CTD rig work is complete

3. Ensure a back-pressure valve is installed, the flow line and wellhead removed if necessary, leaving the master valve

4. Inspect roads, bridges, overhead lines and locations and identify any weight or height limitations

5. Inspect location for any hazards, e.g., electrical fire, environmental, etc.

6. Locate and mark underground flow lines, power cables, injection lines and ground wires

7. Request equipment to level the well site in preparation for the rig move

8. Submit a rig move form 24 hours in advance or as required by the regulatory agent and verify that the proper departments are informed

9. If an offshore operation (Figure 19):

- review platform deck loading constraints as specified in the construction drawings

- Identify Class I, Division 1 and 2 hazard areas on the platform as outlined in API RP 500

- Determine the crane lifting capacity and the maximum practical load limits relative to boom length and load placement radial distance from pedestal. Crane inspection, testing, maintenance records and operator qualifications must be present on location.

- Identify deck space constraints for equipment rig up and propose a preliminary plan for equipment placement.

- Identify any areas with general hazards; mark or replace as necessary.

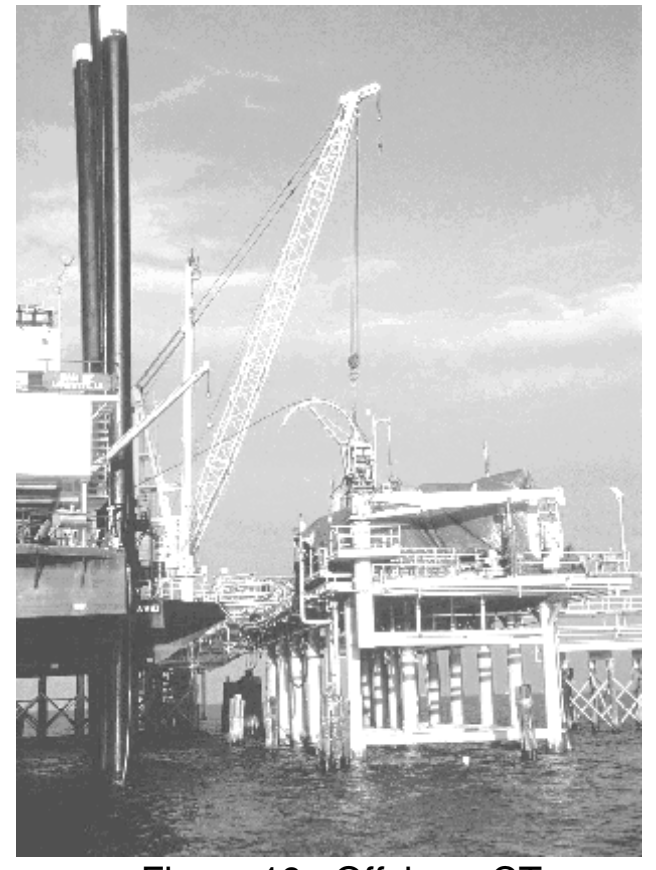

Figure 19. Offshore CT Operation 
- Prepare for potential consequences and hazards resulting from proposed well work.

The following notifications should be made:

1. MWD supplier needs to be on location at least 4 hours prior to picking up MWD tools

2. Notify regulatory representative 24 hours prior to BOP test

3. Bit companies as needed

4. Directional driller

5. Production Field Superintendent/Engineer prior to removing wellhead

6. Perforating and logging company

7. Liner equipment supplier

8. Send the Cement Company a copy of the cement procedure

Move rig and set up

1. The driller should notify the regulatory agency prior to moving

2. Request transportation to move low boy, geologist shack and MWD trailers to location as needed

3. Ensure that a triplex and air compressor are brought to location. Light plants and heaters as needed in the winter (Figure 20).

4. Spot three return tanks and two or three upright tanks (two for water in summer and one extra for $\mathrm{MeOh}$ in winter, if necessary)

5. Fill two uprights and rig pits with fresh water for cement P\&A (heated fresh water if in cold climate)

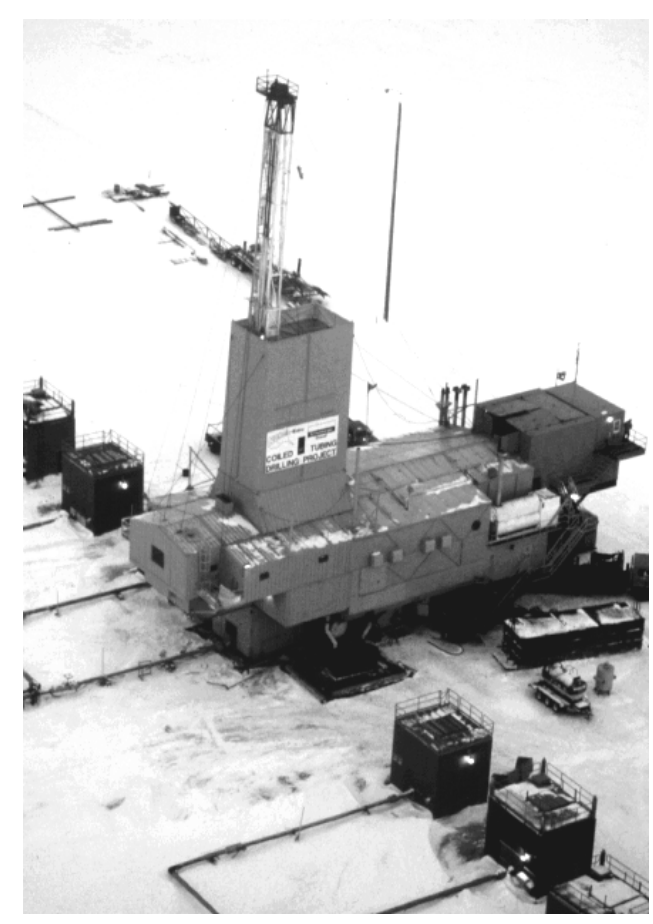

Figure 20. Winterized CT Rig 


\subsection{CT MANAGEMENT AND SAFE OPERATIONS}

\section{Overview}

There are several conditions that may affect CT string reliability as a direct result of inadequate care and attention (maintenance). In the majority of cases, the consequences are not immediate, but instead will lead to a rapid worsening of condition (e.g., accelerated fatigue) and ultimately result in string failure significantly before predicted or anticipated. The principal objectives of pre- and post-job maintenance procedures are to:

1. Prevent or control internal and external surface corrosion that may affect string performance

2. Prevent restrictions to the work-string drift diameter

\section{CT Management}

The CTD contractor should ensure that the tubing and equipment have been properly maintained and prepared for the CTD operation. Prior to arrival on location, the following should be performed or provided to the CTD Supervisor and/or Engineer.

- The service history of the CT string should be established, including the remaining bend-cycle fatigue life (and maximum pumping pressures), exposure to acids or other corrosive chemicals and detection or observation of surface defects and pipe deformity.

- CT should be cleaned and flushed prior to dispatch to location. Additional pickling may be required to remove debris from the tubing. Any acid should be displaced with a neutralizing soda ash solution and sand pills for scouring the ID of the CT should be displaced with fresh water (it's important that no salts remain in the string) and elastomer plugs (where possible).

- CT and the service reel must be pressure tested to at least the maximum anticipated surface pumping pressure and held for a minimum of 30 minutes.

- Displace fluid in the CT with nitrogen and allow the pressure to bleed down to maintain a nitrogen blanket in the CT string.

- Use an approved storage inhibitor.

One of the key factors for string life is storage and maintenance. The rigorous quality checks and tests performed by the manufacturer ensure a competent CTD string when first used. However, the mode of operation for most CTD projects seems to frequently be a "one-of" type of operation, where CT is used for a job and then stored for several months before being used for 
another project. Careful management and inventory of the CT at this point will significantly reduce the cost of the project.

When CT is to be stored, even for a relatively short period of time, several considerations should be made to ensure that the work string and associated documentation package are kept in satisfactory condition. CT made of carbon steel materials that can quickly corrode when exposed to atmospheric, industrial and marine environments. Such corrosion can occur on the inside of the tubing (internal corrosion), as well as on the outside (external corrosion).

Internal corrosion has an obvious detrimental effect on the working life of a CT string. Small amounts of moisture condensing inside the tubing can cause localized corrosion, leading to thinning of the tubing wall and stress risers. An internal corrosion inhibitor is applied to ensure that the CT is delivered in a condition as close to as-manufactured as possible. This inhibitor protects the CT under various transportation and storage conditions, but does not adversely affect tubing performance.

Once the string has been used, protection of the ID begins with the flushing and neutralizing of the reel contents. Subsequent purging with nitrogen is frequently required to allow safe loading and transportation of the reel. Whenever possible and practical, reels should be blown dry with nitrogen to minimize the residual fluid which collects at the bottom of the tubing wraps. Currently, for storage the CT manufacturer recommends that the ID and OD be coated with Nalco $9281 \mathrm{~A}$ or equivalent corrosion inhibitor.

As with internal protection, inhibitors are used to keep corrosion to a minimum on the outside of the CT string. To prevent surface rust, the following conditions must be met:

1. The tubing surface must be clean and free from corrosive fluids or moisture.

2. A suitable protective coating must be applied to the entire tubing surface.

3. The coating must not interfere with the operational use of tubing, measurement or well control equipment.

4. The coating and its means of application must not cause a hazard to personnel or environment.

5. The best external protection can only be applied to the tubing's OD as it is being spooled onto the reel (either during operation or during maintenance procedures).

Fatigue damage, as a result of internal pressure and bending cycles, is the primary consideration when attempting to define the useful life of a CT string. However, fatigue is an unusual parameter since it cannot be measured and must be predicted. The computer models feature complex mathematical algorithms that were derived from an extensive CT fatigue testing program. This model calculates the damage that occurs to the tubing due to the sequence of 
pressure and bending cycle. By analyzing the cumulative data for a CT string, the model can predict when the first cracks in the tubing will be initiated. By applying a safety factor to this prediction, the CT string may be withdrawn from service before a fatigue-induced operating failure occurs.

To provide data for the computer model to function effectively, the following parameters must be accurately recorded during every operation.

1. Bending cycles

2. Pressure cycles

3. Major and minor diameters

4. Chemical environment

5. Flow rate

With these parameters input to a model, a plot can be made to display the percentage tubing life versus the length of the string (Figure 21). Most models

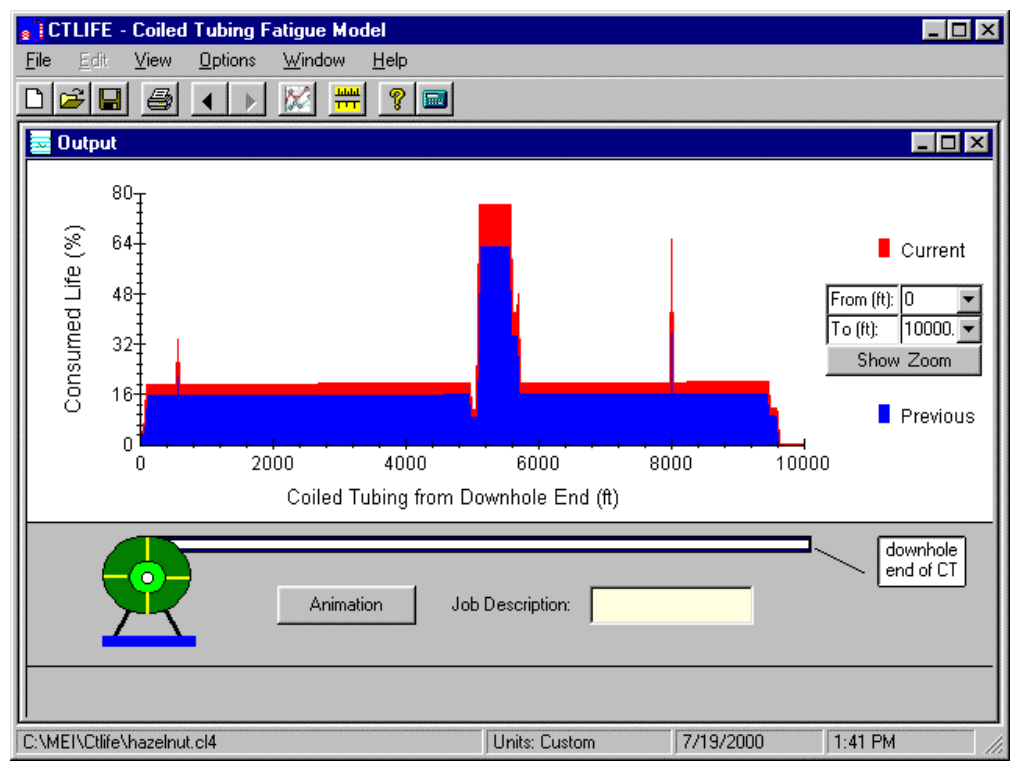

Figure 21. Modeling CT Fatigue for Planned Operation (from MTI's CTLIFE Model) incorporate a means of inputting the proposed pumping and tubing movement schedules for the intended operation. The resulting plot may then be analyzed to verify the ability of the CT string to safely complete the operation within the fatigue limits of the string. CT work strings containing tubing elements that have been used in excess of $95 \%$ should typically be removed from service to allow repair or replacement.

\subsection{HYDRAULICS}

The CTD Supervisor along with the CT Operator and Tool Pusher must determine the optimal hydraulics for the CTD project. A hydraulics program should be used to ensure that the drilling operation is conducted in an efficient manner and within the limits determined during the engineering design process. It can take the form of a simple, informal checklist and pumping schedule or of a computer-based system providing continuous monitoring, recording and realtime modeling. The objective of the hydraulics program is that all components, elements or parameters of the circulating system are reviewed and checked so that circulation of an appropriate fluid at the desired rate and pressure achieves the required results. Ultimately, the effect that any variable has on the hole cleaning efficiency must be assessed and understood. There are some important parameters that must be considered for most operating conditions: 
- Fluid flow rate - pump rate (in), wellbore returns rate (out)

- System pressure - circulating pressure (pump), bottomhole pressure (available at the tool string), wellhead pressure

Factors which directly or indirectly influence hydraulic performance include:

- Bottom-hole and surface temperature (ambient)

- Fluid flow - CT string (ID and length), geometry of tool string components, rheology of drilling fluid(s)

- Fluid system pressures - separator or process equipment back pressure, solids (cuttings) loading

- Pump capacity - operating (and maximum peak operating) pressure, rate and horsepower of the pump system

- Fluid capacity and handling - ability to safely prepare, store and deliver varying quantities of different drilling fluids at the desired rate, e.g., pumping high viscosity slugs; pumping crude to free stuck pipe

- Fluid processing - on a recirculating system, the ability to process fluids at an adequate rate to maintain the desired solids, gas or reservoir fluid content is important. Subsequent fluid conditioning or treatment may also require a minimum "residence time" before the fluid is recirculated

The crew must be kept informed of the operational limits of the circulating system and given the guidelines that are not to be exceeded without approval of the CTD Supervisor. Any necessary remedial action to the system should be discussed before proceeding with the drilling project.

\subsection{EQUIPMENT MAINTENANCE}

In addition to procuring the proper equipment, ensuring that maintenance and inspection of the equipment is performed and completed is a top priority for starting the project. The CTD Supervisor must ensure that the proper documentation operation and maintenance manual is available for each piece of surface equipment. Documentation for the equipment should include

1. A copy of the applicable location safety and loss prevention standards

2. A copy of any applicable local, state or national regulations, codes or insurance requirements

3. A copy of the current inspection record

4. A copy of the record of any repairs or changes to the equipment 
5. A certification form indicating the equipment is rated for the conditions for which it will be used

6. Certified equipment operators

The CTD contractor should provide the CTD Supervisor with the maintenance schedule and program for all equipment supplied. The maintenance schedule should be adhered to and fully understood by all involved parties. An inventory of all spare parts is to be maintained by the CTD contractor and a copy should be provided to the CTD Supervisor. All critical equipment components are to have spare parts or replacements available (e.g. pumps, injector head, CT, crane, BOP). The CTD Supervisor should perform a pre-job inspection in the CTD contractor's yard prior to moving the rig.

All data-acquisition equipment should be calibrated and the CTD Supervisor should witness the calibration or a certified document supplied to him for that equipment. This equipment includes, but is not limited to:

- $\quad$ CT string monitoring

- drilling fluid monitoring

- directional drilling and navigation

- formation evaluation

\subsection{CONTINGENCIES}

The CTD Supervisor and the CT Operator should meet and discuss contingencies and the appropriate contingency measures. The objective here is to attempt to review possible unplanned events and minimize the response time or downtime. Due to the complexity of the CTD operations, contingency planning is required prior to starting the job. Unplanned conditions that may be encountered during an operation include emergency procedures to maintain control of well pressure or surface equipment. CTU operators must be fully familiar with these procedures.

The primary areas for contingency plans or guidelines are:

1. Stuck or damaged drillstring (due to hole conditions)

\section{Open-hole sidetrack}

3. Drillstring integrity

\section{Open-hole logging}

\section{BOP equipment}




\section{Off-bottom drilling practices}

\section{Lost circulation}

\section{Liner running and cementing}

\section{Well control}

\section{Injector head failure or problems}

\section{Perforating}

Contingency plans for each of these areas must be developed and fully discussed by the CTD Supervisor and the CT operator. Most of these areas of problems or failures will require suspension of the operation pending repair or replacement. Along with the understanding of the contingency plans, there should be full agreement between the CTD Supervisor and the CT operator as to the responsible party for coordinating and conducting the contingency plans. The parties should also determine and ensure that adequate material and equipment are available to implement the contingency measures. To supplement the contingency plans, the CTD Supervisor should document the source and availability of any special equipment or services for future reference.

\subsection{WELL CONTROL}

Regardless of the complexity of well-control issues associated with a drilling operation (underbalanced or overbalanced), the necessary checks, procedures and responsibilities must be identified and understood by the personnel involved. In most cases, it is the responsibility of the CT driller to ensure that relevant checks are made and that the data/information on which the drilling operation is proceeding are current and accurate. However, to perform this, the CT driller must typically rely on the assistance of the CTD Supervisor, specialists or other personnel who should in turn be aware of their responsibilities and the need for safe drilling practices.

The CT driller and CTD Supervisor together should verify that adequate well-control equipment and procedures are in place. Any procedural questions or changes should be confirmed with the CTD Engineer. The parties must thoroughly check all well-control equipment and test the equipment as required prior to moving to location. The CTD Supervisor should ensure that quality assurance has been conducted on the well-control equipment and all of the equipment certified for the project as required. 


\section{Operations Execution}

\section{Summary}

The basic objective of most drilling operations is to provide a safe, stable wellbore, fit for the intended purpose and accessing a specific target. CT operations should be executed with minimal risk to personnel or equipment, ensuring the pressure integrity of the well at all times. Maintaining pressure integrity not only requires that wellbore or reservoir fluids are controlled against release at surface, but that the fluids are controlled against uncontrolled cross-flow between high-/low-pressure zones, or similar damaging conditions. Second only to the safety aspect of the operation is data acquisition and quality assurance of the data. There are numerous parameters that must be monitored and recorded during the CTD process.

\subsection{SAFETY}

Safety is JOB ONE in all CTD operations. Because CTD involves the combination of traditional drilling and CT well intervention, personnel used for CTD may have limited experience in one facet or phase of the business, and this can create situations where risks are not readily identified. Also, the intermingling of equipment and techniques can be confusing and create potential hazards. Typically, a hazard identification and review meeting should be held with key personnel from both the client and contractor present. This meeting should review the entire project in terms of individual tasks and attempt to identify/eliminate/minimize the risks and hazards. The CTD Supervisor should develop a safety checklist to suit the specific needs of the project, but it should be usable and effective. The purpose of the checklist is to verify that the equipment and/or procedures are in place and functioning as intended. The checklist should be developed to include the following:

- Safety equipment

- Safety procedures

- Safety Management Systems (How the safety system is managed and monitored for effectiveness)

- Mechanical review/audit of all equipment

- CT unit and tubing maintenance records

- Emergency procedures

- Alarms

- Communications 
- Safety drills

- Safety meetings

- Safety training

- Written instructions

- Posted information

- Regulatory compliance (company and governmental)

Attachment 1 is an example of a checklist for a project. Once this verification has been made along with the responsibilities and assignment of duties, execution of the project can proceed. All safety drills, records, meetings and maintenance should be recorded and reported to the CTD Supervisor. If at any time there are questions or doubts about the upcoming operation, operations should be shut down and a safety check/meeting should be held to ensure a safe operation.

\subsection{DATA ACQUISITION}

Acquisition of quality data during the CTD operations is crucial to the success of the well and for future CTD wells. The importance of proper calibration of the sensors, meters and dataacquisition devices cannot be over-emphasized. The CTD Supervisor should obtain a record of the calibration and function testing of the equipment to be used before and during the operation. During the operations, the CTD Supervisor should monitor and interpret the data from the downhole tools as well as the surface sensors and meters. This will allow him and the CTD personnel to quickly identify any deviations of the operational parameters and act accordingly to avert or mitigate problems before they arise. Regular monitoring of the data will also help ensure the quality of the data being recorded and/or reported. Communications between the CTD Supervisor and the CTD crew are a must for quality assurance. Some of the equipment to be monitored regularly are BOP controls, mud system sensors and solids removal, gas sensors, BHA equipment, and CT data-acquisition devices.

\section{Reporting}

All necessary reports and logs must be completed in a timely and accurate manner. Any additional reports regarding problems or issues during the project should be completed and collated to enable follow-up of the well events in a sequential order. Data that should be reported/recorded continually are fluid properties, directional data, pump rate and pressure, differential pressure across the motor, weight on bit, run-in-hole weight of CT, pull-out-of-hole weight of $\mathrm{CT}$, string weight, drilling hours on bit/motor, cycle life of $\mathrm{CT}$, rate of penetration, wellhead pressure and annular pressure. The CT Driller and CTD Supervisor must be informed about these data and any changes that occur. 
Maintaining efficient communication channels between all parties will enable quick and proper response to any changes and allow for a safe operation. The crews should be briefed on any changes and before all pertinent activities. CTD requires close coordination between all the elements that make up the project. It is essential that everyone knows the operational plan from an overall viewpoint as well as on a day-to-day basis. Some ideas for successful information transfer are as follows:

- Develop a comprehensive drilling program that details each stage of the well, individual responsibilities, and reporting procedures.

- Hold daily review/planning meetings with key personnel. Establish daily objectives and provide instructions.

- Maintain a system of recording events as they occur. A daily drilling report should be kept, as well as logs concerning actual drilling parameters, hole conditions, directional drilling, mud system, and problems encountered.

- Ensure that issues are communicated between shifts as they change over.

- Document the entire well in a detailed end-of-well report. This report should include all problems and their resolution and any suggestions for improvement. (See Chapter 5 - Post-Job Review)

\subsection{BOTTOM-HOLE ASSEMBLY AND CT DEPLOYMENT}

\section{Overview}

The type of drilling to be done determines the bottom-hole assembly (BHA) configuration for a particular well. This section includes the following:

1. A typical BHA

2. A description of each component

3. A discussion of tripping and wiper trips

The CTD Supervisor and the Directional Driller (DD) must complete a review of the compatibility of the BHA with the drilling procedure and anticipated formations to be penetrated. They along with the CTD engineer select the BHA configuration and make adjustments as drilling progresses. Each of the involved parties for the BHA must check and inspect their respective tools for proper operation prior to making up the BHA. Alignment of the directional tools and the bent motor, if used, is the responsibility of the DD and the directional engineer on location. The $\mathrm{DD}$ is also responsible to ensure the BHA components have been measured and all dimensional data recorded. All connections in the BHA must be made up to the torque specified by the manufacturer with some type of thread lock compound or set screws to help ensure the 
connections will not back off. No BHA should be run into a well until the DD has verified the dimensional data and confirmed the BHA makeup with the CT driller and the CTD Supervisor.

\subsubsection{Typical Bottom Hole Assembly}

A typical BHA is comprised of the following components:

- CT Connector

- Dual Check Valve

- Hydraulic Disconnect

- Circulation Sub

- Non-Rotating Joint

- Orientor

- Drill Collars (may house any required data acquisition or survey tools)

- Equalizing Sub (for mud-pulse systems)

- Downhole Motor (if directional drilling, with bent housing)

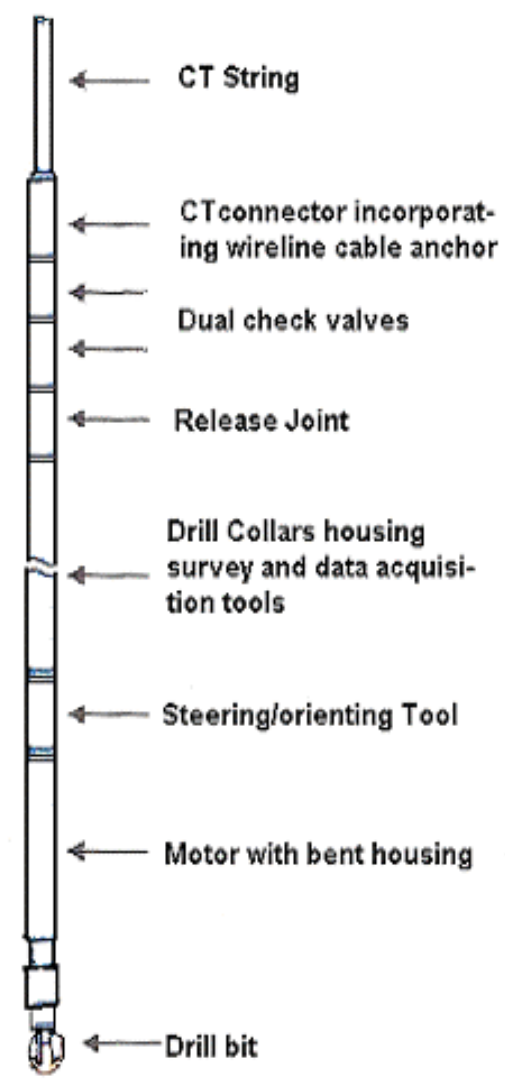

Figure 22. Wireline BHA for Deviated Well

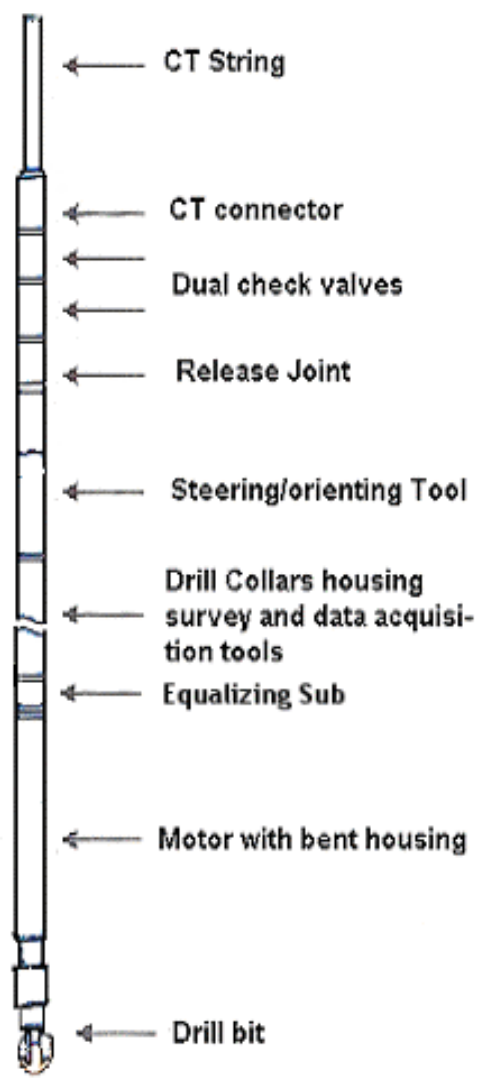

Figure 23. MWD BHA for Deviated Well

- Bit

Figures 22 and 23 illustrate key BHA components for different applications.

\subsubsection{CT Connector (CTC)}

Connectors are commercially available in a wide range of designs and sizes. However, three general categories of connectors are typically recommended (see Figure 24).

1. Grapple connector

2. Setscrew/dimple connector

3. Roll-on connector 
Grapple connectors use a wedge or slip collar arrangement to lock the CT string inside the connector housing. A wide variety of designs are available including single- and bi-directional slip assemblies. A double acting bi-directional design is recommended since the CTC may be exposed to significant compression forces in both directions, i.e., tension/compression. This connector is used with set screws as back-up in some CTD projects.
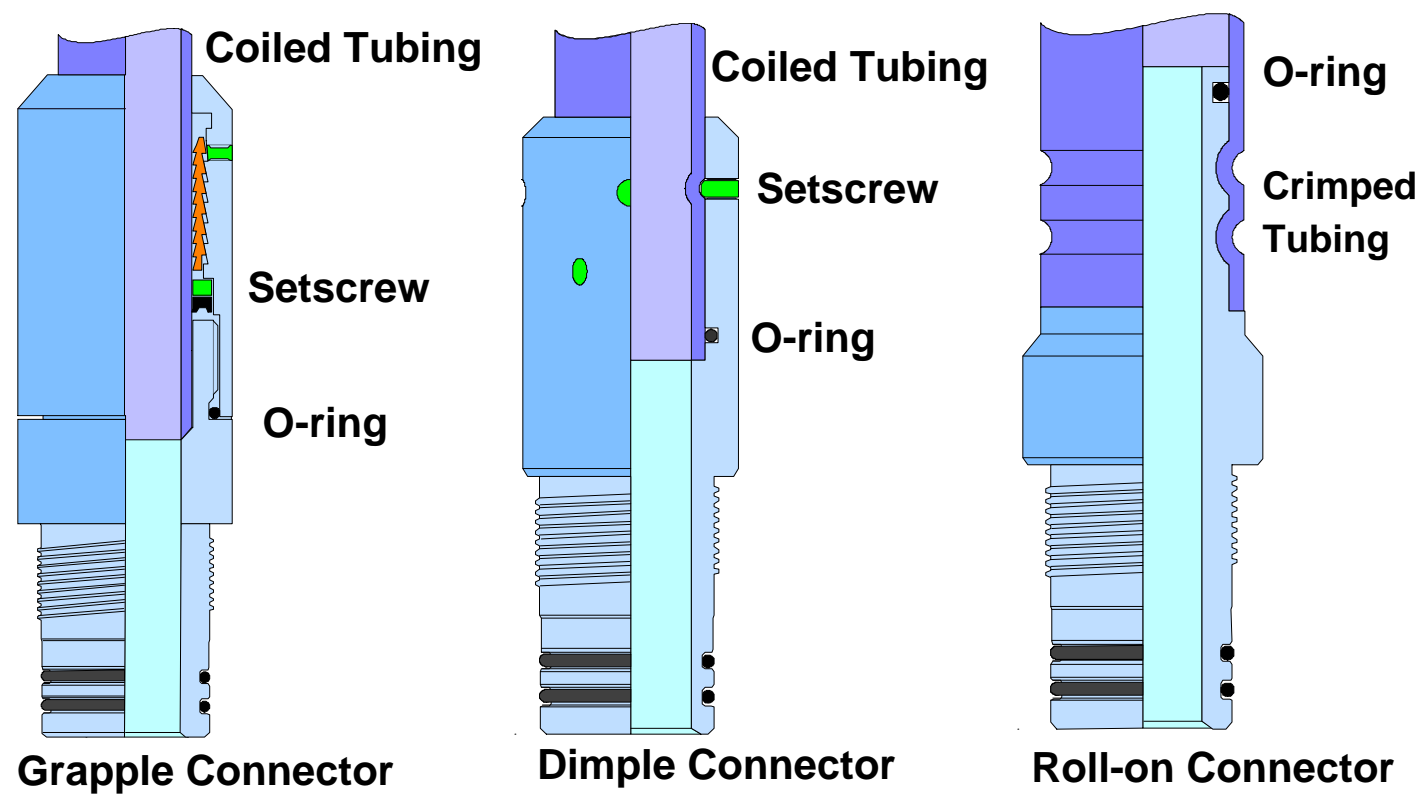

Figure 24. CT Connectors

A dimple-type connector that is secured to the CT with set screws is typically used for CTD. A dimpling tool is used which forms dimples in the CT aligned with the set screw holes in the connector. The dimple-type connector is recommended because of its superior ability to withstand torque, overpull, and drilling shock. Its durability has been established through repeated field use in high vibration and impact applications.

The roll-on connector attaches to the internal diameter of the CT and is held in place by crimping the CT around a connector profile with a special crimping tool. However, the roll-on connector poses a significant obstruction to fluids, darts or balls pumped through the CT.

A profiled neck is also incorporated for contingency fishing. The CTC is usually replaced once or twice during drilling operations, but should be checked for signs of slippage on every trip. Every time the CTC is replaced, a pull test (equal to $80 \%$ of yield strength of CT minus the weight of the $\mathrm{CT}$ ) and pressure test (based on tubing burst and maximum allowable system pressure) should be performed and documented.

Note: Extreme care must be exercised with connectors for larger diameter CT. Ovality and residual curvature of the CT can significantly reduce connector "grip" when used with largediameter, powerful mud motors. Many standard connectors are not suitable in these applications. 


\subsubsection{Dual Check Valves}

A dual-flapper check-valve system (Figure 25) is utilized to prevent unwanted migration of wellbore fluids back into the CT drill string. Tandem check valves are recommended to provide some redundancy of operation. The full-bore (or near full-bore) opening permits the use of more complex CT tools, fluids and operating techniques by allowing balls, darts and plugs to pass through to the tool string from the CT without restriction.

\subsubsection{Hydraulic Disconnect}

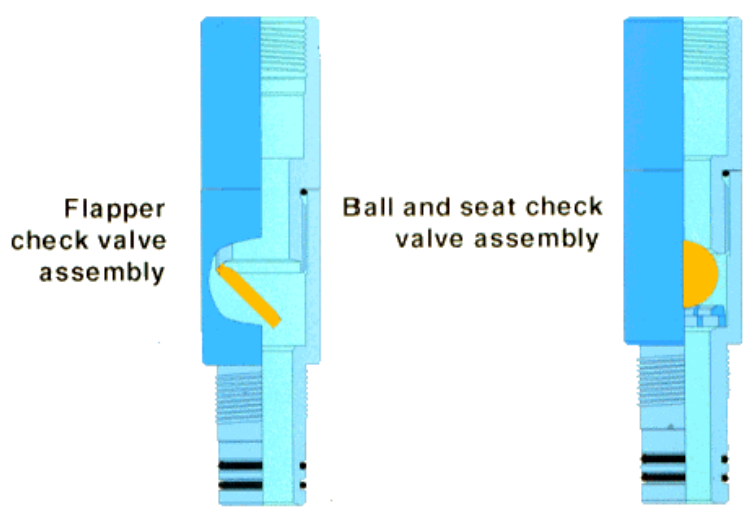

Figure 25. CT Check Valves

A ball-actuated hydraulic disconnect is located below the check valves. The disconnect provides the option to release the BHA should it become stuck in the wellbore. It is recommended that the hydraulic disconnect be pinned at a high shear value (about 5000 psi) and a separate pumping unit be required for disconnecting. For cases where wireline tools are used, the hydraulic disconnect cannot be incorporated. Instead, an electrical disconnect and/or straight pull/shear disconnect is employed.

\subsubsection{Circulation Sub}

Circulating a ball onto a seat activates the circulation sub. When opened, the fluid path is diverted above the measurement-while-drilling (MWD) tools and mud motor, and directed radially through side exit ports. This is a "one-shot" opening device (once the circulation ports are open, they cannot be closed with subsequent balls). The circulation sub allows increased circulation rates by eliminating the pressure loss and flow constraints through the BHA. When tripping out in cased hole, the sub is normally open to improve cuttings removal. This also makes circulation to surface possible without concern for bit or production tubing damage because the bit is not rotating.

\subsubsection{Non-Rotating Joint}

If it is necessary to deploy the BHA into the well in two or more sections, a non-rotating joint (Figure 26) will be required to make up the BHA to the CT string. Once the lower portion of the $\mathrm{BHA}$ is deployed into the well, it is held in place by the BOP slips. String rotation is then no longer possible and a splined non-rotating joint is used to make up this connection. The two pieces slide together and are interlocked with internal splines to alleviate rotation. A threaded collar slides over the splined section to secure the BHA. 


\subsubsection{Orienter and Equalizing Sub}

The orienter is required for wells where directional capability is desired and is designed for use with single-phase fluids. It rotates or indexes the lower portion of the BHA to adjust the tool face in the desired direction. A clutch and cam are incorporated to rotate the tool in a clockwise direction typically in $15^{\circ}$ increments per pump cycle. As normally configured the orientor generates up to $500 \mathrm{ft}-\mathrm{lbs}$ of torque. The indexing force of the orienter is derived from the differential pressure inside the orienter and the annulus pressure outside the orienter. The greater the differential pressure, the greater the torque generated by the orienter for rotating the BHA. When orienting with the choke to increase differential pressure at the orienter, slow pumps down to $\sim 2$ BPM, turn off pump, open choke, bleed pressure to nearly zero, close choke and restart pump.

An equalizing sub can be installed below the orienter to increase the pressure drop through the tool string and enhance the torque generated. Also, there is a bleed port that allows for bypass of approximately $10 \%$ of the drilling fluid and allows pressure to equalize below the orienter that might be otherwise trapped by the motor when the pumps are shut down. Pressure trapped in the tool string as a result of the high viscosity mud can prevent the orienter from cycling.

\subsubsection{MWD Equipment}

The three main components of the MWD system for single-phase drilling fluid operations are the pulser generator assembly, directional probe, and gamma-ray sensor (for single-phase fluids). For most operations with two-phase fluids, a CT e-line system is used and a pulser generator is not incorporated in the BHA. When the components are assembled, they fit inside the nonmagnetic collar which constitutes the MWD system. The collar in turn is situated below the hydraulic orienter and above the motor and equalizer sub.

The MWD system provides real-time tool-face data plus directional survey information to steer the motor bend to the desired orientation for control of the well trajectory. The gamma ray sensor is used for geologic steering and depth control. A resistivity sensor is added in wells where steering away from water contacts is desired. The pulser generator assembly provides both electric power for the directional and gamma sensors as well as hydraulic power to drive poppet extension for producing positive pulse telemetry. Drilling fluid pumped down the coil 
drives the turbine of the generator. This same fluid is the medium for pulse telemetry data being transmitted to the surface computers.

Flex interconnect sondes can be added between individual tool components as well as flex subs above the flow tube and orienter. This should allow the bending moment to occur in the flex area instead of in the rigid flow sub. It is important to remember that flexibility of integral components must be maintained for the system to function properly. Any OD upsets, sharp shoulder transitions, and BHA stiffness impact CT drilling dynamics. Decreasing the size has added more flexibility and flexible components to the BHA and improved drilling. The most flexible points are 1) in the collar flex area below the flow sub, 2) in the flex sub above the flow tube and 3 ) in the flex sub above the orienter.

The MWD equipment should be made up and torqued by the MWD personnel on location and should be checked by the DD and the CT driller. Critical items to check are: 1) the motor/MWD orientation and 2) the orienter movement. After the collars are made up with correct torque on connections at bottom and top of the sub, transfer a scribe line (with a piece of angle iron) from the hang-off collar down to the top of the motor along the axis of the bottom scribed collar. The DD and the CT Supervisor should verify orientation measurements and numbers. It is recommended that while making up the drilling $\mathrm{BHA}$, the orienter should be checked for movement prior to running. Check for movement by setting the slips on the bottom section of the orienter and spinning the orienter with a pipe wrench (counter-clockwise looking down) to ensure that the tool is free to turn.

For safe drilling of the directional program, the CT crew must be informed of the directional objectives of the well. The DD, MWD engineer, CT operator and the CTD Supervisor should be aware of the drilling parameters and of any changes in these parameters. Remedial actions should be discussed, prepared for and performed safely and as efficiently as possible. If there are any doubts about the directional drilling and associated parameters, the operation should be shut down safely and quickly and the way forward discussed in detail. High-quality data is a must for directional drilling to proceed effectively. Every effort should be made by the DD and MWD personnel to ensure that the data received are accurate and validated before being used. Because decisions have to be made quickly in high build holes, it is very important that all dataacquisition equipment is in good working order. Any misplaced or unrecorded data could result in failure to reach the desired target of the well.

\subsubsection{Downhole Mud Motors}

The most commonly used mud motors are $27 / 8$-in. OD with a 7:8 lobe ratio and have adjustable bent housings. Generally they are high flow rate, medium speed motors. Recommended flow rates are 60-120 GPM and 200-400 rpm. Larger motors can be used depending on the tubulars to be run through and the open-hole size to be drilled. Non-magnetic rotor/stator combinations are available and recommended for use while drilling through the formation. Use of nonmagnetic material reduces magnetic interference sufficiently to allow steering tools to be placed 
within 2 feet of the motor. Conventional steel motors require the use of 10-15 ft of monel collars below the directional probe to eliminate magnetic interference, resulting in bit-to-sensor spacing of 20-25 ft. Bit-to-sensor spacing is reduced to about $11 \mathrm{ft}$ with non-magnetic power sections. Wellbore trajectory projections are greatly improved with shorter bit-to-sensor spacing, resulting in more precise directional control.

The box-to-bend length for these motors is in the range of 2.9-3.3 ft. For planning purposes, a "theoretical" build rate of $12.5 \times$ motor bend angle can be used. Field experience has shown that actual build rates are highly dependent on the motor/bit combination used. The DD should know the motor/bit combinations that can be used for a particular build rate. Some common ranges of build rates for $27 / 8$-in. bent motors are shown in Table 5.

Table 5. Build Rates for Bent Motors

\begin{tabular}{|c|c|}
\hline Motor Bend & $\begin{array}{c}\text { Build Rate } \\
(\mathrm{deg} / 100 \mathrm{ft})\end{array}$ \\
\hline $1.0^{\circ}$ & $7-13$ \\
\hline $1.5^{\circ}$ & $10-25$ \\
\hline $2.0^{\circ}$ & $15-35$ \\
\hline $2.5^{\circ}$ & $29-36$ \\
\hline $3.0^{\circ}$ & $25-40$ \\
\hline
\end{tabular}

Recommended drilling parameters that should be monitored by the DD (as well as the CT Driller and CT Supervisor) are weight on bit (WOB), differential pressure and flow rate. Stall pressure for a new motor varies with size; for $2^{7} / 8^{-i n}$. motors it should be about 1000 psi. As a general rule, motors should be able to drill for 60 hours before rebuilding is required. Typically, if the motor becomes stuck and there is an overpull greater than $20 \mathrm{klb}$, the motor should be replaced. Surface indicators of downhole motor problems include low stall pressures and tagging bottom with good weight transfer, but not seeing any differential pressure.

If the BHA is pulled and rerunning the motor is planned, the following should be checked by the DD and CT Driller and reported to the CT Supervisor:

1. Visually inspect the bent housing to ensure that the motor setting has not changed down hole

2. Check bit for rubber (from stator). If present, do not rerun motor.

3. Check lower compression coupling by trying to turn the motor housing section between the adjustable bent housing and the lower nut located directly above the output shaft exit point. If it turns or is loose, do not rerun the motor.

4. Check the bearings by checking for side-to-side or up and down movement. If any movement is noted, do not rerun the motor. 


\subsubsection{Drilling Bits}

The bit is often considered the focal point of a drilling system or assembly since it alone performs the role of cutting a hole through the rock formation. Just as there are many types of formations to be drilled, there is an extensive selection of bit designs and materials, many of which are designed to suit specific conditions. Consequently, selection of an appropriate bit is vital to ensuring optimized drilling results (typically assessed on ROP). When drilling rock formations, bit size ultimately determines hole size (diameter). However, formation movement during and after drilling can result in hole sizes ranging from significantly over gauge (caving and washouts) to under gauge (sloughing or tight hole). Only by combining the bit with an appropriate BHA, drilling fluids program and the application of "good drilling practices," will an accurate and stable wellbore be constructed.

In addition to providing efficient drilling action, bits must fulfill several other functions.

- Bit face cleaning - enable cuttings or drilled materials to be removed from the area once cut

- Hole gauge - create a wellbore not less than the nominal bit size, throughout the life of the bit (wear resistant gauge)

- Connect to the BHA - the bit must be securely and reliably connected to the motor or BHA

To provide these fundamental functions, the majority of bits (regardless of specific design) contain the following design elements.

- A cutter assembly or matrix which provides complete and even drilling action within the nominal bit circumference

- Ports and nozzles directing drilling fluid through the bit and around the bit face to ensure cuttings and debris are removed and to prevent overheating of cutters or mechanical components

- "Gauge wear protection", i.e., the hole drilled at the end of a bit's life should not be smaller than when new. Typically, hard-face treatments or hardened material inserts are used to reinforce friction surfaces. Experience has shown that the ability to accurately steer and/or adjust the BHA trajectory during drilling of a short-radius build-up section is hindered by long gauge protection on the bit. This should be carefully considered during the well-planning stage of a directional well and specific aspects of the well (trajectory, build-up rate, bit-type, etc.) planned accordingly.

- An appropriate tool joint capable of withstanding the forces exerted by the bit/drilling system. In addition, some means of securing the bit for makeup/breakout is either incorporated into the bit design or provided for in a separate torque adapter. Since standard bits come with standard thread connections, the making up of the bit to the BHA at the well site can be problematic due to the 
required torque values of the larger connections. A common practice in such cases is to have the bit pre-torqued and sent to the well site as part of the BHA. Otherwise, bits can be torqued at the well site by laying them out horizontally and using various mechanical devices, such as chain tongs, hydraulic tongs or the crane. This aspect should be recognized and addressed in the well planning stage. Typical connections are:

$$
\begin{aligned}
& \text { a } 33 \frac{4}{4} \text { to } 4 \frac{1}{2} \text { in.; } 23 \frac{3}{8} \text { in. API REG } \\
& \text { a } 4 \frac{5}{8} \text { to } 5 \text { in.; } 2 \frac{7}{8} \text { in. API REG } \\
& \text { a } 5 \frac{1}{8} \text { to } 7 \frac{3}{8} \text { in.; } 3 \frac{1}{2} \text { in. API REG } \\
& \text { a } 7 \frac{1}{2} \text { to } 93 / 8 \text { in.; } 4 \frac{1}{2} \text { in. API REG } \\
& \text { a } 91 / 2 \text { to } 14 \frac{1}{2} \text { in.; } 65 \% \text { in. API REG }
\end{aligned}
$$

On bits that contain moving parts (e.g., roller cone bits), additional features are required to ensure components are adequately lubricated throughout the lifetime of the bit. Because the interaction between bit/motor/formation is critical to optimized drilling performance, the bit selection process typically includes consultation with bit manufacturers/suppliers with the following information or specifications.

1. Formation type, hardness and abrasiveness

2. Motor torque (high torque motors are recommended)

\section{Motor RPM}

\section{Available WOB}

5. Drilling fluid type and flow rate

To reduce the likelihood of subjecting a bit to damaging forces, it is essential that a new bit be allowed to establish its unique bottom-hole cutting pattern, especially when the type of bit, or bit cutter pattern, has been changed. Operating procedures should include the following precautions:

- When approaching bottom, rotation and circulation should be started to clear any fill material and prevent plugging nozzles.

- The hole bottom should be lightly tagged with low RPM, with the RPM and WOB slowly increased to operating values.

- Circulating pressure should be closely monitored to ensure that the optimum bit/motor hydraulic performance is being achieved. With a constant flow rate, downhole motors exhibit a differential pressure between off-bottom and onbottom. This differential pressure will have a range depending on the specific motor size and lobe configuration, with the lower end being the off-bottom circulating pressure, and the upper end the maximum circulating pressure prior to 
motor stall. Once the motor stalls, there is an immediate increase in circulating pressure far above the upper end of the differential pressure range. With most motors, it is possible for an experienced CT operator to utilize this pressure differential to optimize the drilling performance of a given bit and motor for the formation being drilled.

In CTD, bit speed is often higher while WOB is always less than in conventional drilling, requiring consideration of the following factors:

- CTD bits should be compatible with high speed operation.

- Roller-cone bits, which use a crushing action, do not operate as efficiently with the lower WOB inherent with CTD.

- Fixed-cutter bits (Figure 27) require lower WOB and are better suited for CTD in uniform formations. However, performance can be sensitive to WOB fluctuations although, in general, WOB is more easily controlled with CTD than with rotary drilling.

- Major variations in WOB may induce stalling which may impact the reliability and performance of both the bit and motor.

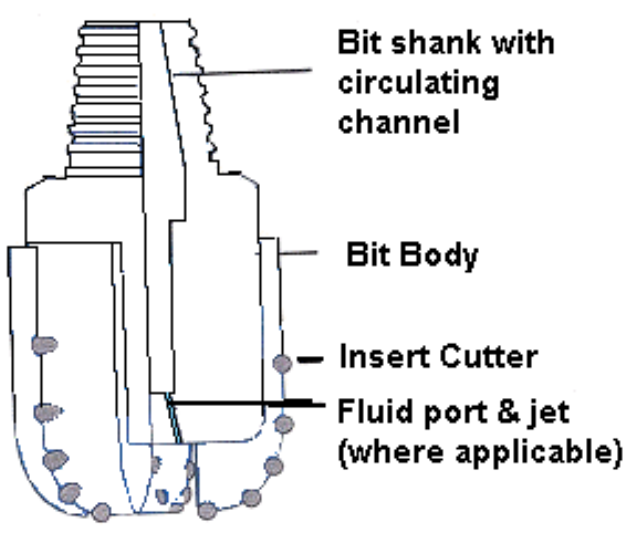

Fixed-cutter bits are generally available in smaller sizes than are roller-cone bits.

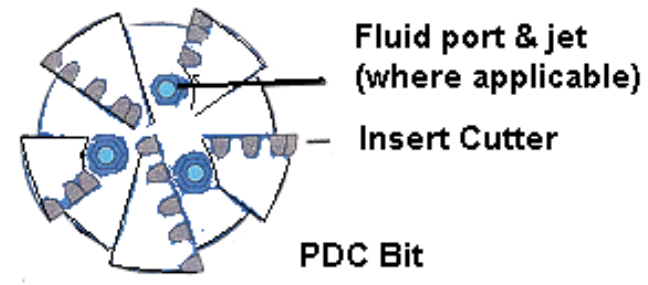

Figure 27. Fixed-Cutter PDC Bit

- The relatively low flow rates associated with CTD can have a significant effect on bit hydraulics, e.g., cleaning efficiency and jetting effects available at the bit face.

- Gauge protection is important, but should be considered in terms of steerability in directional drilling, especially in the build-up section.

- The ability to backream with CTD is an important advantage in the drilling operation and this feature should be built into bits run for CTD.

\subsubsection{Tripping and Wiper Trips}

The greatest efficiency gain that CTD has compared to conventional drilling is tripping speed. Surface equipment (not downhole conditions) generally limits tripping speed. The primary surface limitation for running or pulling CT is the hydraulic pressure to the chains on the injector and associated wear and tear on the injector equipment. Tripping speeds in the tubing and casing above the window should range from $70-120 \mathrm{fpm}$ for $23 / 8$-in. or smaller CT. A speed of $70 \mathrm{fpm}$ should be used while $\mathrm{POOH}$ in low gear with a string weight of $>30 \mathrm{klb}$. A speed of 120 fpm should be used in high gear with a string weight of $<30 \mathrm{klb}$. Speeds should be intentionally 
reduced in the open hole to improve hole cleaning while $\mathrm{POOH}$ and to minimize the chance of sidetracking if a ledge is tagged while RIH. Some guidelines for tripping are listed below:

- The hole should be kept full with drilling fluid at all times. Tripping in tubing and casing should be done at a low pump rate to minimize CT fatigue, but high enough to maintain returns.

- When tripping in the well for the first time with the drilling BHA, speed should be reduced while going across any downhole jewelry and or restrictions. Any problem areas should be noted and reported to the CT Supervisor.

- A function test of the MWD equipment should be performed near the surface when RIH to ensure all equipment is working properly. If the motor bend is greater than 1.5으, this shallow-hole test should not be performed because of possible damage to the bit.

- As the drilling BHA approaches the window while $\mathrm{RIH}$, pump rate should be shut down or minimized, and then the BHA run through the window without the motor turning. If unable to run through the window without the motor turning, pull up into the casing, orient to the tool face at which the window was milled, shut down pumps again and try to run through the window. Several attempts may be required to orient the $\mathrm{BHA}$ at the tool face needed to get through the window. This tool-face direction should be well documented and reported. Once the bit is in the open hole, increase to full pump rate. This process for working the tool past the window helps prevent bit damage.

- While running in hole in the open hole, maintain full pump rate, but reduce the run-in-hole speed to $<50 \mathrm{fpm}$ and be very cautious of setting down especially in the build section. If the tools take any weight or if any motor work is observed, pick up immediately and check and/or adjust tool face, then proceed in the hole slowly. If aggressive working of the BHA is needed to get past a problem area (ledge or high dogleg areas), it may be necessary to minimize the pump rate to avoid inadvertently sidetracking the well.

- Depth control and tie-in are of utmost importance while performing CTD operations. A logging pass should be made on the initial trip in the well with the BHA. This logging pass should be in the casing above the whipstock (mechanical or cement) and tied into the preferred gamma ray log (BHCS or equivalent). This location or tie-in point should be used on subsequent tie-ins. The mechanical whipstock may also have a radioactive (RA) marker in it for reference that can also be used. If the RA marker is used, ensure that the bit is outside the window before bringing the pumps on to log. It should be a routine operation to tie in and flag (paint a mark on) the CT before pulling out of the hole for a BHA change. Regardless of when the tie-in log is done, always flag the CT with the BHA above the window.

Frequent wiper trips may be required to stir the cuttings so that the drilling fluid can transport them to surface. (Note: frequent wiper trips reduce CT fatigue life.) Removal of the cuttings from the open hole is critical for good weight transfer to the bit, reducing the chance of stuck pipe, and for optimizing hole conditions for running and cementing a liner. An added benefit of 
the wiper trips is a considerable reduction in CT fatigue life consumed due to lower pressure inside the CT and less wall friction in the open hole. Recommended wiper trip guidelines are as follows:

- A full wiper trip should be made to the window and back to bottom for every 150$200 \mathrm{ft}$ of new hole drilled (when drilling overbalance). A running speed of 20-30 fpm at full pump rate is recommended. In horizontal holes, repeat passes or slower speeds in low points should be made.

- Short wiper trips, typically the length of the BHA, can be made if there is repeated stacking of weight at the bit. These short trips should not be used for general hole cleaning for which a full wiper trip is required.

- Once at TD, a full wiper trip with tie-in log at the window is recommended. Prior to pulling out of the hole to run the liner and with the BHA above the window, it is recommended to drop the ball to open the circulation sub and lift any solids that have accumulated in the larger ID casing or tubing.

\subsection{DRILLING FLUID}

This section addresses fluid properties and fluid handling in an overbalanced drilling project. (Underbalanced drilling fluid is discussed in Section 4.10). CTD is challenged by the inability to rotate the CT string, small annular clearances in the open hole, low annular velocities inside the tubing and casing, high fluid friction losses in the CT, low initial WOB and rapidly diminishing weight transfer as the hole is drilled. Critical design criteria for a fluid that meets these challenges include minimizing formation damage, fluid loss, pump pressure, and stuck pipe while maximizing cuttings suspension, cuttings transport, weight transfer, shale stability and overall hole conditions for successful liner cementing. A typical recommended fluid for CTD overbalanced drilling is a solids-free bio-polymer consisting of:

1. Brine based liquid with $5 \% \mathrm{KCl}$ and $3 \% \mathrm{NaCl}$

2. Premium grade, highly clarified Xanthan bio-polymer

3. Interfacial tension reducer and lubricant

4. A biocide

5. $\mathrm{KOH}$ for $\mathrm{pH}$ control

"Solids-free" means that no particulate matter is put in the fluid for either density or fluid loss control. If needed, the resulting fluid density of $8.8 \mathrm{ppg}$ can be increased to $10 \mathrm{ppg}$ by adding $\mathrm{KCl}$ and $\mathrm{NaCl}$. This fluid relies on the viscoelastic properties (note: viscosity is not a function of time; when circulation is stopped viscosity rises quickly to low shear-rate viscosity and remains there; when static viscosity does not increase) and the increased low shear-rate viscosity (LSRV) of the fluid to control filtrate invasion into the formation. The LSRV is measured at 
$0.0636 \mathrm{sec}^{-1}$ on a Brookfield viscometer. With a LSRV of $60,000-80,000 \mathrm{cps}$, leak off to the formation can be controlled in permeable formations up to 5 darcies. Depth of filtrate penetration will vary with LSRV, temperature, overbalance pressure, formation permeability and formation fluid viscosity. This fluid is able to control fluid loss at overbalanced differential pressures of 500 psi under static conditions and 1000 psi while circulating.

It is recommended that this fluid be mixed at the drilling fluid company's mixing facility and transported to location, due to the special shearing and filtering facilities required. Control parameters for a typical CTD fluid are:

$\begin{array}{ll}\text { Weight: } & 8.5-8.9 \mathrm{ppg} \\ \text { LSRV: } & 60,000-80,000 \mathrm{cps} \\ \text { Lubricant: } & 3 \% \text { by volume } \\ \text { PV: } & 8-9 \\ \mathrm{pH}: & 9.0-9.5\end{array}$

Even though solids content of the fluid is initially zero, drilled cuttings that are not removed by solids-control equipment build up in the system. Increasing levels of drilled solids will increase PV, pump pressure, chip hold-down and drag while decreasing ROP and weight transfer. A linear motion shaker and a high-speed centrifuge are used to maintain total solids concentration to below $1 \%$. A new fluid system should be used at the start of the horizontal section and fluid from the build section discarded. Once solids content is above $1 \%$, it is recommended that the fluid be traded for a new fluid system. Maintenance at the rig of this fluid requires monitoring and maintaining LSRV above 60,000 cps by adding either dry or liquid bio-polymer as needed.

Solids-control equipment should have a linear-motion shale shaker with a minimum 210 mesh; 250 mesh is preferred when available. The centrifuge is a high-speed unit that can process approximately half of the flow stream while drilling. To take advantage of every opportunity to remove solids, the centrifuge should be run while tripping as well as while drilling.

\subsection{WINDOW MILLING OPERATIONS}

The method for milling the window is determined based on the wellbore configuration and any downhole problems (e.g., corroded casing). A casing caliper should be run to determine the condition of the casing. If no problems are encountered and the wellbore is competent, the preferred method is via a mechanical whipstock. Ditch magnets are required for the window milling operation and should be used for several circulations after drilling has been started to remove metal shavings that will interfere with MWD tools.

One of two window-milling methods is typically used to mill a smooth exit window in the existing well. The two methods discussed below are: 


\section{From a cement plug in the casing}

\section{From a mechanical whipstock set in the casing}

\subsubsection{Cement Whipstock}

After it is determined that a cement whipstock is required, the desired kick-off point (KOP) is confirmed with the CTD engineer and directional driller. The recommended slurry for a cement whipstock is $17 \mathrm{ppg}$ Class G neat cement. As a rule of thumb, a firm cement top needs to be a minimum of $30 \mathrm{ft}$ above the expected top of the window. Compare this depth to any known restrictions (if through-tubing then check depth of tubing tail) and the $\mathrm{BHA}$ length. This $30 \mathrm{ft}$ of firm cement allows the entire motor assembly to be buried in the low-side pilot hole before turning the tool face to the high side to drill the ramp.

An example method for milling a window off of cement follows:

1. After setting the cement plug in place, the cement should be allowed to reach a compressive strength of $3000-4000$ psi before milling the low-side pilot hole. Mill low-side $\left(\mathrm{TF}=180^{\circ}\right)$ pilot hole with viscosified field seawater to approximately $10 \mathrm{ft}$ above the planned window depth. The $\mathrm{BHA}$ for milling the pilot hole should consist of the following:

- diamond speed mill

a mud motor with $1^{\circ}$ bent housing

- MWD with gamma ray

a Orienter

- circulation sub and hydraulic disconnect

a cross-over

- two joints tubing

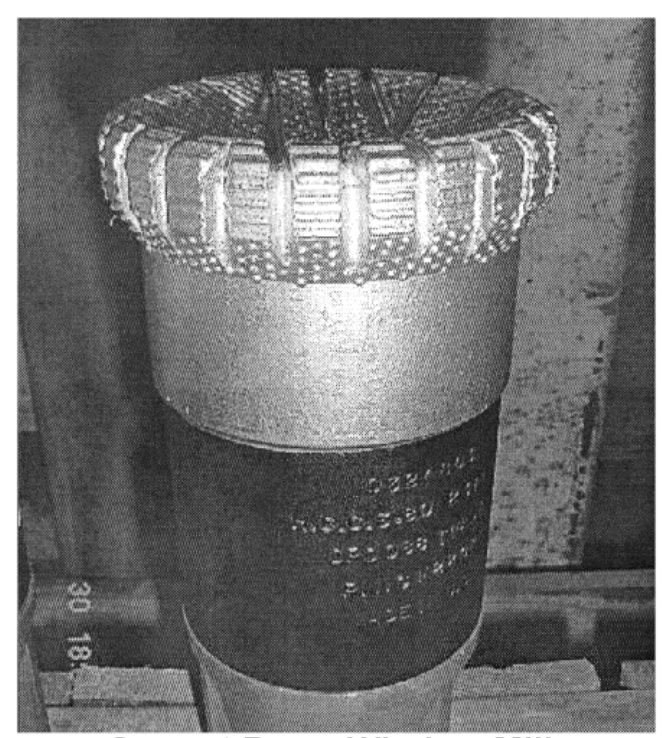

Cement Ramp Window Mill

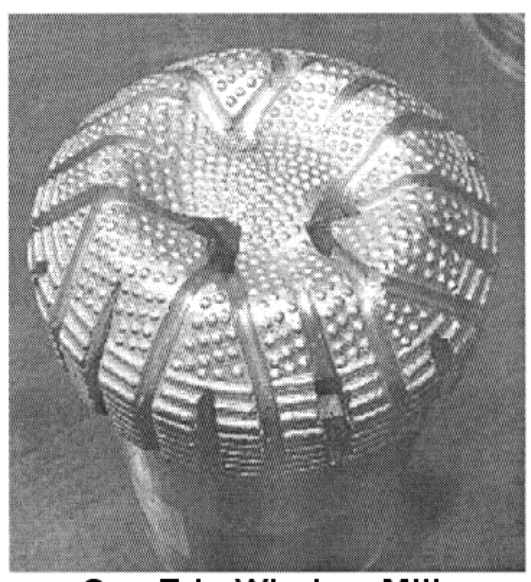

One-Trip Window Mill

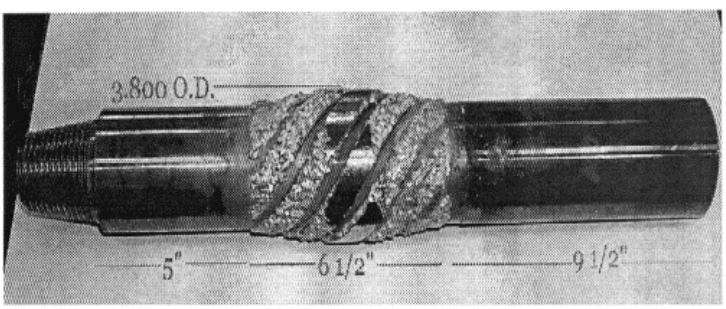

Smooth OD String Reamer

Figure 28. CT Window Mills

(Hupp et al., 2001) 
- CT connector

2. Approximately $2000-\mathrm{lb}$ WOB should be used while milling the pilot hole. After the pilot hole is milled, pull up above the top of cement and orient to high side. Run BHA back into pilot hole and mill high side pilot/ramp until casing contact is indicated by a significant counter-clockwise roll-off in TF. The CT should be flagged at this point prior to pulling out of the hole to pick up the window milling assembly which consists of the following:

a window mill (Figure 28)

mud motor with $3^{\circ}$ bent housing and a $1.5^{\circ}$ sub on top

- MWD with gamma ray

orienter

a circulation sub and hydraulic disconnect

a cross-over

ㄴ two joints tubing

a CT connector

3. Run in hole, tie in with gamma ray and stop BHA $10 \mathrm{ft}$ off bottom in preparation for time drilling sequence. The time drilling sequence will start the window, but the remainder of the window will be drilled by gradually increasing the WOB with penetration rates ranging from $0.5-2 \mathrm{ft} / \mathrm{hr}$. Once the mill has drilled off of the casing and into the formation, there should be a significant increase in rate of penetration. Drill $5 \mathrm{ft}$ of formation, flag the CT and pull out of hole for windowdressing operation. The BHA for this operation includes a $3^{\circ}$ motor, string reamer, and pilot mill.

\subsubsection{Mechanical Whipstock}

After the caliper log has been run, the KOP is confirmed with the CTD engineer and the directional driller. The mechanical whipstock is run and set at the predetermined depth on e-line if the wellbore is vertical and on CT if well inclination is greater than $65^{\circ}$. This depth is selected to coincide with the KOP as well as to avoid casing collars, corroded casing and troublesome shale intervals. The same milling fluids are used for this operation as are used in the cement whipstock operation.

A typical example of window milling off of a mechanical whipstock follows:

1. The BHA for starting the window consists of :

๑ carbide dimple mill 
a mud motor

a circulation sub

- hydraulic disconnect

- two joints of drill collars or tubing

- CT connector

2. This BHA is run in the well to the top of the whipstock. It will then move $3 \mathrm{ft}$ down the whipstock and contact the casing. Here the window milling process begins. Due to the aggressive nature of the carbide mill, getting the window started is the most critical stage. A minimum of 6-8 ft should be milled with the first mill. After milling $\pm 8 \mathrm{ft}$, the mill is typically in the formation and the ability to drill will stop because this mill is not designed to drill formation. It is recommended to run this first mill until it stops drilling and with WOB limited to $2500 \mathrm{lb}$. This BHA is pulled out of the hole and a second BHA is run consisting of:

- formation mill

- carbide string reamer

a mud motor

a circulation sub

a hydraulic disconnect

- two joints of drill collars or tubing

a CT connector

3. This second assembly is used to enlarge and dress off the window such that subsequent drilling BHAs can pass through the window. The formation mill should allow the formation to be drilled faster, and its undergauge design should minimize the wear in the window. Because of the aggressive design of the formation mill, it will tend to grab the casing at the window and cause motor stalling. This mill and reamer are not designed to lengthen the window, and therefore it is important to mill a sufficient length with the initial BHA. Drill enough formation to move the string reamer past the window. Then ream across the window at least three times to ensure the window is clean. Shut down the pump and make a pass up and down through the window without the motor turning. Pull out of the hole with this BHA and prepare to pick up the drilling assembly.

A technique has been developed more recently to mill a window off of a mechanical whipstock in one trip. The whipstock is set in place as before and the following assembly is run:

- $\quad$ modified one-trip window mill (see Figure 28)

- $\quad$ smooth OD string mill (see Figure 28) 
- $\quad$ high speed mud motor (7:8 lobe) RPM range: 150-250

- two joints of tubing

- circulation sub

- hydraulic disconnect

- CT connector

The window is milled in the same process as the first BHA. The need for the second BHA is eliminated, along with a reduction in window milling time.

\subsection{PRODUCTION LINER: RUNNING AND CEMENTING}

\section{Overview}

One of the more crucial operations for the CTD Supervisor, following the drilling of the hole, is the running of the completion liner and cementing the liner if necessary. This operation requires some upfront planning and management of the tubular inventory. The points discussed in this section for running and/or cementing a liner are:

1. Type of liner to be run - blank or pre-perforated/slotted

2. Cement parameters

Even though the liner top depth can be determined before drilling begins, the depth at which the liner will be set can only be determined once the well has reached TD. This means that planning and management of the tubing must take into consideration the desired footage to be drilled plus a $10-15 \%$ additional amount in case additional hole is required. The liner material should also be tallied, drifted and inspected prior to coming on location. Once received, the liner should be re-tallied and drifted to ensure it is correct. The Supervisor should specify the amount of liner to be run and the joints numbered for running in the well. All of the correct handling tools should be ordered out with the tubing and checks made of all of the make-up equipment to confirm that the equipment has been properly maintained and calibrated. Due to the slim holes that are typically drilled in CTD, a flush-joint-type connection is required to provide annular space for cementing and prevent cement build-up/dehydration at the connections. These types of connections are not usually designed for high bending stresses and heavy loads. Therefore, a confirmation with the CTD engineer as to the size, weight, grade, and tubing thread to be used is recommended. Some of the other important points to check prior to running the liner are:

- Ensure that the TIW stabbing valve is tested, labeled, and ready in the open position for the liner size / thread being run. If pre-perforated or slotted liner, a joint of blank tubing should be made up to the TIW valve. 
- Ensure that the wellbore fluid level is monitored and the hole kept full at all times.

- Confirm liner sized slip rams are in place in the BOP stack (needed to pull test the liner/running tool).

- The liner lifting nubbins should be tightened with a 24-in. pipe wrench and a back-up.

- Use "YT" type elevators.

- Use the proper size bowl, slips, and safety clamp for the liner.

- Strap and drift all pipe. Install turbolizers as described in the procedure.

- Determine size and type of deployment sleeve based on tubing size and need for a liner top packer. The standard deployment sleeve for $2^{7} / 8$-in. liners is 3.75 -in. OD, 3.00-in. ID, $4 \mathrm{ft}$ long and has a 3.13 in. GS profile on top. Modifications to this may include a larger entry guide on top for different sizes of tubing or increased length for seal movement in long straddle applications.

- Ensure that a short trip to the window has been made as well as a tie-in run with the GR and run back in to confirm TD prior to pulling out with the drilling BHA.

- $\quad$ Pig the CT with the CT wiper plug to be pumped behind the cement. Check the accuracy of micromotion meters, if used, in and out against known reel volume and against counter on triplex pump. Note any damage to the dart when retrieved.

- Hold on-site safety meeting to review issues related to running the liner.

\subsubsection{Liner Running: Blank Liner}

The CTD Supervisor will inspect and confirm the integrity of the liner and all associated equipment. Following is an example for safely running the blank liner and placing it at the desired depth prior to cementing:

1. Ensure that the CT liner running tool (CTLRT) is set to release at the desired pressure. Check the releasing ball size and the ball seat shear value. The liner should be pinned to release from the CTLRT at about 1000 psi above the ball seat value and should shear after the CT dart latches up.

2. Liner should be made up in the following order:

dual float shoe with tapered nose

a one joint of liner

a float collar 
口 one joint liner

a landing collar

口 liner

口 liner deployment sub

a CTLRT with liner wiper plug and shearable ball seat with catcher sub

- hydraulic disconnect

a swivel

cross-over

- CT connector

3. Because this liner has a flush-joint connection thereby causing difficulty in identifying collar locations for tie-in, at least one 10-ft pup joint with integrated turbolizers above and below should be installed in the liner for future collar location tie-in.

4. Turbolizers are recommended to be installed on the liner with the number and placement dependent on hole conditions. Recommended placement is one integral turbolizer per joint in the open hole (one integral turbolizer or one slip-on turbolizer per joint above the window).

5. All connections should be torqued to the thread manufacturing company's recommendation.

6. Fill the liner while running it.

7. Close the BOP slip rams on the liner and pull test the CTLRT to $30,000 \mathrm{lbs}$.

8. Recommended run-in-hole speed is $100 \mathrm{ft} / \mathrm{min}$ while circulating at minimum rate. Speed should be reduced to $50 \mathrm{ft} / \mathrm{min}$ when running through the window and in the open hole.

9. Run in hole $(\mathrm{RIH})$ and pull out of hole $(\mathrm{POOH})$ weights should be recorded above the window. RIH to TD and confirm full circulation. If hole conditions allow, slowly reciprocate liner in 15-20 ft strokes for 3-4 cycles while pumping at a maximum pressure of $2200 \mathrm{psi}$. Pressure is limited to minimize risk of premature disconnect at CTLRT.

10. Set liner on bottom and displace well while monitoring well pressure and returns.

11. Pump a ball to the CTLRT ball seat. You must maintain liner running tool in compression (+/-10 klb down at tool) for tool to release liner. Pressure up to release the CTLRT and shear out the ball. pick up to confirm release, but try to avoid pulling seals out of the polished bore. Slack-off and stack $10 \mathrm{klb}$ on liner. Resume circulation at maximum rate until cement is ready to pump. 


\subsubsection{Liner Cementing}

To ensure a competent cement job, the CTD Supervisor should calculate the volumes of cement and spacers required. Cement parameters should be verified as well as a check of and confirmation of lab testing performed on the cement to be pumped. The cementing company should be notified at least 12 hours prior to running the liner to secure their timely arrival on location. A safety meeting should be held to brief all involved parties and warn everyone of the areas where high-pressure lines will be run. Verification of the volumes and pressures to be pumped should be discussed and resolved between the CTD Supervisor and the cementing engineer. The following parameters are recommended for cementing the liner in place: (Note: shear and setting pressures should be determined on a well-by-well basis. The fluid type in the wellbore is critical to establish these.)

1. The desired volume of pumpable cement should be calculated based on openhole volume plus $40 \%$ excess, shoe joint(s) volume, and liner by production liner/casing annulus volume. This volume should bring the top of the cement to a minimum of $20 \mathrm{ft}$ above the window. The cement should be mixed to the same parameters as the lab test performed for the cement design in the planning stage.

2. Cement should be pumped by staging off the cementing company's meter, and measuring out of a calibrated displacement tank. After the desired cement volume is pumped, shut down pumping, load dart in launcher on CT reel and launch dart. Pump 1-2 bbl of field water displacement and shut down. Close reel valve and check to confirm that CT wiper dart left the launching chamber. It is recommended to flush cement from dead space between the reel valve and the filter by-pass. Continue displacing cement at maximum rate.

3. Displacement should be slowed to 1 BPM, 2 bbl prior to picking up liner wiper plug to improve chance of seeing the latch up. After latch up, the liner wiper plug should shear at the predetermined value $( \pm 15 \%)$. If latch up is not seen, stop displacement at $2 \mathrm{bbl}$ less than calculated bbl to bump.

4. Shear liner wiper plug and continue displacement at maximum rate possible. Slow pumps to 0.5 BPM about $1 \mathrm{bbl}$ before planned plug bump. If plug does not bump, do not over-displace more than liner volume below landing collar. Liner wiper plug will latch into the landing collar and provide two-way check. Bleed off pressure to check floats. Repressure to $500 \mathrm{psi}$ and sting out of the polished bore.

5. Prior to $\mathrm{POOH}$, circulation at the liner top should be done to clear any excess cement.

6. A nozzle and CNL logging run is recommended to be run following the cement job (a work string with enough tubing to keep the CT connector above the liner top may be required). The liner should not be entered until there is an indication of at least $200 \mathrm{psi}$ compressive strength on the cement. This run will serve to clean out any remaining cement as well as provide a tie-in log for perforating and verify the depth location of the liner top. If there are any indications of cement 
or uncertainty over depth of latch collar, pick up a motor and parabolic diamond speed mill to mill inside of liner. Make sure BHA is made up with a shear disk in the circulation sub below the work string. There should not be a circulation sub with the upper disconnect, above the work string.

7. Spot a filtered $2 \% \mathrm{KCl}$ with 120k-150k LSRV per pill in the liner after the CNL trip.

8. After POOH with CNL log, check to ensure that the cement has at least 2000 psi compressive strength from the UCA test. (The Ultrasonic Cement Analyzer is a lab tool that measures ultrasonic velocity of the cement under simulated wellbore conditions. This directly measures the compressibility of the sample.) Then the liner/lap should be tested to 2200 psi for 30 min and any leak reported.

\subsubsection{Liner Running: Pre-Perforated or Slotted Liner}

The CTD Supervisor will inspect and confirm the integrity of the liner and all associated equipment. Following is an example for safely running a pre-perforated/slotted liner and placing it at the desired depth prior to cementing:

1. Ensure that the CT Liner Running tool (CTLRT) is set to release at the desired pressure. Check the releasing ball size and the ball seat shear value.

2. The liner should be made up in the following order:

a guide shoe with tapered nose

one joint of liner

口 "O-ring" sub

a pre-perforated/slotted liner

口 liner deployment sub

口 internal work string stung into "O" ring sub

- CTLRT with shearable ball seat and cage

․ hydraulic disconnect

a swivel

c cross-over

CT connector

3. Turbolizers are recommended to be installed on the liner with the number and placement dependent on hole conditions. Recommended placement is one 
integral turbolizer per joint in the open hole; one integral turbolizer or one slip-on turbolizer per joint above the window.

4. All connections should be torqued to the thread manufacturing company's recommendation.

5. Close the BOP slip rams on the liner and pull test the CTLRT to $30,000 \mathrm{lb}$.

6. Recommended $\mathrm{RIH}$ speed is $100 \mathrm{ft} / \mathrm{min}$ while circulating at minimum rate. Speed should be reduced to $50 \mathrm{ft} / \mathrm{min}$ when running through the window and in the open hole.

7. $\mathrm{RIH}$ and $\mathrm{POOH}$ weights should be recorded above the window. RIH to TD and confirm full circulation.

8. Pump a ball to the CTLRT ball seat. You must maintain liner running tool in compression $( \pm 10 \mathrm{klb}$ down at tool) for tool to release liner. Pressure up to release the CTLRT and shear out the ball. Pick up to confirm release.

\subsection{LOGGING/PERFORATING}

Because all rig personnel will be involved in the make up and handling of the logging and perforating tools, a safety meeting should be conducted prior to any logging or perforating operation, as well as during the operation as personnel or objectives change. The majority of the tools to be run will be perforating guns and incorporate explosives, so most of the items for the safety meetings will center around running and pulling perforating guns. Some of these items are:

1. Identify all people on site, introduce the Logging/Perforating Specialist, and discuss pick up, make up, and break out procedures.

2. Rough handling of logging tools/guns could result in poor performance of the system. The guns are fired using percussion detonators, not electrical detonators. Hence, radio silence is not needed. No welding or open flame is allowed near the guns.

3. Keep non-essential personnel away while assembling guns. Establish personnel assignments.

4. Logging tool/gun will be assembled with the rig crew and with the Logging/Perforating Specialist's assistance and supervision. Exercise caution when removing thread protectors and installing lifting subs. Trapped pressure precautions will be used when breaking out guns. Use appropriate handling equipment: dog collar, slips, and elevators. The Logging/Perforating Specialist will provide lifting subs.

5. Gauge $\mathrm{H}_{2} \mathrm{~S}$ risk from the well and from the guns. Determine spill prevention needs. 
6. Consider well-control issues. Establish safe pump pressures and rates.

7. Identify all hazards going in the hole. Liner tops, tight spots, windows, doglegs, plug back total depth, etc. Determine connection from firing head to BHA and the correct ball size and type to be used. Note the disconnect ball size.

The CTD Supervisor should contact the perforating service company with an estimate of interval, gun and charge type as soon as drilling is begun. Once the well is at total depth, determine final perforation depths, and give the service company latitude for meeting these chosen intervals plus or minus a few feet. The following recommendations should be incorporated to ensure a safe and effective operation:

- The service company will provide a detailed tool-string diagram. All equipment will be strapped and calipered.

- Drifting the work string is recommended to ensure passage of the ball used to fire the guns.

- Clean fluids are essential. Cement debris can be very detrimental and could cause failure of the ball to seat and possibly not fire. A chunk of cement can actually seat and fire the guns in some instances.

Following is a recommended BHA for perforating. Logging tools run are typically memory type tools and will not require any downhole mechanism (i.e., firing head) to enable the tool:

- Bullnose, tapered, with water courses (for liner entry)

- Perforation guns, loaded and blank

- Safety spacer (to keep live guns below floor when installing firing head)

a Firing head

- Hydraulic disconnect

- Work string (if needed)

- Hydraulic disconnect

a Check valve

ㄱon-rotating joint

- CTC

The CTD Supervisor and CT Driller should ensure the following recommendations are followed during the logging/perforating operation: 
- Compare the gun layout to original selected intervals and to the guns themselves. Commence picking up guns. Use correct dog collar, slips, elevators, and lift subs. Make up the firing head.

- Make up the disconnect. Drop the firing head ball through the disconnect before making it up to ensure ball passes and will not operate the disconnect.

- Run the work string. All starts and stops with the pipe should be smooth; do not set slips while moving.

- The ability to pump at any time is normally available, but the Logging/Perforating Specialist must be present, and rate/pressure limits must be discussed. Trip in the hole at normal speeds; if weight loss is encountered try to keep it less than $5000 \mathrm{lb}$.

- Tie in to up-hole flag on CT. Slow down to 30-50 ft/min when approaching bottom. Tagging bottom is normal for depth control when perforating. Logging tools are more fragile and tagging bottom with them should be done only if necessary. Pick up and correct depth. PUH to shooting depth.

- Drop ball (may have to move the coil to position ball launcher for ball drop). Once ball is loaded, pressure up to 500 psi minimum and open reel valve to launch ball. Bring pumps on line, 1.5 BPM for $1 / 2$-in. ball or 2.5 BPM max for $5 / 8-$ in. ball, maximum rate. Keep the pumps rolling and PUH to shooting depth. At 8-10 bbl from the calculated volume, decrease rate to 0.5 BPM until pressure build-up and drop-off is noted. Firing head generally will be set to fire at $3000 \mathrm{psi}$ differential. Fluid loss should be monitored and documented after firing.

- Monitoring the well volume while POOH is very important. Maximum safe pull weight should be determined prior to running in the hole.

- Caution must be exercised when starting to break out the BHA, as trapped pressure can be encountered. Procedures should be incorporated for this as necessary; typically, a mud box is used and the relief hole bled off. Continue breaking out guns and monitor well fluid level at appropriate times. Inspect guns for misfires and misaligned shots.

- Rams should never be closed on live guns or on logging tools. Fishable lift subs should be used when possible in case the guns need to be dropped.

\subsection{OPERATIONAL PROBLEMS}

There are several operational problems for which contingency plans need to be in place prior to starting the CTD operation. The CTD engineer, CTD Supervisor and CT Driller should meet and determine what contingency planning is necessary for a particular well and the proposed drilling operation. The primary or typical problems are discussed in this section. 


\subsubsection{Lost Circulation}

Drilling fluid losses that result from the wellbore intersecting conductive faults, fault related fractures, underpressured sands or high permeability thief zones are the most common and costly for CTD operations. Every lost circulation situation is unique, and the strategy to control, slow, or eliminate the losses is dependent on many factors such as severity and ultimate well objectives. The decision can range from "do nothing" to "cement plugback and sidetrack." Losses range from minimal $(<1 / 4 \mathrm{BPM})$, which heal in time from drill solids, to massive (no returns at full pump rate). While continued drilling is possible with severe losses, attempts should be made to slow the losses if they are in excess of about $1 / 2$ BPM. Drilling without returns means that the cuttings are being lost to the formation/loss zone. These types of losses make hole cleaning difficult, increase the risk for stuck pipe and could compromise the liner cement quality.

There are numerous types of lost circulation materials (LCM) that can be pumped. The success of a specific recipe at a particular severity is difficult to determine. It should be remembered that most LCM pills cannot be pumped through the drilling BHA because of MWD plugging. A trip is usually required to install a nozzle. Drilling fluid needs should be planned accordingly for this trip time. In determining the LCM to use, the following should be considered:

- LCM pills that bridge at the face of the loss zone are good for only a short time. Usually, losses return to the same level when drilling is resumed and the LCM is washed or mechanically removed from the formation face.

- LCM pills that are designed to penetrate the loss zone and then build a low compressive strength are good for a longer length of time. These pills require a certain amount of thickening time at a given temperature to become "immobile," so it is usually critical to include a bridging additive in the tail to keep the well from drinking while the slurry is setting up. The ultimate compressive strength target should be about 300-400 psi to prevent an inadvertent sidetrack when the LCM is drilled out.

- If a plugback/sidetrack is planned, it is still desired to slow or stop high losses before laying in the cement kick-off plug because it is critical to have control of the depth of the top of cement. For these situations, an LCM that bridges at the formation face is usually sufficient.

- For losses at total depth, an open-hole inflatable bridge plug (IBP) may be considered.

- In extreme cases where losses are very high and the conventional LCM recipes mentioned above have failed, a diesel/bentonite "gunk" pill may be considered.

- Treating losses as they occur should result in minimizing both cost and risk. It is difficult to stop or slow losses when there are multiple thief zones in the wellbore because there is less control over LCM placement/squeezing, and contamination is more likely. Generally, when losses are observed, attempt to drill another 30 
to 50 feet to get past the lost-circulation zone. However, continued drilling beyond that point, especially for high losses, may reduce the chance of successfully treating that particular loss zone and increase the chance of becoming stuck.

Some guidelines to follow if lost circulation is encountered while drilling are:

- Stop drilling, pick-up off bottom, keep pipe moving, and establish severity of loss at full pump rate via pits and flow meters. If the open hole becomes sticky or pipe movement is a problem, pull the BHA above the window.

- If conditions allow, drill another 30 to 50 feet in an attempt to get past the lost circulation zone. Assess losses again.

- For low losses $(<1 / 4$ BPM), continue drilling and monitor any change in loss rate. The losses may slow or stop as drill solids provide bridging. With reduced return rates, hole cleaning is a big concern and an increased frequency of wiper trips to the window should be considered.

- If it is decided to pump an LCM pill, then flag the CT and POOH with the drilling $\mathrm{BHA}$ to install a nozzle. To minimize losses, $\mathrm{POOH}$ without pumping down the coil and fill the well through the kill line and into the annulus. Make up the following BHA:

- CT connector

a non-rotating joint

๑ hydraulic disconnect

a check valves

- two joints of tubing

a bullnose nozzle

- RIH to flag, correct depth, and continue to TD. Pump LCM following manufacturing company's procedure, if reasonable. In general, lay the pill in from TD (about 1.0 BPM; $70 \mathrm{ft} / \mathrm{min}$ ), pull to safety (>100 ft above calculated top of pill), and then circulate at minimum rate while monitoring returns. Additional back pressure (squeeze) is not recommended at any time during the operation.

- Determine if another pill is needed. Typically, if any losses are apparent, another pill will be required. With the small volumes of pills normally used, it doesn't take long for the well to "drink" the entire LCM even with minor losses.

- If the losses have stopped, $\mathrm{POOH}$ while filling the hole. Make up the drilling assembly. RIH and wash through the open hole slowly and monitor returns continuously. If any motor work is seen, ensure that the tool face is positioned where the hole was drilled to avoid an inadvertent sidetrack. Wash/ream to TD 
and proceed with drilling new hole if losses have returned to an acceptable level or stopped.

\subsubsection{Stuck Pipe}

Conditions that can lead to stuck pipe are differential sticking, hole instability (shales/clay), ledges, mechanical sticking, and key seating. Differential sticking is by far the most common form of sticking and usually occurs while drilling when the BHA comes in contact with a newly exposed section of the reservoir still taking mud filtrate. This often occurs during "stacking" conditions when the BHA stops moving because of insufficient weight transfer. Sticking due to hole instability can be observed in shale-like sections of the reservoir. Extruding clays or swelling shales are seen particularly during tripping and tend to get worse with time. Reaming these problem areas thoroughly on each BHA trip or wiper trip is usually a sufficient remedy.

Sloughing shales in the reservoir section are rare but are extremely difficult to contend with, and conditions usually do not improve by increasing mud weight. Ledges rarely cause sticking but can be encountered both while $\mathrm{RIH}$ and $\mathrm{POOH}$. Shale/sand interfaces in the build section are where ledges are most commonly found. The danger with ledges is that a well can be sidetracked inadvertently if a ledge is tagged while $\mathrm{RIH}$ at full pump rate. Mechanical sticking occurs when a piece of debris (rock, junk, etc) wedges beside the BHA. Key seating (where the pipe wears a groove in the formation that will not allow the BHA to pass through) normally is not a problem in CTD; however, it should be considered in the rare cases when long-term pumping could cause vibration of the coil across an area of high dog-leg severity, especially in an area where hole inclination is lost. Recommendations for these conditions are as follows:

- A good rule to follow for sticky hole conditions is to always keep the pipe moving, but be aware of the effect on the life of the CT. Also, with the exception of ledges seen while $\mathrm{RIH}$, always maintain full pump rate when tripping pipe in open hole.

- For differential sticking:

- Continue circulating at full pump rate to clean up cuttings. Note any packing off.

- If nitrogen is available, develop an underbalanced condition to free the string. This approach does not contaminate mud, and also avoids working the CT.

a With overbalanced fluids, work stuck pipe in $20,000-\mathrm{lb}$ increments to maximum pull (usually $80 \%$ of CT yield strength)

a Reduce pump to minimum rate (to lower ECD's). Work stuck pipe. Consider CT pipe fatigue management when working pipe in one spot for an extended time.

- Spot crude oil (if available) per procedure below. 
- Once tools pull free, perform a wiper trip to the window before resuming drilling.

- If sticky shales are observed, ream the problem area in and out until clean. Reaming should be done with the same tool face used to drill this section of the wellbore. While $\mathrm{RIH}$, sticky conditions may occur with or without motor work. ("Motor work" refers to the differential between pressure indicated on the CT pressure gauge with the bit off bottom and that with the bit on bottom drilling. When the bit is on bottom drilling, the pressure at the surface increases, giving an indication that the motor is turning/rotating the bit. Any time this differential pressure is observed it indicates that the motor and bit are turning.) If motor work is indicated, it is important to keep the pipe moving and prevent sidetracking. It may be necessary to minimize pump rate and push the bit through a small portion of the problem area, and then backream slowly at full pump rate. If no motor work is observed (i.e., no increase in pump pressure), but a weight reduction is observed (common for long, stiff BHAs), maintain full pump rate.

- Ledges (particularly those found while RIH) should be treated with caution to prevent sidetracking the well. If the tools take any weight, immediately pick up and check tool face. It may be necessary to reduce pump rate and attempt to "bounce" the BHA over the ledge. If unsuccessful, run a hole opener or bicentered bit, which allows more aggressive motor work and reduces the risk of sidetracking. After the BHA moves past the ledge, backream the area thoroughly to ensure clean passage of the tools.

- Mechanical sticking can occur anywhere in the wellbore and can involve any portion of the BHA. It usually occurs while $\mathrm{POOH}$ when debris or sand-duning meets the BHA. It's not uncommon to be able to visualize (via the weight indicator (Figure 29)) the debris rolling along the BHA until it catches an upset or the bit. If the bit becomes stuck, it is

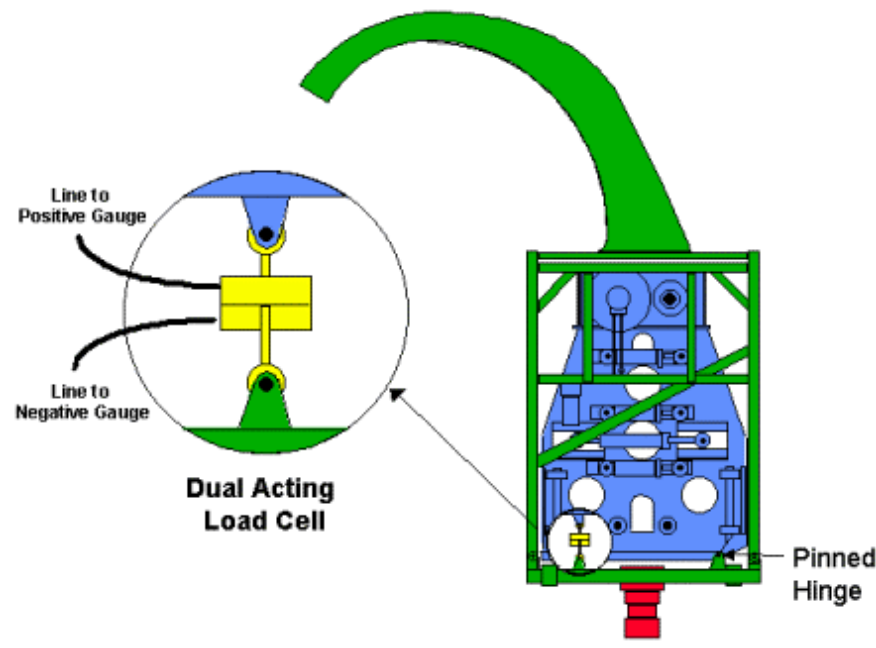

Figure 29. Weight Indicator readily apparent from the motor work (pump pressure). For mechanical sticking, follow these guidelines:

- Maintain maximum pump rate to keep debris above the $\mathrm{BHA}$, and keep the pipe moving.

- If continued upward movement stops at about 20,000-30,000 lb overpull (this is dependent on CT size), stop working pipe up and start attempting to get downward movement. The key is to maintain high pump rate and keep the tools moving, even if moving in the downward direction. 
- If movement stops in both directions, attempt to orient to work the debris in a different manner. Continue working pipe, primarily in the downward direction.

- If tools are still stuck, spot crude oil or other hole "slicking" or lubricating fluids. It's unlikely that crude oil will solve these sticking problems, but it should be attempted before disconnecting. In carbonate formations, pump acid to dissolve rock cuttings.

- Drop ball, disconnect, and proceed with fishing operations.

- For underbalanced conditions with two-phase fluids, use water hammer technique.

\section{Crude Oil Spotting Procedure}

Once it has been decided to pump crude (or other lubricating fluid), proceed as follows:

1. Call for approximately $20 \mathrm{bbl}$ of dead crude for pumping two separate $10-\mathrm{bbl}$ jobs.

2. If field crude is being used, do not pump any crude unless the Reid vapor pressure at $100^{\circ} \mathrm{F}$ is less than $1.5 \mathrm{psi}$. Obtain a sample from the truck and perform a vapor test per rig contractor's procedure. Otherwise, commercially available crude oil should be used, which will alleviate vapor problems.

3. Rig up the vacuum truck discharge hose to the inlet side of the centrifugal pump feeding the rig pump. Ground all equipment. Use only hammer unions (Camlocks). Ensure the driver stands by the truck throughout the operation.

4. Hold safety and operational procedure meeting. Discuss risks and hazard mitigation, including well control (pumping lower density fluid).

5. Pump $10 \mathrm{bbl}$ of crude oil, zeroing the totalizer when density drops. Displace with drilling fluid.

6. When approximately $2 \mathrm{bbl}$ of crude are out of the bit, shut down the pumps, and let crude soak for about 5 minutes with pipe at neutral weight.

7. Work the stuck pipe without pumping. If unable to pull free, pump a few more bbl of crude around to the backside. Soak. Work pipe.

8. Once the BHA is free, pick up 20 to $30 \mathrm{ft}$, continue moving pipe and circulate the crude to surface. Divert the strung-out crude to the cuttings tank or divert tank. Expect 50 to $100 \mathrm{bbl}$ of contaminated drilling fluid to be lost (discarded).

9. Have the vacuum truck operator suck back his hose until dry.

10. Perform a wiper trip to the window and back. Resume drilling. 


\subsubsection{Open-Hole Sidetracks}

Sidetracks out of an open hole are common in CTD operations. Reasons for drilling sidetracks include geologic target changes, unexpected faults, inability to control hole direction and hole conditions. There are three methods generally used for sidetracking out of the drilled hole: 1) off a cement plug; (2) off a mechanical plug; and 3) open hole. Sidetracking off a cement plug is relatively fast and eliminates potential future problems (both drilling and production) caused by leaving the original hole open without any isolation from the sidetracked hole. In cases where isolation is not a concern, sidetracking from the open hole using time drilling is the most common approach.

\subsubsection{Sidetrack from a Cement Plug}

This operation involves a little more planning than the open-hole sidetrack, but the results are generally better and future operations are less hindered. Following are recommendations for performing a sidetrack of the open hole off a cement plug:

1. A neat cement slurry with the following parameters should be used:

- Density: $16-17 \mathrm{ppg}$

๑ Fluid loss: $70-90 \mathrm{cc}$

- Thickening time: 2 to 3 hours (based on hole conditions) plus one hour surface time

- The cement design should be based on $1 \mathrm{hr}$ at surface plus any warming back from BHCT (assume about $30^{\circ} \mathrm{F}$ below BHST if not measured by MWD) to BHST over 4 hours.

- Volume: at least enough to cover $200 \mathrm{ft}$ above the desired kickoff point. Volumes will be small; for example, $1.37 \mathrm{bbl}$ is required to fill $100 \mathrm{ft}$ of 3.75-in. hole.

2. Select a location in a fairly continuous sand if possible. This allows a quick direction change from the original wellbore.

3. The cement should be placed from 10-20 ft above TD to 200-400 ft above desired kick-off depth. It should then be contaminated to 30-40 ft above the desired kick-off depth. This allows for losses to the formation while the cement is setting up as well as errors in depth control.

4. RIH with a dart catcher/cementing stinger and cement nozzle BHA. Tag bottom and correct depth. Plan to lay in cement starting 10-20 ft off bottom. This allows moving the CT "in hole" in case a "temporary immobile" condition arises. Circulate and condition mud while mixing cement. Note CT pressure at 0.5 and 1.0 BPM. 
5. No fresh-water spacers should be pumped ahead of the cement other than 1-2 bbl pressure test water. This is to prevent any swelling clays from sticking the BHA. Also, no fresh-water spacer is needed behind the cement. The cement should be pumped to the manifold bypass sample port and a barrel count started at a cement weight of $14.5 \mathrm{ppg}$ or greater. This will account for any cement dilution while pumping. Then the desired volume should be measured while pumping from a displacement tank. After pumping the desired volume, the reel should be shut in and the surface lines flushed of cement.

6. Set the rig stroke counter (or fluid meter) to zero. Load wiper dart. Launch the dart with up to $2 \mathrm{bbl}$ of mud. Check to confirm that the dart is gone.

7. Displace with mud at 2.5 to $3.0 \mathrm{BPM}$ and slow to 0.7 to $1.0 \mathrm{BPM}$ when cement exits the nozzle. Cement will be U-tubing at this point. Don't be surprised to see the CT pressure fall to less than 500 psi as the rate is slowed. It is not necessary to apply any backpressure with the choke. Cement volume and annular space are so small that equilibrium is quickly reached. The density difference between the cement and mud will leave a small contaminated area which will be at the top of the plug at the end of the job. It's more important to lay a good plug in the next step.

8. After 1-2 bbl of cement is out of the nozzle, begin POOH. Generally, string weight is too large for the injector motor to be set in high gear, so pulling speed will be about $70 \mathrm{ft} / \mathrm{min}$ in low gear. Higher pulling speed and faster rate are preferred if possible. Therefore, the speed/rate combination most likely will be 73 $\mathrm{ft} / \mathrm{min}$ at $1.0 \mathrm{BPM}$. CT pressure will gradually increase as the plug becomes balanced.

9. Adjust POOH speed/rate (drop to 0.5 BPM with about half the cement gone if speed cannot be increased) so that the nozzle will be from $100 \mathrm{ft}$ below to near the calculated cement top when the dart hits. It's important to not outrun the cement since a contaminated plug will be the result. Washed out hole and initial water spurt loss from the cement will make the calculated top of cement deeper than anticipated.

10. Stop pumping if the dart hits early and pull to the calculated cement top (slowly to prevent swabbing and contamination).

11. Shear the dart at the calculated cement top. Then pull up the hole another $200 \mathrm{ft}$ or to safety (cased hole) while pumping enough fluid to keep the hole full (0.5-1.0 BPM).

12. Circulate at a low rate (0.5-1.0 BPM) to minimize ECD while waiting 30 minutes for the cement to settle and develop some gel strength. Compare to the initial rate/pressure. Note: It is not necessary to apply any "squeeze" pressure. It is actually detrimental to apply pressure since the formation could break down or a dehydrated area could form leaving a bridge that cannot be jetted and a cement top higher than planned.

13. $\mathrm{RIH}$ to calculated cement top and then begin circulating at $2.5 \mathrm{BPM}$ while $\mathrm{RIH}$ at 30-40 ft/min and contaminate the cement to 30-40 ft above the desired kick-off 
depth. Zero the returns meter and chase the contaminated cement to surface while $\mathrm{POOH}$ (don't outrun it). Plan ahead for disposal of the contaminated cement (usually 40-70 bbl). Clean out tanks as soon as possible.

14. Plan ahead for replacing any lost volume and be certain there is enough mud in the pits after dumping the contaminated cement to still pump while $\mathrm{POOH}$.

15. RIH with sidetracking BHA. The bit should be an aggressive PDC with a fairly flat bottom. The motor bend should be based on the requirements of getting back to the new target, but a $1.5^{\circ}$ bend motor or larger is preferred.

16. WOC until cement has developed 3000-psi compressive strength. This is about two times the thickening time. Believe the lab test! The cement downhole will be hard, and waiting more than 3 times the thickening time is a waste of time.

17. Get on depth using a GR tie-in or a previous flag. Be sure that the back cutters are not damaged in the window if a tie-in is at the RA marker on the whipstock.

18. As a precaution, ream from the window to TOC preferably with a tool face similar to the original hole. This is important if the hole was drilled with a smaller bend motor.

19. Orient to set the correct tool face for the kick-off of the new hole. Perform a 5-10 $\mathrm{ft} / \mathrm{min}$ pass from TOC to $40 \mathrm{ft}$ above the TOC to be certain the tool face will hold for the entire length. Make any final adjustments and repeat the scribe. This is very important and must be correct before continuing.

20. RIH and tag the TOC. Flag the CT in the down mode. Pull up hole slowly and note the hanging weight and then the stretch length (usually 5-8 ft). Pull the CT up hole by the stretch length. Since depth measurements are taken in the down mode, this is the depth of the TOC in the up mode.

21. Begin drilling using the weight/rate parameters that the directional driller specifies to maintain the correct tool face.

22. At this point, the directional driller usually needs to orient to get back to a tool face similar to the old hole. This is difficult to accomplish in one orienting session if a $2.0^{\circ}$ or larger motor is used because the bit will be in a bind due to a radical directional change. Also, future BHAs that would follow this radical change tend to pull tight and/or tear up the formation. Therefore, it is prudent to perform the complete tool face change in stages of about $60^{\circ}$ per $5 \mathrm{ft}$, which results in a smooth turn.

\subsubsection{Sidetrack from a Mechanical Plug}

This operation is not as tedious as the cement plug, but in many ways requires more preparation of the hole. One of the difficulties with sidetracking from a mechanical plug is setting the plug and keeping it in place. Following are recommendations for performing a sidetrack of the open hole off a mechanical plug: 
1. Select a location in a fairly continuous sand if possible. This allows a quick direction change from the original wellbore.

2. Prior to $\mathrm{POOH}$ with the drilling $\mathrm{BHA}$, flag $\mathrm{CT}$ and perform a slow backream over the interval where the mechanical plug will be set to remove any cuttings that might hinder setting the plug.

3. RIH with mechanical plug, setting tool and directional tools Tie in with GR above the window. Continue in the hole slowly (about $30 \mathrm{ft} / \mathrm{min}$ ) to the desired setting depth. Check hanging weight approximately $200 \mathrm{ft}$ above setting depth.

4. Remove stretch from CT. Pull up hole slowly and note the hanging weight and then the stretch length (usually 5-8 ft). Pull the CT up hole by the stretch length. Since depth measurements are taken in the down mode, this is the setting depth in the up mode. Drop ball and circulate to the setting tool. Pressure up to mechanical plug company representative's requested pressure and set plug. Log off of plug with CT. RIH slowly and tag top of plug. $\mathrm{POOH}$.

5. RIH with sidetracking BHA. The bit should be an aggressive PDC with a fairly flat bottom. The motor bend should be based on the requirements for getting back to the new target, but a $1.5^{\circ}$ bend motor or larger is preferred.

6. Position the CT at depth using a GR tie-in or a previous flag. Be sure that the back cutters are not damaged in the window if a tie-in is at the RA marker on the whipstock.

7. As a precaution, ream from the window to top of plug preferably with a tool face similar to the original hole. This is important if the hole was drilled with a smaller bend motor.

8. Orient to get the correct tool face for the kick-off of the new hole. Perform a 5-10 $\mathrm{ft} / \mathrm{min}$ pass from top of plug to $40 \mathrm{ft}$ above it to be sure the tool face will hold for the entire length. Make any final adjustments and repeat the scribe. This is very important and must be correct before continuing.

9. RIH and tag the top of plug. Flag the CT in the down mode. Pull up hole slowly and note the hanging weight and then the stretch length (usually 5-8 ft). Pull the CT up hole by the stretch length. Since depth measurements are taken in the down mode, this is the depth of the TOC in the up mode.

10. Begin drilling using the weight/rate parameters that the directional driller specifies to maintain the correct tool face.

11. At this point, the directional driller usually needs to orient to return to a tool face that is similar to the old hole. This is difficult to accomplish in one orienting session if a $2.0^{\circ}$ or larger motor is used because the bit will be in a bind due to a radical directional change. Also, future BHAs that would follow this radical change tend to pull tight and/or tear up the formation. Therefore, it is prudent to perform the complete TF change in stages of about $60^{\circ}$ per $5 \mathrm{ft}$ which results in a smooth turn. 


\subsubsection{Open Hole}

This operation requires patience for successfully creating a useable hole for drilling and completing. The main objective for this type of sidetrack is to drill a new hole that future drilling BHAs and the liner will follow without entering the old hole. Some recommendations for performing an open-hole sidetrack are:

1. Pick an area (from the MWD GR) that is above any hole problem areas and that sacrifices as little hole as possible. Choose a point in a continuous sand where the wellbore has a building trend and an azimuth change. This will permit a quick direction change away from the old hole, that will ideally be about $180^{\circ}$ from the old hole and in the lower quadrants. Gravity is your friend - take advantage of it. Consideration should be given to the least torturous route for reaching the new target even if it requires sacrificing more hole; the drilling ROP is generally high and will be regained rapidly.

2. Once a tentative point has been identified, confer with CTD engineer to be sure that the target can be reached without excessive dogleg severity or multiple motor bend changes. It may appear easy to reach looking at the directional map, but the numbers must be calculated. This may require evaluating several points to find one that meets the requirements.

3. Depending on the formation, the bit should be a fairly aggressive gauge protection and include back cutters. The motor bend should also be rather aggressive - recommend bends of 2.0-2.75o. If possible, select a bend that will drill the most hole with the least number of tool-face changes after the sidetrack has been completed. A locking-type orienter is recommended over an adjustable type.

4. RIH with the open-hole sidetrack BHA and get on depth using a GR tie-in or a previous flag. Be sure that the back cutters are not damaged in the window if a tie-in is at the RA marker on the whipstock.

5. As a precaution, ream from the window to TOC preferably with a tool face similar to the original hole. This is important if the hole was drilled with a smaller bend motor.

6. Orient to obtain the correct tool face for the kick-off of the new hole. Perform a 5$10 \mathrm{ft} /$ minute pass (light scribe or trough in open hole) from $20 \mathrm{ft}$ below to $40 \mathrm{ft}$ above the planned kick-off point to be sure the tool face will hold for the entire length. Make any final adjustments and repeat the scribe. This is very important and must be correct before continuing.

7. RIH to the planned kick-off. Flag (F1) the CT in the down mode. Pull up hole slowly and note the hanging weight and then the stretch length (usually 5-8 ft). Pull the CT past the flag by the stretch length. Since depth measurements are taken in the down mode, this is the depth of the kick-off point in the up mode. Flag the CT here also (F2). This is the starting point of the first backream pass. 
8. At this point, the directional driller usually needs to orient to return to a tool face that is similar to the old hole. This is difficult to accomplish in one orienting session with a $2.0^{\circ}$ or larger motor because the bit will be in a bind due to a radical directional change. Also, future BHAs that would follow this radical change tend to pull tight and/or tear up the formation. Therefore it is prudent to perform the complete tool-face change in stages of about $60^{\circ}$ per $5 \mathrm{ft}$ which results in a smooth turn.

9. Begin the initial scribe with the bit parked at this depth for 10 minutes. Then begin a timed $15 \mathrm{ft}$ backream at $0.5 \mathrm{ft} / \mathrm{min}$.

10. At the top of the backream, RIH (slowly) the stretch length and begin a timed down ream at $0.1 \mathrm{ft} / 3 \mathrm{~min}$ for $15 \mathrm{ft}$ to the first flag on the reel $(\mathrm{F} 1)$.

11. Slowly pull the stretch out of the CT to the second flag on the reel (F2). Begin the second scribe up at $1.0 \mathrm{ft} / \mathrm{min}$ for $15 \mathrm{ft}$.

12. At the top of the backream, RIH (slowly) the stretch length and begin a timed down ream at $0.1 \mathrm{ft} / \mathrm{min}$ for $15 \mathrm{ft}$ until the first flag $(F 1)$ is reached. These passes have now established a trough for the BHA to lay in. There should now be a ledge at bit depth that is about half the diameter of the bit depending on the firmness of the formation..

13. Continue by drilling new hole at $0.1 \mathrm{ft} / \mathrm{min}$ for 5 feet. This step is important don't hurry!

14. Increase penetration rate to $0.25 \mathrm{ft} / \mathrm{min}$ for 5 feet.

15. Increase penetration rate to $0.5 \mathrm{ft} / \mathrm{min}$ for 5 feet.

16. Begin adding weight to increase penetration up to $1.0 \mathrm{ft} / \mathrm{min}$ for 5 feet. A survey should now show a slight change in angle.

17. Begin drilling using the weight/rate parameters that the directional driller specifies to maintain the correct tool face.

18. After drilling about $30 \mathrm{ft}$ from the kick-off point and/or before a tool-face change, it is advisable to make up to three back-reams/down-reams at $5 \mathrm{ft} / \mathrm{min}$ from the new TO to $50 \mathrm{ft}$ above the kick-off point. This extends the trough so future BHAs will drop in and follow.

19. At this point, the directional driller usually needs to orient to return to a tool face that is similar to the old hole. This is difficult to accomplish in one orienting session if a $2.0^{\circ}$ or larger motor is used because the bit will be in a bind due to a radical directional change. Also, future BHAs that would follow this radical change tend to pull tight and/or tear up the formation. Therefore it is prudent to perform the complete tool face change in stages of about $60^{\circ}$ per $5 \mathrm{ft}$ which results in a smooth turn. 


\subsection{WELL CONTROL}

There are several methods for controlling a kick that can be employed. The preferred method is called the "Driller's Method," in which the kick is circulated out of the well before increasing the mud weight. Three primary reasons for using the "Driller's Method" over the "Wait and Weight Method" (in which the kill-weight mud is mixed and the kick circulated out with the new mud) are: 1) the kick is displaced from the hole faster using the "Driller's Method," thereby minimizing gas migration; 2) the weak point in the open hole will not be subjected to any higher pressure using the "Driller's Method" versus the "Wait and Weight Method" because the kick will always be above the window before any kill mud starts up the annulus (open-hole annulus volume usually <20 bbl; CT volume 60 bbl); 3) an "accurate" shut-in CT pressure (SICTP) can be difficult to obtain because, with drilling fluids typically used, CT pressure drops off very slowly when the pumps are disengaged. There will always be some doubt initially regarding the mud weight required to kill the well. The following recommendations should be used as guidelines for well control during CTD operations:

- Circulating a gas kick out will usually require reducing the pump rate when the gas arrives at the surface to improve separation in the gas buster and/or frac tank, thereby minimizing the potential of a spill (mud spraying out of buster/tank). Make sure that slow pump rates are recorded on daily kick sheets and that constant bottom-hole pressure is maintained. Diversion options should be discussed during rig-up on the well.

- Kick recognition is a primary concern and returns should be monitored at all times during the drilling operation. Other kick indicators include an increase in flow to the pits, an increased pressure drop through the choke and other surface piping (higher wellhead pressure), gassy fluid samples, etc.

- "Hole Fill" and "Displacement" calculations should be performed for tripping operations. The amount of mud to fill the hole on the trip out, and the amount of mud displaced on the trip in must be monitored, and any deviation from these calculations must be investigated to detect a kick while tripping. Recorded trip sheets are required.

- To ensure that a slow pump rate/pump pressure is known prior to a kick or pressure increase, it is necessary to establish an off-bottom "Slow Pump Rate" (Usually $\pm 1 / 2$ the normal pump rate while drilling). The slow pump rate and pressure should be recorded for future reference during kill operations. Slow pump rate should be checked and recorded every 12 hours or 500 feet of new hole drilled.

- If a kick is detected while drilling, the following are recommended:

a Pick up off bottom, shut in the pump, and check for flow. If the well continues to flow, shut in the HCR (hydraulically controlled remote valve on the choke line that is full opening) and record SICTP and shut-in wellhead pressure (SIWHP). The pipe should be kept moving during this 
time to avoid danger of sticking, and the pack-off should be monitored for leakage.

a Circulate the kick out of the hole using the Driller's Method. Note: When using bio-polymer based drilling fluid, the CT pressure is very slow in dropping off when the pump is disengaged. This could give a false SICTP reading. If there is uncertainty, bring the pump to "Kill Speed" holding constant WHP (equal to SIWHP) until a stable CT pressure is achieved. Use the choke to maintain this CT circulating pressure plus a 100-150 psi safety margin while pumping out the kick. After pumping open-hole annular volume, pull bit to cased hole slowly, leaving uncontaminated mud in the open-hole portion. The kick should continue to be circulated out from this point while monitoring pack-off, surface lines, and BOP equipment.

a Use caution when taking gas returns at surface to avoid a spill. Reduce circulation rate as necessary and ensure constant BHP with the choke.

- When the kick has been displaced out of the hole, shut in the well again. If SICTP $=$ SIWHP $=0$, perform a flow check. Investigate potential reasons for the kick, and evaluate if increased mud weight is desired. If there is positive pressure, calculate new mud weight and continue with the second circulation of the Driller's Method to displace the old mud with new mud. Circulate new mud to the bit, holding WHP constant at the SIWHP reading. When new mud is at the bit, record CT pressure, and hold it constant until new mud is at surface.

- If a kick is detected while tripping, RIH circulating at minimum rate holding WHP constant with choke at the SIWHP reading. Monitor in and out volumes while $\mathrm{RIH}$ at constant WHP. If pit gain is equal to coil OD displacement, continue to bottom. If any discrepancy is noted, stop RIH and SI well again to verify surface pressures. Gas influx migration will be confirmed by increasing surface pressure when the pipe is stationary. Continue to RIH holding a higher WHP (if SIWHP was higher) and adjust WHP up as necessary such that returns from the well equal coil OD displacement. (Implementing the Volumetric Method can control gas migration. However, it will be rare to implement this procedure in CT Drilling, as trip time to bottom is fast.) RIH to bottom and circulate kick out with Driller's Method.

- If flow is detected while making up liner, stab TIW valve and close. Shut annular preventer on liner leaving HCR open. Set BOP slips on liner. Shut in well with HCR. Make up CT to TIW valve. Open TIW valve. Strip down injector and make up to riser. PT riser. Equalize and open annular and liner slips. $\mathrm{RIH}$ with liner to kill well as per a kick detected while tripping recommendation above. A TIW valve should be on the rig floor with all crossovers required for make up to liner and back to CT. If liner is slotted/pre-perforated, the TIW valve should be made up to a blank liner joint and positioned for rapid deployment.

- In the event of a kick while out of the hole, shut in the well and record shut-in pressure. Shut in master valve, make up BHA with nozzle that can be lubricated above the master, and then RIH using the stripping procedure above. Do not run 
into open hole. Perform well kill from window. If it is not possible to run into the hole and a BHA is hanging across the stack and master valve, then it may be necessary to bullhead to kill the well.

\section{Responsibilities}

Regardless of the complexity of well-control issues associated with a drilling operation, underbalanced or overbalanced, it is essential that the necessary checks, procedures and responsibilities are identified and understood by the personnel involved. In most cases, it is the responsibility of the driller to ensure that relevant checks are made and that the data/information on which the drilling operation is proceeding is current and accurate. However, to enable this, the driller must typically rely on the assistance of specialists or other personnel who should in turn be aware of their responsibilities and the need for safe drilling practices. The following wellcontrol issues relating to job responsibilities and procedures are provided for guidance in the preparation of procedures for a specific CTD operation.

- It is the CTD operator's responsibility to close in the well if a kick is indicated or suspected. It is better to shut in the well as a precautionary measure than to hesitate when conditions may require closure of the BOP equipment.

- The hole must be kept full of fluid at all times. This is central to the philosophy of overbalanced drilling, but may not be such a requirement in some underbalanced operations.

- Flow checks should be performed during all drilling breaks.

- When tripping pipe, a trip sheet should be completed and a flow check performed:

$\square$ at the lowest casing shoe

a prior to pulling BHA through the BOP

- Slow circulation rate check should be taken:

a the beginning of every tour/prior to every RIH

a any time the drilling fluid density is changed

- When lost circulation occurs and cannot be regained by circulation through the CT string, the annulus should be filled with the lightest fluid available (typically water) and volumes recorded.

- Tripping out the hole without full return is potentially dangerous and should only be permitted under known conditions with permission of the CTD superintendent.

- Drillers should be provided with procedures detailing the actions to be taken if a well kicks while drilling surface hole. 
- Unless the following materials are available for use at the rig site, drilling operations should be reviewed and if necessary suspended:

a enough salt $(\mathrm{KCl}$ or $\mathrm{NaCl})$ to raise the fluid weight in the active mud system at least $120 \mathrm{~kg} / \mathrm{m}^{3}$ or $1 \mathrm{ppg}$.

a enough cement to place at least a $120-\mathrm{m}$ or $400-\mathrm{ft}$ plug in open hole.

- Kick drills should be held on a weekly basis or more often if the rig superintendent considers it necessary. Details and results of any drills should be logged in the drilling report.

- BOP and related equipment should be pressure- and function-tested at least every 14 days.

- A float or check valves should be run while drilling and opening hole prior to setting surface casing.

- An appropriate safety valve (TIW) to fit the top of any BHA left hanging in the slips should be kept on the rig floor.

- Casing/liner strings will be completely filled from the top at least every five joints, irrespective of the type of float equipment in use.

- Wells should be shut in following the procedures described in the well site Standards of Operation. The relevant step-by-step procedures for shutting the well in should be posted in the vicinity of the driller's panel.

- The CT driller should check and confirm all choke manifold, kill and choke lines for correct positioning at the beginning of each tour.

- The driller should know the true vertical depth (TVD) measurements at all times.

- Prior to spudding, it is the responsibility of the CTD Supervisor to review the well plan and ensure that all primary well-control/pressure-control issues have been addressed.

- If the well cannot be closed in with the BOP, the well should be properly secured and tested by setting a plug.

- A well-control report should be completed by the CT driller and CT Supervisor after all well-control operations.

\subsection{UNDERBALANCED DRILLING}

One of the key advantages of CTD, through its unique pressure control capabilities, is that it enables safe underbalanced drilling (UBD). In preventing or avoiding drilling damage, UBD is often perceived to be the ideal solution to formation damage, especially in depleted reservoirs where CTD techniques can be so effectively applied. However, designing and conducting an 
UBD operation can be a complex process which requires a thorough knowledge of the risks (e.g., formation/wellbore collapse) and hazards (e.g., safe handling of reservoir fluids in the returned wellbore fluids).

\subsubsection{Underbalanced Drilling Applications}

CTD and conventional applications utilizing UBD techniques include the following:

1. Limiting lost circulation while drilling through elevated outcrops with low water table

2. Air drilling in competent crystalline rocks (where changes in confining pressure do not impact borehole stability)

3. Depleted reservoirs in which infill drilling is performed to produce bypassed oil may be hampered by lost circulation. These operations can be simplified by UBD.

4. A growing number of horizontal wells with uncemented completions have caused an increasing interest in preventing formation damage rather than curing it. In UBD, impairment of the reservoir is largely prevented by producing the reservoir section while it is being drilled.

There are three general methods of achieving underbalance, and the method used depends on the relationship between formation pressure and normal pressure gradient:

1. Formation is below normal pressure gradient. To achieve conditions in which the well will flow, use a liquid phase commingled with a gas phase to lighten the annulus hydrostatic pressure. The gas phase can be delivered via gas lift (if installed) or commingled on surface and circulated downhole.

2. Formation is at normal pressure gradient. The well will flow if low-density drilling fluids such as oil-base mud or crude-base systems are used.

3. Formation above normal pressure gradient. The well will flow simply by decreasing the drilling fluid density below that which would normally be used in overbalanced drilling. A fluid density equal to or slightly less than the formation gradient can be used in conjunction with the equivalent circulating density (ECD) providing a "balanced condition" while drilling. Decreasing the ECD or back pressure at the choke will allow the well to flow.

The following basic principles apply to flow control in underbalanced drilling:

- A state of flowing equilibrium must exist that is both controllable and within the operating limits of the wellbore and surface equipment. This state of equilibrium should create a constant BHP and flowing rate. 
- There must be a means of monitoring this state of equilibrium to ensure that it is maintained within the specified limits.

- There should be a convenient means of returning the well to an overbalanced mode (killing the well) in an emergency.

Control and regulation of wellbore pressures are obtained by circulating well returns through an adjustable surface choke. A second method of regulating wellbore pressures in low-pressure reservoir applications, is the injection of lift gas into the drilling fluid system. Bottomhole pressure is best measured by means of a downhole pressure gauge. The liquid phase of the drilling fluid system generally has sufficient density to serve as a kill fluid if an emergency occurs. If it does not, a separate batch of special kill fluid must be available at the site.

\subsubsection{Deployment Systems}

If impairment reduction is the reason for choosing UBD on a particular operation, it is generally preferable that the complete operation be performed underbalanced. Considerable impairment reduction can be expected if a well is drilled underbalanced, circulated clean and produced to fill the open-hole section with reservoir fluid before it is brought under primary well control. However, the benefits of UBD will be lost to some extent if this procedure is followed for every trip. Also, spotting a heavy pill on top of a lighter hydrocarbon column easily leads to "flip-over," where the heavy fluid changes position with the lighter fluid. If it is known that a reservoir will not free flow due to its low pressure and gas/oil ratio, allowing a well to kill itself through its own production before it is opened for BHA deployment can be considered. However, for most wells this is not a safe option. If it is not intended to bring the well under primary well control, some sort of sluice mechanism is required to deploy the BHA in a pressurized well. A temporary subsurface valve can be used, or a deployment riser at surface may be considered. If the reservoir section is drilled through the completion string, a permanent subsurface safety valve may be an option.

\section{Pressure Deployment}

Probably the greatest feature that CT brings to UBD is the ability to maintain a continuous state of underbalance while drilling, tripping, and running completions. However, during operations where the injector must be removed (installing/removing the BHA and running a completion), the well must be maintained in an underbalanced condition. Pressure deployment of the BHA is achieved using techniques developed for CT logging of live wells. The procedure used depends on factors such as:

- Length and diameter of the BHA

- BOP configuration

- Number of pressure barriers required 
Following is a general guide for pressure deployment and should be modified to suit specific circumstances. Since most wells drilled underbalanced with CTD will involve directional drilling, these procedures reflect the deployment of a BHA of about $40 \mathrm{ft}$ in length. Also, since most drilling would be for small hole sizes, the bit is assumed to be $43 / 4$ in. with the BHA having a nominal diameter of $3 \frac{1}{2}$ in. A simple method of deploying short BHAs with mud-pulse MWD is to use a wireline lubricator type deployment riser made up to the appropriate length (Figure 30). This requires a set of slip/seal rams and a set of blind/shear rams to be located in the BOP stack and the use of a deployment bar (a special sub that installs in the BHA and allows closing of the of the specified slip/seal rams on the correct diameter).

1. Using the wireline system, pull the assembled BHA up inside the lubricator.

2. With the blind/shear rams closed, install the lubricator onto the BOP stack (Figure 31) and equalize pressure.

3. Open blind/shear rams and lower the BHA with the wireline system to allow closure on the deployment bar.

4. When located properly, close the slip/seal rams on the BHA.

5. Bleed off and remove the lubricator.

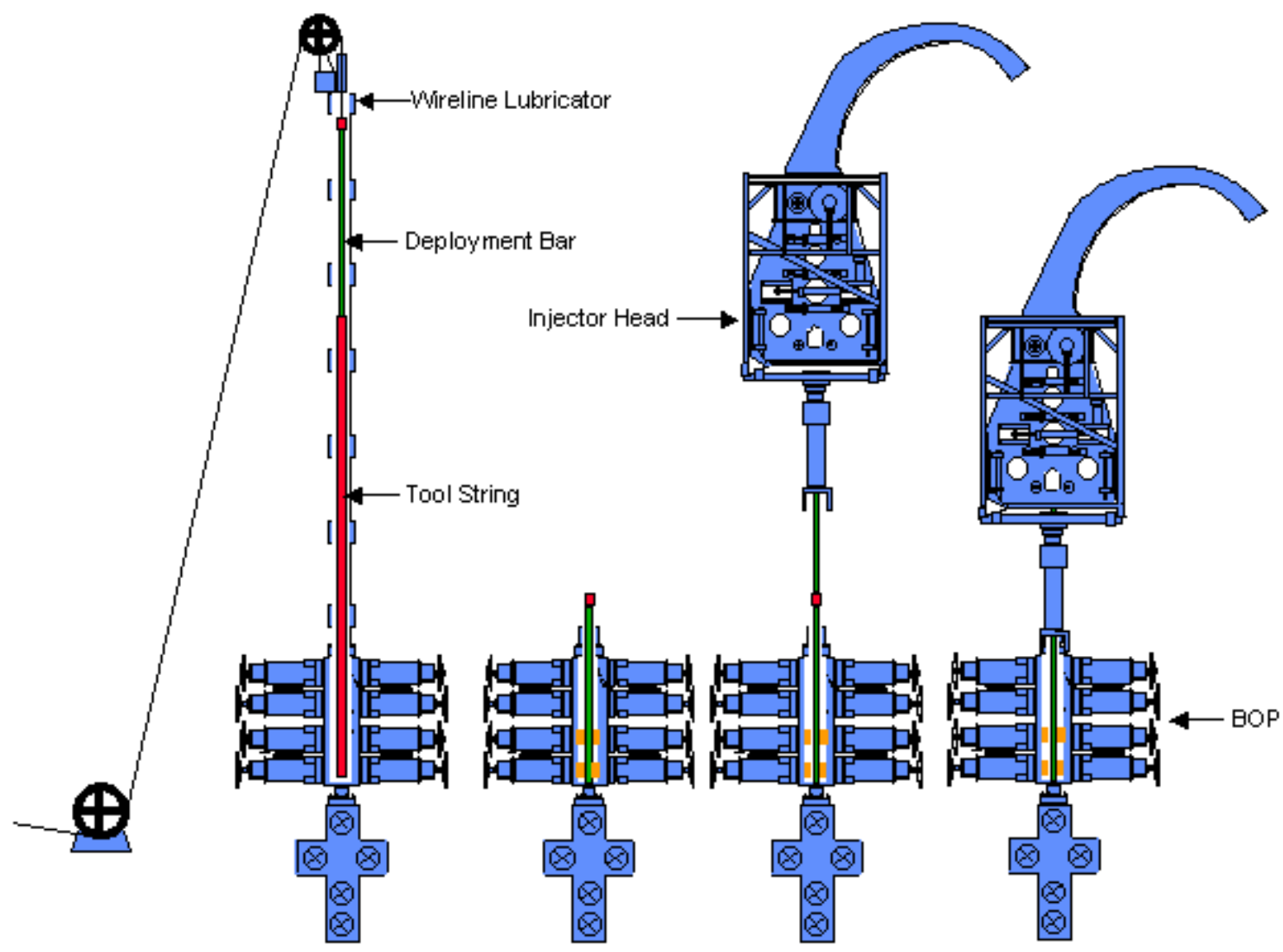

Figure 30. BHA Deployment Under Pressure (with Mud-Pulse MWD Svstems) 
6. Make up the tubing to the BHA and lower the injector to make up to the BOPs and equalize pressure.

7. Open slip/seal rams and run in with the BHA.

The reverse applies for pulling the $\mathrm{BHA}$ from the well.

However, the most commonly used short BHAs are run on CT with wireline installed inside. These BHAs are typically made up and pulled up into the lubricator. With the blind/shear rams closed, the injector and lubricator are installed on the BOPs and the pressure equalized. The blind/shear rams are then opened and the BHA run into the well.

For longer BHAs, or where a lubricator of sufficient length cannot be obtained, it may be necessary to deploy the $\mathrm{BHA}$ in stages (see Figure 31):

1. Using the wireline system, pull the first section of the $\mathrm{BHA}$ up inside the lubricator.

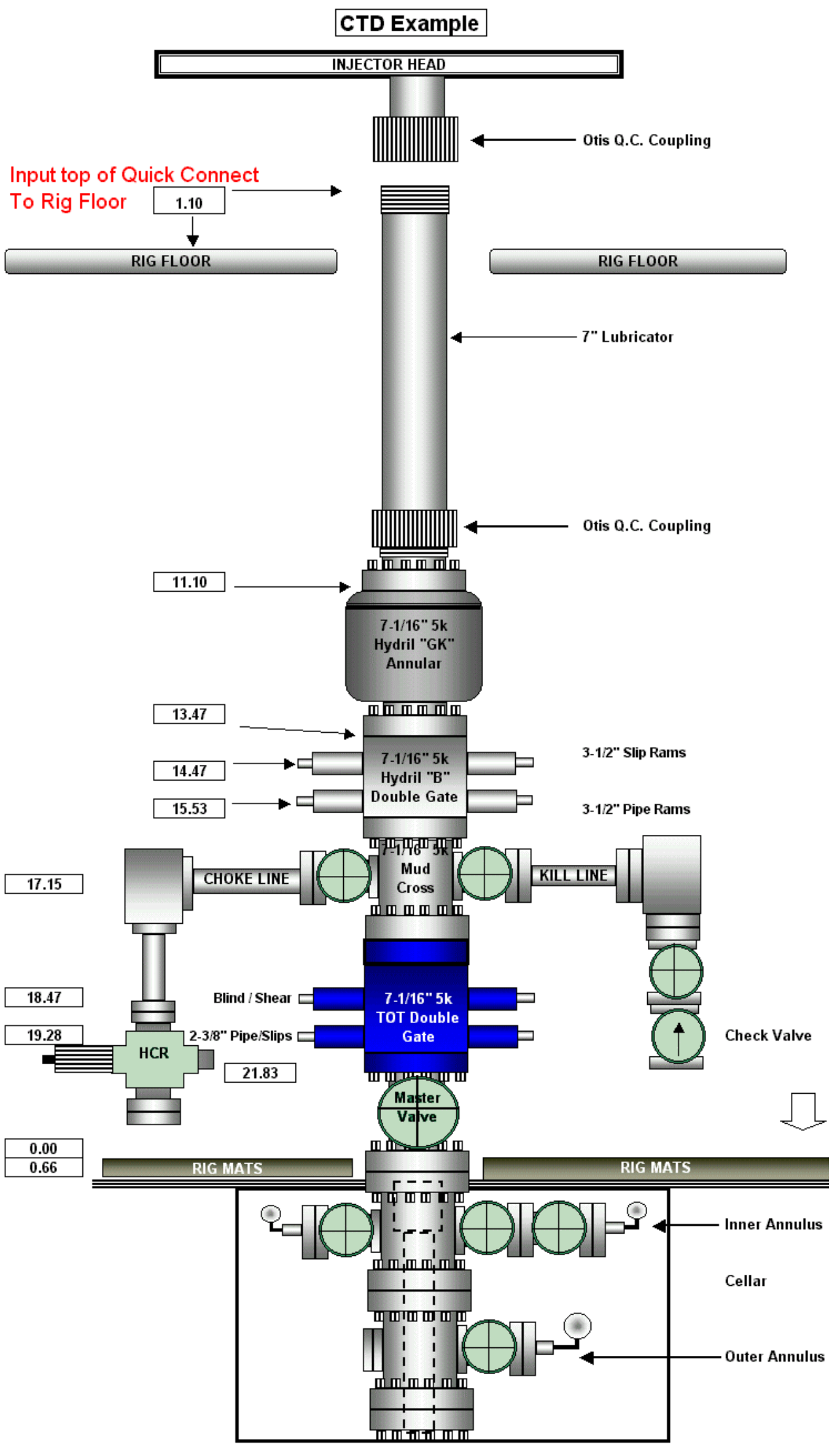

Figure 31. Typical CTD BOP Stack 
2. With the blind/ shear rams closed, install the lubricator onto the BOPs and equalize pressure.

3. Open blind/shear rams and lower the BHA section with the wireline system to allow for closure on the deployment bar.

4. When properly located, close the slip/seal rams on the deployment bar.

5. Remove the lubricator.

6. Pull the second section of BHA up inside lubricator and equalize pressure.

7. Move lubricator over and make up the second BHA section to the first BHA section. This may require some rigging up to enable screw-ing together the sections. Lower lubricator and make up to BOPs.

8. Open the slip/seal rams and lower the BHA.

9. When properly positioned, close the slip/seal rams on the deployment bar and bleed pressure.

10. Remove the lubricator, install the injector and equalize pressure.

11. Run the BHA into the well.

Deployment of completions systems in an underbalanced well can be done in much the same manner as for the BHA. If the completion involves a CT completion, deployment is simpler than for jointed-pipe completions. The deployment bar is a special sub installed in the BHA that allows closing the specified slip/seal rams on the correct diameter. The bar has shoulders above and below the closing diameter to prevent the bar from sliding through the rams.

\subsubsection{Mechanical Considerations}

The following mechanical aspects of UBD should be considered:

1. Hydraulically operated BHA components

2. Tubing collapse pressure

3. $\mathrm{H}_{2} \mathrm{~S}$ corrosion/embrittlement

\subsubsection{Hydraulically Operated BHA Components}

Some BHA components are operated hydraulically, using the pressure differential between the drillstring and the annulus. This mechanism is likely to be disturbed when drilling in an underbalanced mode. This is due to the different fluid compositions in the drillstring and annulus, caused by hydrocarbon production and gas injection. These different fluid columns 
create a permanent pressure differential, preventing unlocking hydraulically operated tools. Note that mud-pulse MWD systems will not work with two-phase fluid systems.

\subsubsection{Tubing Collapse Pressure}

When deep gas wells are drilled underbalanced, the massive gas influx can cause surface pressure in the annulus to rise well above drill-pipe pressure. Special attention must therefore be paid to the collapse pressure rating of the drillpipe. This applies particularly to CTD, since CT has a lower collapse rating than conventional drill pipe.

\subsubsection{3 $\underline{\mathrm{H}}_{2} \underline{\text { S Corrosion/Embrittlement }}$}

If hydrogen sulfide is produced with hydrocarbons, allowance must be made for aggravated corrosion of drillstring components. In UBD, these components are in contact with much larger amounts of $\mathrm{H}_{2} \mathrm{~S}$ than would be the case with overbalanced drilling.

Very important: Do not use high-strength CT grades; do use $\mathrm{H}_{2} \mathrm{~S}$ inhibitors, take good care of the CT string; and avoid mechanical damage.

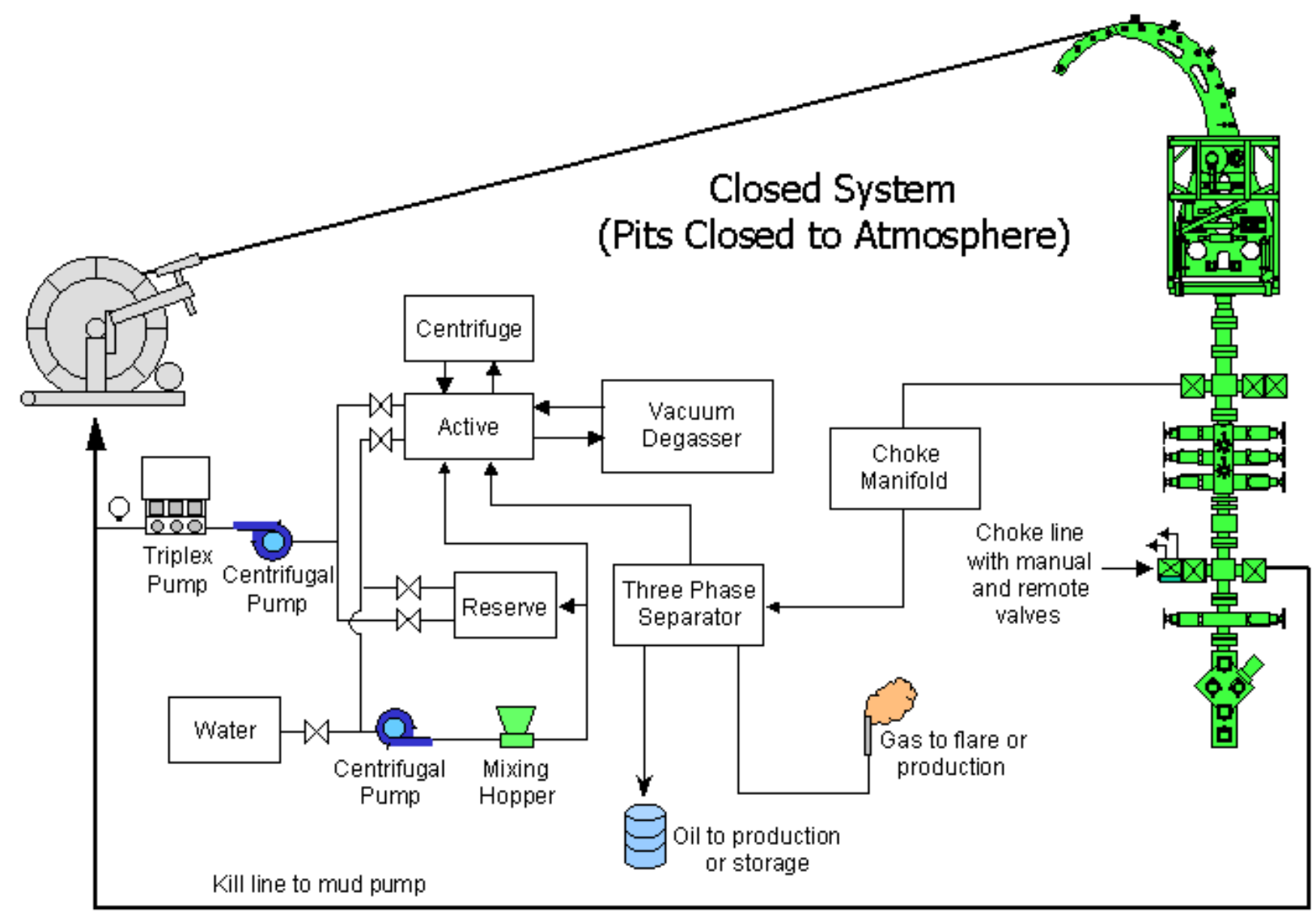

Figure 32. Closed CT Surface System 


\subsubsection{Surface Equipment}

Surface systems can either be open or closed (pressurized). Closed systems are used to handle potentially dangerous gases. This type of system is closed to the atmosphere and all operations take place under pressure (Figure 32). The major difference between closed and open systems is that in closed systems returns are taken from the choke and routed through a series of enclosed vessels that separate gas/oil/water and solids. A closed system is desirable for environmental concerns, and for wells producing $\mathrm{H}_{2} \mathrm{~S}$. Closed systems are generally restricted to use when surface pressures are low, although high-pressure systems can be built.

An open system essentially comprises standard equipment used on many rigs for well testing (Figure 33). Returns are taken through an adjustable choke, which is used to help regulate the flow rate and bottomhole pressure. Generally, the choke is fully opened and the flow/BHP controlled by adjusting gas/liquid injection rates. In a very simple system, returns are then routed through an atmospheric degasser (or series of degassers) to remove any gas. At this stage, the returns still contain oil, water and cuttings. Next, the returns are routed through a series of settling/skimming tanks where the oil is removed and the cuttings settle out. The drilling fluid is then flowed to a tank for re-use.

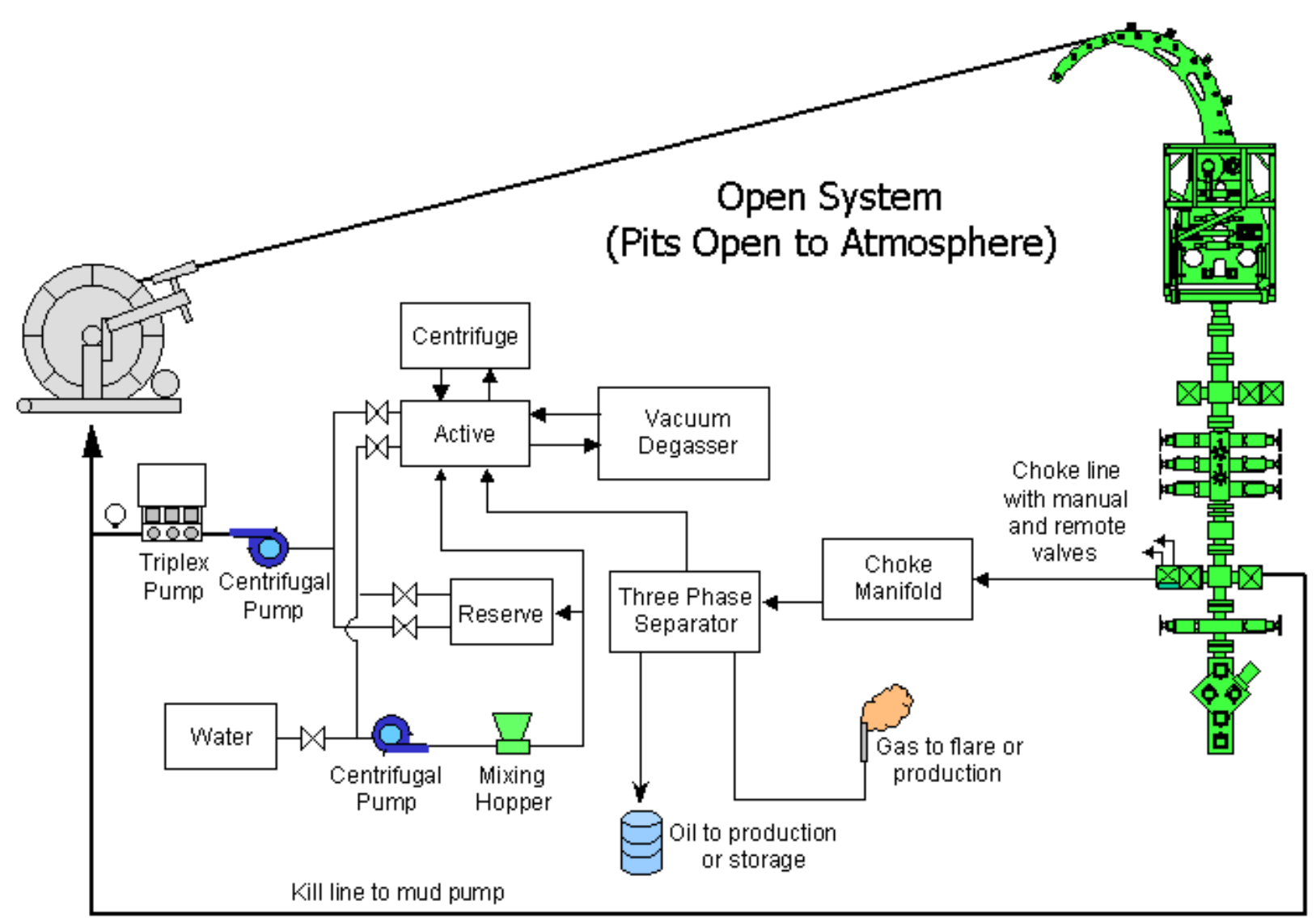

Figure 33. Open CT Surface System 


\subsubsection{Well Control}

In underbalanced drilling (UBD), the well is "encouraged" to flow. Nevertheless, there must also be constant "well control" in that the fluid influx is controlled at all times (from the time it enters the wellbore until it exits at the surface). This control is achieved by maintaining a constant flow and BHP. Another key factor is that in UBD operations, primary well control is not maintained by the drilling fluid. Instead, the CT equipment (stripper) and associated pressure-control equipment (drilling manifold) are the primary defense against blowouts. In almost all UBD operations, there should be an means available of returning the well to a static condition (i.e., killing the well and circulating out any formation influx). The method used to overbalance the well depends on how underbalance was originally achieved. There are three basic methods of achieving underbalance; the approach selected depends on the relationship between formation pressure and normal pressure gradient:

1. Formation pressure is below normal pressure gradient. For the well to flow, commingled fluids (e.g., Newtonian liquids and nitrogen), gas lift or foam must be used to reduce annular pressure. Parameters can be adjusted as needed and reducing gas injection rate can kill the well easily and quickly. Downhole conditions must be controlled to ensure that circumstances do not arise where sections of the wellbore are subjected to pressures above what they can withstand, which could result in an underground blowout.

2. Formation is at normal pressure gradient. The well should flow if light fluids such as oil-base mud or crude are used as a base for the drilling fluid (constraints on pumping flammable fluids apply). The degree of underbalance is not as easily adjusted, since light drilling fluid cannot be made heavier as easily. However, having a suitable fluid on hand and injecting this into the well can kill the well in an emergency. Again, the pressures encountered are not likely to cause problems within the wellbore.

3. Formation is above normal pressure gradient. The well will flow simply by decreasing fluid density below that which would normally be used in overbalanced drilling. However, there may be a significant risk that sections of the wellbore will experience higher pressures than they can withstand if the flow rate and BHP are allowed to fluctuate significantly. Killing the well will require significantly higher density fluid and circulating a kick from the well would entail risks as described previously for overbalanced drilling. The use of UBD for wells of this nature should not be considered unless there is a high degree of certainty relating to the pressures that are likely to be encountered and the overlying formation strengths. Common to all these cases is the possibility of wellbore collapse due to UBD. Some formations are highly unstable (e.g., sloughing shales) and require significant wellbore hydrostatic pressure to prevent collapse. Should UBD be attempted in such conditions, there is a significant risk of losing the well and perhaps drilling assembly. Also, depending on the pressure characteristics of the well, wellbore instability could contribute to an underground blowout or unwanted cross flow between formations of dissimilar pressure. 


\section{Post-Job Review}

\section{Summary}

After the well has been drilled and completed, a comprehensive post-job review should be conducted. This final step or process is often neglected. A complete review of the CTD planning and execution will ensure that all data and information from that data are generated, reported, interpreted and used advantageously. This review should provide background for future CTD operations and input to the CTD data base for monitoring operational efficiency and cost reduction. If the data are of good quality (as this process will prove), then any modifications that are necessary can be implemented quickly and effectively to move the CTD operations to a safer and more efficient level.

The time commitment required to prepare a post-job summary should not be so great as to discourage this valuable part of the process. It should be kept as simple and straightforward as possible to encourage completion. A fill-in-the-blank format and computerization are recommended to make the exercise as efficient as possible.

\subsection{CTD PLANNING AND EXECUTION REVIEW}

This first step in the review process is the responsibility of the CTD engineer and requires identifying and communicating to all involved parties the reporting requirements and expectations from each company/individual. These requirements should also be given along with a scheduled due date for returning the information. Some of the data that must be requested and furnished to the CTD engineer are (see examples in Attachments):

- final directional survey and plot of the well

- final copy of any logs recorded

- geology description of the cuttings collected

- complete record of bottom hole pressure data including date and time

- BHA record

- $\quad$ bit and motor performance records

- completion liner tally

- revised wellbore sketch

- $\quad$ perforating record

- CT life data and estimated remaining life of CT 
- bottom-hole pressure records (if data recorded)

- fluids report

- cementing data

- vendor performance reports

- full copy of all daily reports and accident reports

After collecting these data, the CTD engineer needs to interpret operational results and generate a final well report that should at least answer the following questions:

1. What went well?

2. What went poorly?

3. What were the main problem areas/cost drivers?

4. What modifications can be agreed on?

5. What were the most cost-effective operations?

6. What were the least effective operations?

Several computer programs are available that can help store and generate this information and also aid in setting up the data base needed to assimilate the data. These can provide the engineer with the ability to quickly generate information to determine areas of critical need so changes or modifications can be performed expeditiously. Questions about data acquisition during the job can also be answered, such as:

1. Were the data complete, accurate and useful?

2. Which data were not required?

3. Was the quality of the data sufficient? Was it excessive?

The engineer should be able at this point to generate all of the information necessary to report to the regulatory agency.

\subsection{CTD OPERATIONS REVIEW}

The CTD engineer should meet with the CTD Supervisor, Reservoir Engineer, and Geologist and discuss the entire operation. This meeting must be an open communication process for all to gain insight into the CTD performance and what is needed to meet the requirements of future wells. Several important items that must be discussed are: 
- Evaluate the performance of all vendors

- Must be evaluated with respect to both personnel and equipment

a Record the amount of downtime associated with each vendor

- Describe in detail the reason(s) for downtime

- What were the root causes of failures?

a Should there be an incentive contract with the vendor?

- What solutions were or should be implemented?

․ Who should implement?

Timing of implementation

- What testing should be done?

a How should solutions be implemented?

- What operating cost reductions should be implemented?

a How will it impact the operation as a whole?

- Is it safety oriented or does it sacrifice safety?

- How should implementation take place?

- Who is responsible for implementation?

- Were the CTD operations performed safely and the wellbore objectives met?

- What safety issues have not been resolved and how can they be resolved?

- If we missed our objectives, what part(s) of the operation contributed to the problems?

a Were the objectives clear and agreed on as obtainable?

- Is there additional testing that needs to be done to meet these objectives in the future?

․ What lessons were learned from this project?

- Were all procedures in place for the operations?

- Did any contingencies occur that were not planned for? 
After this meeting of the operating company personnel, the CTD Engineer and CTD Supervisor should then meet individually with each vendor and review any issues that need the vendor's action. There should also be a collective meeting with all of the vendors to review and discuss the operation(s) and any potential problems or solutions to problems that occurred or could arise. Do not let this become a "finger-pointing" session, but direct it toward an enhancement of the entire operation. In this meeting, a team mentality should be conveyed to complete the work safely and efficiently. Anything from the planning of the well to the final operation should be open for suggestions or solutions to improve the CTD operation. The main point to remember is that the CTD operations must be performed safely and wellbore objectives met.

\subsection{ACTION PLAN}

As a result of the Operations Review meetings, an action plan should be in place with responsibilities assigned as well as a time frame for completing each action item. A complete list of modifications required prior to the next CTD job should be generated and maintained by the CTD engineer. All responsible parties are to report back to the CTD engineer on the modifications implemented and the status of any action items assigned on an agreed upon schedule. If a vendor cannot implement the needed modifications, other options should be discussed to determine suitability for the upcoming CTD operations, else a possible change of vendors may be required. No part of the CTD operation should be performed that inhibits the safety of the operation and precludes obtaining the wellbore objectives agreed on.

Finally, time and money has been spent to generate a safe and efficient operation. Therefore, take the time and effort required to update and maintain a database for continually monitoring CTD operations. There are many computer software products on the market to help in developing and maintaining a database. Additionally, this should bring about two desired results: 1) operations improvement and 2) cost reduction. 


\section{CTD References}

1. Adams, N.J., Mack, S.K., Fannin, V.R., and Rocchi, Thierry, 1996: "Coiled-Tubing Applications for Blowout-Control Operations," Journal of Petroleum Technology, May.

2. Al-Hathy, Salim Said and Kalam, Mohammed Zubair, 1997: "Coiled Tubing Applications in the Sultanate of Oman," SPE 38396, presented at the 1997 SPE/ICoTA North American Coiled Tubing Roundtable held in Montgomery, Texas, April 1-3.

3. Allbee, James D., 1999: "Coiled Tubing Hang-offs: A Simple, Yet Effective Tool for the Future," SPE 52121, presented at the 1999 SPE Mid-Continent Operations Symposium held in Oklahoma City, Oklahoma, March 28-31.

4. American Oil \& Gas Reporter Staff, 1999: "CTD Proves Tough to Top in Right Applications," American Oil \& Gas Reporter, March.

5. Atherton, G.M. and Davis, M., 1996: "Coiled Tubing Drilling of Horizontal Re-Entry Wells, UK Land," SPE 35546, presented at SPE (location unknown).

6. Balen, Mark, Foose, Joe, Schershel, Steve and Strashok, Gary, 1997: "Horizontal Coiled Tubing Drilling A Multi-Well Project at Clive, Alberta," Paper No. 97-116, presented at the CADE/CAODC Spring Drilling Conference held in Calgary, Alberta, Canada, April 8-10.

7. Barney, Harvey E. and Overstreet, Charles C., 1999: "Successful Underbalanced Drilling by Pumping Nitrogen Through Coiled Tubing and a Vane Motor in the Low Pressured Pettit Lime Formation," SPE 54497, presented at the SPE/ICoTA Coiled Tubing Roundtable held in Houston, Texas, May 25-26.

8. Bass, A.C. and Hearn, D.D., 1995: "North Slope Coiled Tubing Drilling Experience," World Oil's 3rd International Conference and Exhibition on Coiled Tubing Technology: Operations, Services, Practices; Houston, Texas, March 13-16.

9. Beckman, Jeremy, 1997: "Coiled Tubing, Reamer Shoes Push Through Barriers in North Sea Wells," Offshore, February.

10. Bell, G.; Fleck, A.; Hoekstra, T.; van Beelen, N.; van Venrooy, J.; and Weihe, A., 2000: "Underbalanced Drilling with Coiled Tubing in Oman", SPE 57571, presented at the 1999 SPE/IADC Middle East Drilling Technology, Abu Dhabi, November 8-10.

11. Bell, Steven S., 1997: "Adjustable Stabilizers Increase Rotary Drilling Performance," World Oil, June. 
12. Bijleveld, A.F., 1999: "ICoTA's CT Drilling Training and Competence Guidelines - How to Use Them," SPE 54462, presented at the 1999 SPE/ICoTA Coiled Tubing Roundtable held in Houston, Texas, May 25-26.

13. Bingham, Brian, 2000: "Rotational Toolface Orientation to Facilitate Coiled Tubing Target Acquisition", IADC/SPE 62738, presented at the 2000 IADC/SPE Asia Pacific Drilling Technology held in Kuala Lumpur, Malaysia, September 11-13.

14. Blount, C.G., Gantt, L.L., Hearn, D.D., Mooney, M.B., Smith, B.E., Quinn, D. and Larson, E.B., 1998: "Development Update of an MWD Directional Drilling Package for 23/4" Openhole: Tiny Tools," SPE 46016, presented at the 1998 SPE/ICoTA Coiled Tubing Roundtable held in Houston, Texas, April 15-16.

15. Blount, C.G., Mooney, M.B., Smith, B.E., Quinn, D. and Larson, E.B., 1997: "Development and Case Histories of an MWD Directional Drilling Package for 23/4" CT," SPE 38613, presented at the 1997 SPE Annual Technical Conference and Exhibition held in San Antonio, Texas, October 5-8.

16. Boberly, L., Brazier, R., Giddings, C. and Cox, R., 1997: "Coiled Tubing Horizontal Underbalanced Drilling Project; Costs and Operational Analyses," SPE 38399, presented at the $2^{\text {nd }}$ North American Coiled Tubing Roundtable held in Montgomery, Texas, April 1-3.

17. Borbely, L., Brazier, R., Giddings, C. and Cox, R., 1997: "Costs and Operational Analyses of a Coiled Tubing Horizontal Underbalanced Drilling Project," Paper No. 97-102, presented at the CADE/CAODC Spring Drilling Conference held in Calgary, Alberta, Canada, April 8-10.

18. Bouroumeau-Fuseau, Patrick; Mackay, Stuart; and Simondin, Armel, 2000: "Coiled Tubing Drilling Cost-Efficient in Chasing Alwyn's Small Oil Pockets", Offshore, April.

19. Brunskill, D. and Campbell, A., 2000: "Advances in Coiled-Tubing Jetting Technology", SPE 60721, presented at the 2000 SPE/ICoTA Coiled Tubing Roundtable, Houston, April 5-6.

20. Burge, P., 1996: "Horizontal Drilling Using Coiled Tubing - from Demonstration to Growth," THERMIE Project No. OG/216/93, presented at the $19965^{\text {th }}$ European Union Hydrocarbons Symposium held in Edinburgh, Scotland, November 26-28.

21. Buset, Per and O'Neil, John, 1998: "Coiled Tubing Sidetrack Taps Bypassed Reserves," World Oil, April.

22. Byrom, T.G., 1999: "Coiled-Tubing Drilling In Perspective," JPT, June.

23. Cheung, V., Christensen, D., Davis, R., Lee, J., MacKinnon, M. and Hollies, D., 1997: "Application of Coiled Tubing Underbalanced Horizontal Drilling in the Hussar Glauconitic 
'A' Pool," presented at the SPE/CIM $6^{\text {th }}$ Annual One-Day Conference on Horizontal Well Technology: "Improving Profitability in Diverse Horizontal Well Applications," held in Calgary, November 12.

24. Chitty, Greg H., 1998: "Corrosion Issues with Underbalanced Drilling in $\mathrm{H}_{2} \mathrm{~S}$ Reservoirs," SPE 46039, presented at the 1998 SPE/ICoTA Coiled Tubing Roundtable held in Houston, Texas, April 15-16.

25. Choe, Jonggeun and Juvkam-Wold, Hans C., 1996: "A Simplified Well Control Model for Horizontal Slimholes and Coiled Tubing Drilling," SPE 37076, presented at the 1996 SPE International Conference on Horizontal Well Technology held in Calgary, Canada, November 18-20.

26. Comeaux, Blaine, 1997: "Update on Applications of Coiled Tubing Drilling Orientation and Monitoring," presented at the PNEC $5^{\text {th }}$ International Conference on Coiled Tubing Technology, Philip C. Crouse \& Associates, held in Dallas, Texas, January 8-10.

27. Comeaux, Blaine, 1998: "Coiled Tubing Drilling Operations Experiences," presented at the 1998 IBC Coiled Tubing Conference held in Houston, Texas, June 29-30.

28. Cox, R., 1996: "Horizontal Underbalanced Drilling in a Sour Gas Carbonate Using Coiled Tubing: A Case Study," SPE 37075, presented at the 1996 SPE International Conference on Horizontal Well Technology held in Calgary, Canada, November 18-20.

29. Cox, R.J., 1999: "Coiled Tubing Horizontal Underbalanced Drilling in the Elkton Formation of Central Alberta," Paper 99-107, presented at the CADE/CAODC Spring Drilling Conference, Calgary, April 7-8.

30. Cox, R.J.; Li, Jeff; and Lupick, G.S., 1999: "Horizontal Underbalanced Drilling of Gas Wells with Coiled Tubing," SPE Drilling \& Completion, SPE 55036 (revised from SPE 37676), March.

31. Crouse, P.C. and Lunan, W.B., 2000: "Coiled Tubing Drilling - Expanding Application Key to Future," SPE 60706, presented at the 2000 SPE/ICoTA Coiled Tubing Roundtable held in Houston, Texas, April 5-6.

32. Crouse, Philip C., 1997: "Jointed Pipe, Snubbing, Hybrid, or CT Rigs - Options and Risks for the $21^{\text {st }}$ Century Drilling and Operator," presented at the $19975^{\text {th }}$ Annual International Conference on Coiled Tubing Technology, Philip C. Crouse \& Associates, held in Dallas, Texas, January 8-10.

33. Crow, Walter, 1999: "Coiled Tubing Safety Manual," DOE/SW/41286-1, Topical Report for National Petroleum Technology Office, U.S. Department of Energy, January. 
34. Curtis, Fred and Lunan, Brian, 1997: "Horizontal Underbalanced Drilling - A Canadian Overview," PNEC 5CT-\#15, presented at the $5^{\text {th }}$ International PNEC Conference on Coiled Tubing held in Dallas, Texas, January 8-10.

35. Cuthbertson, Robert L. and Vozniak, John, 1997: "Coiled Tubing Drilling: Applications for Underbalanced Drilling - Surface Design and Systems," presented at the $5^{\text {th }}$ International PNEC Conference on Coiled Tubing held in Dallas, Texas, January 8-10.

36. DeRouen, Mark, 1999: "Wells Successfully Drilled and Completed with CT in the Gulf of Mexico," presented at the 1999 SPE/ICoTA Coiled Tubing Roundtable held in Houston, Texas, May 25-26.

37. Dickinson, Wade, 1997: "Petrolphysics Petro Jet Multi-Lateral System and Petro Jet Extended Reach System," presented at the $19975^{\text {th }}$ Annual International Conference on Coiled Tubing Technology, Philip C. Crouse \& Associates, held in Dallas, Texas, January 8-10.

38. Drilling Contractor Staff, 1996: "UK's $1^{\text {st }}$ Underbalanced, Multi-Lateral, CT-Drilled Well Boosts Production 400\%," July.

39. Elsborg, C., Carter, J. and Cox, R., 1996: "High Penetration Rate Drilling with Coiled Tubing," SPE 37074, presented at the 1996 SPE International Conference on Horizontal Well Technology held in Calgary, Canada, November 18-20.

40. Elsborg, C.C., Graham, R.A. and Cox, R.J., 1996: "Large Diameter Coiled Tubing Drilling," SPE 37053, presented at the 1996 SPE International Conference on Horizontal Well Technology held in Calgary, Canada, November 18-20.

41. Flynn, T.S. and Jahn, B., 2000: "Vibration Analysis for Coil Tubing Drilling in Prudhoe Bay," SPE 60751, presented at the 2000 SPE/ICoTA Coiled Tubing Roundtable held in Houston, Texas, April 5-6.

42. Gaddy, Dean E., 2000: “Coiled-Tubing Drilling Technologies Target Niche Markets," Oil \& Gas Journal, January 10.

43. Gassø, Gjerde, K. and Samsonsen, B., 1998: "The First Coiled Tubing Sidetrack in Norway, Gulfaks Field," IADC/SPE 39305, presented at the 1998 IADC/SPE Drilling Conference held in Dallas, Texas, March.

44. Gauthier, Sammy, McGavern, Cecil and Sides, Winfield, 1997: "Advancements in SPOOLABLE Completions to Accommodate Wireline Operations," ICoTA/SPE 38401, presented at the $2^{\text {nd }}$ North American Coiled Tubing Roundtable held in Montgomery, Texas, April 1-3. 
45. Gebhardt, Freddy, Eby, Dan and Barnett, David, 1996: "Novel Coiled Tubing Application Controls Large LPG Storage Well Fire," World Oil, June.

46. Geddes, Bob and Sola, Sonny, 1997: "The Continuous Drill String Rig: 'A Drilling Solution to a Drilling Problem,"' Paper No. 97-143, presented at the CADE/CAODC Spring Drilling Conference held in Calgary, April 8-10.

47. Giddings, Charles, 1997: "Operational Practices for Coiled Tubing Drilling," presented at the $19975^{\text {th }}$ Annual International Conference on Coiled Tubing Technology, Philip C. Crouse \& Associates, held in Dallas, Texas, January 8-10.

48. Gleitman, D.D., Hardin, J.R., Hightower, C.M., Ganti, L.L., Smith, B.E., Upchurch, E.R. and Smith, M.B., 1996: "Newly Applied BHA Elements Contribute Toward Mainstreaming Coiled Tubing Drilling Applications," presented at the 1996 IADC/SPE Drilling Conference held in New Orleans, Louisiana, March 12-15.

49. Goodrich, G.T., Smith, B.E. and Larson, E.B., 1996: "Coiled Tubing Drilling Practices at Prudhoe Bay," IADC/SPE 35128, presented at the 1996 IADC/SPE Drilling Conference held in New Orleans, Louisiana, March 12-15.

50. Graham, R., 1997: "Underbalanced Drilling With Coiled Tubing: A Safe, Economical Method for Drilling and Completing Gas Wells," Journal of Canadian Petroleum Technology, Vol. 36, No. 8, September.

51. Graham, R.A., Cox, R.J., Stadlwieser, J.A. and Stinn, R., 1999: "Horizontal Re-Entry Drilling with Coiled Tubing: A Viable Technology," Journal of Canadian Petroleum Technology, Vol. 38, No. 10, October.

52. Graham, Robert A., 1998: "Planning For Underbalanced Drilling With Coiled Tubing? The Feasibility Study and Computer Modeling," SPE 46042, presented at the 1998 SPE/ICoTA Coiled Tubing Roundtable held in Houston, Texas, April 15-16.

53. Grigor, C., 2000: "Development of a Single-Trip Coiled Tubing Sidetracking System," SPE/Petroleum Society of CIM 65532, presented at the 2000 SPE/Petroleum Society of CIM International Conference on Horizontal Well Technology held in Calgary, Alberta, Canada, November 6-8.

54. Gulrajani, S. N. and Olmstead, C. C., 2000: "Coiled-Tubing Conveyed Fracture Treatments," SPE 57432, presented at the 1999 SPE Eastern Regional Meeting, Charleston, West Virginia, October 21-22.

55. Gunningham, M.C., Coe, B., Evans, S. and Wiersma, J., 1997: "Coiled Tubing Drilling Case History, Offshore The Netherlands," SPE 38395, presented at the 1997 SPE/ICoTA North American Coiled Tubing Roundtable held in Montgomery, Texas, April 1-3. 
56. Hall, Jack and Wijingaards, Ben M., 1998: "Slickline Power Unit on Coiled Tubing Provides Innovative Solution for Setting a Nippleless Lock in a Multilateral Completion," IADC/SPE 47847, presented at the 1998 IADC/SPE Asia Pacific Drilling Conference held in Jakarta, Indonesia, September 7-9.

57. Hart's Petroleum Engineer International Staff, 1996: "Downhole Control - The Key To Coiled Tubing Drilling Efficiency," July.

58. Head, P.F., Hanson, T.J., Yuratich, M. and Turner, D.R., 1998: "Electric Coiled Tubing Drilling - The First Steps Toward a Smart CT Drilling System," SPE 46013, presented at the 1998 SPE/ICoTA Coiled Tubing Roundtable held in Houston, Texas, April 15-16.

59. Hearn, D.D., Blount, C.G. and Kamlowsky, P.E., 1996: "Coiled Tubing Window Milling," IADC/SPE 35126, presented at the 1996 IADC/SPE Drilling Conference held in New Orleans, Louisiana, March 12-15.

60. Hecht, Gordon and Jackson, Robert, 1998: "Through Tubing, Rotary Drilling and Coiled Tubing Drilling in Alaska," presented at the IBC Petroleum Engineering Conference, Aberdeen, UK, September 22-24.

61. Hightower, C.M. and Blount, C.G., 1997: "ARCO Coiled Tubing Drilling \& Production Update," presented at the $19975^{\text {th }}$ Annual International Conference on Coiled Tubing Technology, Philip C. Crouse \& Associates, held in Dallas, Texas, January 8-10.

62. Hightower, C.M., 1997: "An Operator's Coiled Tubing Drilling History," presented at the $5^{\text {th }}$ International Conference on: Coiled Tubing and Well Intervention held at the Sheraton Astrodome Hotel, Houston, Texas, February 4-6.

63. Hightower, C.M., 1997: "Operator's Coiled Tubing Drilling Program Gets Good Results," World Oil, October.

64. Hongren, Gu and Walton, Ian C., 1996: "Designing Under and Near Balanced Coiled Tubing Drilling Using Computer Simulations," SPE 35665, presented at the Western Regional Meeting held in Anchorage, Alaska, May 22-24.

65. Hupp, Jeffrey L., et al., 2001: "Improvements in Coiled-Tubing Window-Milling Operations Cut Costs and Increase Reliability, Prudhoe Bay, Alaska," SPE 68432, Coiled Tubing Roundtable, March 7-8.

66. Journal of Petroleum Technology Staff, 1996: "New BHA Tools for Coiled Tubing Drilling," JPI, August.

67. Journal of Petroleum Technology Staff, 1997: "Application of Coiled-Tubing-Drilling Technology on a Deep Underpressured Gas Reservoir," JPT, June. 
68. Journal of Petroleum Technology Staff, 1997: "Brent's First Coiled-Tubing-Drilled Well," $J P T$, June.

69. Journal of Petroleum Technology Staff, 1997: "High-Penetration-Rate Drilling With Coiled Tubing," JPT, June.

70. Journal of Petroleum Technology Staff, 1997: "Large-Diameter Coiled-Tubing Drilling," JPT, February.

71. Kara, D.T., Gantt, L.L., Blount, C.G. and Hearn, D.D., 1999: "Dynamically Overbalanced Coiled Tubing Drilling on the North Slope of Alaska," SPE 54496, presented at the 1999 SPE/ICoTA Coiled Tubing Roundtable held in Houston, Texas, May 25-26.

72. Kazakov, Serguei and Rispler, Keith, 2000: "Optimizing and Managing Coiled Tubing Frac Strings," SPE 60747, presented at the 2000 SPE/ICoTA Coiled Tubing Roundtable held in Houston, Texas, April 5-6.

73. Kirk, Andrew and Sembiring, Taufiq, 1999: "Application of CTD Offshore, Indonesia Phase One Pilot Project," SPE 54502, presented at the 1999 SPE/ICoTA Coiled Tubing Roundtable held in Houston, Texas, May 25-26.

74. Kjell-Inge Sola and Lund, Bjørnar, 2000: "New Downhole Tool for Coiled Tubing Extended Reach," SPE 60701, presented at the 2000 SPE/ICoTA Coiled Tubing Roundtable held in Houston, Texas, April 5-6.

75. Knapp, Paul, van Walsum, Eric and Schuler, Joe, 1999: "Advances in the Control of Coiled Tubing Units," Paper 99-137, presented at the CADE/CAODC Spring Drilling Conference held in Calgary, Alberta, Canada, April 7 and 8.

76. Koper, M.G.M., 1999: "The Galileo Experience," SPE/IADC 57570, presented at the 1999 SPE/IADC Middle East Drilling Technology Conference held in Abu Dhabi, UAE, November 8-10.

77. Lambert, M., 2000: "Multilateral Well Leg Re-Entry Made Possible With a Unique Coiled Tubing Downhole Tool," SPE 60702, presented at the 2000 SPE/ICoTA Coiled Tubing Roundtable held in Houston, Texas, April 5-6.

78. Larson, Eric, Huffman, Alan, William, Brock A. and Snisarenko, P., 1997: "Hybrid Rig Development Aids North Slope CT Operations," World Oil, August.

79. Leising, L.J. and Walton, I.C., 1998: "Cuttings Transport Problems and Solutions in Coiled Tubing Drilling," IADC/SPE 39300, presented at the 1998 IADC/SPE Drilling Conference held in Dallas, Texas, March 3-6. 
80. Leising, L.J., Hearn, D.D., Rike, E.A., Doremus, D.M. and Paslay, P.R., 1996: "Sidetracking Technology for Coiled-Tubing Drilling," Journal of Petroleum Technology, May.

81. Leismer, Dwayne, Williams, Brock and Pursell, John, 1996: "Coiled Tubing Drilling: Real Time MWD With Dedicated Powers to the BHA," OTC 8227, presented at the Offshore Technology Conference held in Houston, Texas, May 6-9.

82. Leniek, Humberto; Paz, Luis; and Solanet, Fernando, 2000: "Coiled Tubing Used as a Continuous-Sucker-Rod System in Slim Holes," SPE 56671, presented at the 1999 SPE Annual Technical Conference and Exhibition, Houston, October 3-6.

83. Lord, D.J., Brinkhorst J.G., Robertson, T.J. and Martin, R.H., 1998: "Coiled Tubing Drilling on the North Cormorant Platform," SPE 46046, presented at the 1998 SPE/ICoTA Coiled Tubing Roundtable held in Houston, Texas, April 15-16.

84. Lord, David and Anderson, David, 1998: "CTD System Allows Simultaneous Offshore Operations," World Oil, February.

85. Lord, David, Brinkhorst, Jan, Townsley, Bill and Bogaert, Philip, 1997: "Shell Expro's First Application of Coiled Tubing Drilling," World Oil, June.

86. Lord, David, Brinkhorst, Jan, Townsley, Bill and Bogaert, Philip, 1997: "Shell Expro's First Application of Coiled Tubing Drilling," presented at the $5^{\text {th }}$ International Conference on: Coiled Tubing and Well Intervention held at the Sheraton Astrodome Hotel, Houston, Texas, February 4-6.

87. Luft, H.B. and Wilde, G., 1999: "Industry Guidelines for Underbalanced Coiled-Tubing Drilling of Critical Sour Wells," SPE 54483, presented at the SPE/ICoTA Coiled Tubing Roundtable held in Houston, Texas, May 25-26.

88. Lunan, Brian, 1997: "Underbalanced Drilling with Coiled Tubing," presented at the $5^{\text {th }}$ International PNEC Conference on Coiled Tubing held in Dallas, Texas, January 8-10.

89. Lunan, Brian, 2000: "Technology Advancements Spur CT Drilling Growth," The American Oil \& Gas Reporter, February.

90. Maranuk, C.A., Gaynor, T.M., Chen, D. C-K and Pruitt, J., 2000: "A Concept of a New Steerable Drilling System for Coiled Tubing," SPE 60752, presented at the 2000 SPE/ICoTA Coiled Tubing Roundtable held in Houston, Texas, April 5-6.

91. Marker, Roy, Haukvik, John, Terry, James B., Paulk, Martin D., Coats, E. Alan, Wilson, Tom, Estep, Jim, Farabee, Mark, Berning, Scott A. and Song, Haoshi, 2000: "Anaconda: Joint Development Project Leads to Digitally Controlled Composite Coiled Tubing Drilling 
System," SPE 60750, presented at the 2000 SPE/ICoTA Coiled Tubing Roundtable held in Houston, Texas, April 5-6.

92. McGregor, B., Cox, R. and Best, J., 1997: "Application of Coiled Tubing Drilling Technology on a Deep Underpressured Gas Reservoir," SPE 38397, presented at the 1997 SPE/ICoTA North American Coiled Tubing Roundtable held in Montgomery, Texas, April 1-3.

93. McMillin, Kevin, 1999: "Downhole Options Developing Around Coiled Tubing," Offshore, February.

94. Meek, Dale E.; Staal, Timo W.; and Tinkham, Scott K., 2000: "Wired BHA for Underbalanced Coiled-Tubing Drilling," IADC/SPE 59161, presented at the 2000 IADC/SPE Drilling Conference, New Orleans, February 23-25.

95. Milligan, M., Andreychuk, M. and Lunan, B., 1996: "Coiled Tubing Drilling of Horizontal Sidetrack in House Mountain Field, Alberta," IADC/SPE 35127, presented at the 1996 IADC/SPE Drilling Conference held in New Orleans, Louisiana, March 12-15.

96. Mix, K., Bell, G., Evans, S.J., 1996: "Coiled Tubing Drilling Case History," SPE 36350, presented at the $1^{\text {st }}$ SPE/ICoTA North America Coiled Tubing Roundtable held in Conroe, Texas, February 26-28.

97. Moon, Robert G., Ovitz, Robert W., Guild, G. John and Biggs, Michael D., 1997: "Program Tests Limits of CT Drilling," The American Oil \& Gas Reporter, February.

98. Moon, Robert G., Ovitz, Robert W., Guild, G. John and Biggs, Michael D., 1996: "Shallow Gas Well Drilling with Coiled Tubing in the San Juan Basin," SPE 36463, presented at 1996 SPE Annual Technical Conference and Exhibition held in Denver, October 6-9.

99. Newman, K.R., 1999: "Coiled-Tubing Stretch and Stuck-Point Calculations," SPE 54458, presented at the 1999 SPE/ICoTA Coiled Tubing Roundtable held in Houston, May 25-26.

100. Newman, K.R., Stone, L.R. and Wolhart, S., 1996: "The Feasibility of Using an Electric Downhole Motor to Drill with Coiled Tubing," SPE 36343, presented at the $1^{\text {st }}$ SPE/ICoTA North America Coiled Tubing Roundtable held in Conroe, Texas, February 26-28.

101. Newman, Ken, 1996: "CTD Poised To Make An Impact on Segments of Drilling Market," The American Oil \& Gas Reporter, April.

102. Offshore Staff, 1996: "Drilling Association Supports a Wider Role for Coiled Tubing," Offshore, October.

103. Offshore Staff, 2000: "Drillship Designed for Coiled Tubing Drilling, Completion of Subsea Wells," Offshore, June. 
104. Oil \& Gas Journal Staff, 1997: "BP Tests Offshore Coiled Tubing Slim Hole Drilling," O\&GJ, May 12.

105. Østvang, Knut, Haukvik, John, Skeie, Terje and Hallundbaek, Jørgen, 1997: "World's First Successful Horizontal Wireline Tractor Operations," presented at the $5^{\text {th }}$ International Conference on: Coiled Tubing and Well Intervention, Houston, Texas, February 4-6.

106. Pedersen, Knut, Ørisland, Svein, Spilling, Ivar, Bralie, Rolf, Hargreaves, Tony, Londdale, Paul, Crawford, Jim and Braddick, Britt, 1997: "Multilateral Branch Drilling Through Tubing, with Coiled Tubing Drilling, Planned for Snorre Field, Snorre TLP (Tension Leg Platform) in North Sea, Norway," presented at the $5^{\text {th }}$ International Conference on: Coiled Tubing and Well Intervention, Houston, Texas, February 4-6.

107. Pitman, Malcolm, Rafferty, Robin and Ferguson, Andy, 1997: "Casing Exit Techniques Using Coiled Tubing: Worldwide Case Histories," SPE 38428, presented at the 1997 SPE/ICoTA North American Coiled Tubing Roundtable in Montgomery, Texas, April 1-3.

108. Portman, Lance, 1999: "Reducing The Risk, Complexity and Cost of Coiled Tubing Drilling," Petroleum Engineer International, July.

109. Qiu, W.Y., Miska, S.Z. and Volk, L.J., 1999: "Effect of Coiled Tubing Initial Configuration on Buckling Behavior in Deviated Wells," Transactions of the ASME, Journal of Energy Resources Technology, Vol. 121, September.

110. Qiu, Weiyong, 1999: "Force Transmission of Coiled Tubing in Horizontal Wells," SPE 54584, presented at the 1999 SPE/ICoTA Coiled Tubing Roundtable held in Houston, Texas, May 25-26.

111. Rose, D., Kehler, T., Proctor, R. and Campbell, B., 1999: "Optimizing Coiled-Tubing Training with Computer Simulation Modeling," SPE 54495, presented at the 1999 SPE/ICoTA Coiled Tubing Roundtable held in Houston, Texas, May 25-26.

112. Salahudin, Sharifudin, Conrad, Bruce and Maatjes, Rein, 1999: "Successful Application of Coiled-Tubing-Conveyed Perforating Techniques in Egyptian Wells," SPE 53297, presented at Middle East Oil Show and Conference held in Bahrain, February 20-23.

113. Samsonsen, B., Jacobsen, B.G., Skagestad, T. and Kerr, S., 1998: "Drilling and Completing a High-Angle Well With Coiled Tubing Technology," SPE 48941, presented at the 1998 SPE Annual Technical Conference and Exhibition held in New Orleans, Louisiana, September 27-30.

114. Sanchez, Alfredo, Samuel, G. Robello, and Johnson, Philip, 1996: "An Approach for the Selection and Design of Slim Downhole Motors for Coiled Tubing Drilling," SPE 37054, presented at the 1996 SPE Horizontal Drilling Conference held in Calgary, Canada, November 18-20. 
115. Sas-Jaworsky II, Alex, 1997: "New Guidelines Should Enhance Coiled Tubing Well Control Security," World Oil, December.

116. Selby, Bruce, Srinivasan, Nagan, Donnally, Bob, Vincent, Randy and Wilke, Jerry, 1998: "Hybrid Coiled Tubing System for Offshore Re-Entry Drilling and Workover," IADC/SPE 39374, presented at the 1998 IADC/SPE Drilling Conference held in Dallas, March 3-6.

117. Sjonberg, Geir, 1997: "Coiled Tubing Drilling: Successful Drilling Offshore in the North Sea," presented at the $5^{\text {th }}$ International Conference on: Coiled Tubing and Well Intervention held at the Sheraton Astrodome Hotel, Houston, Texas, February 4-6.

118. Sola, Sonny and Geddes, Bob, 1997: "Continuous Drilling Rig - CDR-01 'A Driller's Solution to a Drilling Problem,"' presented at the $19975^{\text {th }}$ Annual International Conference on Coiled Tubing Technology, Philip C. Crouse \& Associates, held in Dallas, Texas, January 8-10.

119. Sørgård, Eirik, Østvik, Egil, Grønnerød, Njål, Svanes, Grete, Villa, John, Salvesen, Tom and Tjåland, Lars, 1999: "Coiled Tubing Milling and Temporary Plug and Abandonment Operations," SPE 54472, presented at the 1999 SPE/ICoTA Coiled Tubing Roundtable held in Houston, Texas, May 25-26.

120. Sparkman, Gene, 1999: “Drilling the 'Perfect' Well," Hart's E\&P, December.

121. Stagg, Ted, 1997: "Overbalanced, Through Tubing, Coiled Tubing Drilled Horizontal Sidetracks in Prudhoe Bay West," presented at the $19979^{\text {th }}$ Annual International Conference on Horizontal Well Technologies and Applications, Philip C. Crouse \& Associates, held in Houston, Texas, August 25-27.

122. Stephens, Rodney, 1996: "Update on BPX (Alaska) CT Drilling," presented at the SPE/ICoTA Coiled Tubing Roundtable, held in Montgomery, Texas, February 26-28.

123. Streich, Steve; Briggs, Geoffrey; Blacic, Jim; Schilte, Paul; and Peterson, Carl, 2000: "Drilling Technology for Mars Research Useful for Oil, Gas Industries," Oil \& Gas Journal, April 24.

124. Strickland, David G. and Smith, Mike, 1997: "Concentric Workovers Successful in a Well Recovery Operation," World Oil, June.

125. Surewaard, J., Rea, T., Azoba, H., van Hoorn, Saville, P., van Kleef, R., Verwey, P. and Schoenmakers, J., 1997: "One Year Experience With Coiled Tubing Drilling," SPE/IADC 39260, presented at the 1997 SPE/IADC Middle East Drilling Technology Conference held in Bahrain, November 23-25.

126. Svendsen, Ø., Vassøy, Skogen, E., Mackin, F. and Normann, S.H., 1998: "Optimum Fluid Design for Drilling and Cementing a Well Drilled with Coil Tubing Technology," SPE 
50405, presented at the 1998 SPE International Conference on Horizontal Well Technology held in Calgary, November 1-4.

127. Svoboda, Charles and Murphy, John, 1997: "Overbalanced Coiled Tubing Drilling with Rheologically Engineered Drill In Fluids," presented at the $19975^{\text {th }}$ Annual International Conference on Coiled Tubing Technology, Philip C. Crouse \& Associates, Dallas, Texas, January 8-10.

128. Terry, Jim, 2000: "New Drilling System Bring Technology Step Change to Drilling Operations," The American Oil \& Gas Reporter, July.

129. Thatcher, Darren A.A., Szutiak, Greg A. and Lemay, Marc M., 2000: "Integration Driving New Efficiency, Value in Directional CT UBD," American Oil \& Gas Reporter, September.

130. Tinkham, Scott K., Meek, Dale E. and Staal, Timo W., 2000: "Wired BHA Applications in Underbalanced Coiled Tubing Drilling," IADC/SPE 59161, presented at the 2000 IADC/SPE Drilling Conference held in New Orleans, Louisiana, February 23-25.

131. Toler, Scott, 1997: "High Capacity Injector Head for Large OD CT and Jointed Tubing," presented at the $5^{\text {th }}$ International Conference on Coiled Tubing and Well Intervention, Houston, Texas, February 4-6.

132. Townsend, Steve, Onyia, Ernie and King, George, 1997: "Evaluation of Through Tubing Whipstock System to Exit Both 7-in. and 95/8-in. Casing Strings Using Coiled Tubing," presented at the $5^{\text {th }}$ International Conference on: Coiled Tubing and Well Intervention, Houston, Texas, February 4-6.

133. Turner, D.R., Harris, T.W.R., Slater, M., Yuratich, M.A. and Head, P.F., 1999: "Electrical Coiled-Tubing Drilling: A Smarter Drilling System," a synopsis of SPE 52791, Journal of Petroleum Technology, October.

134. Turner, Daniel R., Head, Philip F., Yuratich, Michael A. and Cameron, Gerald, 1999: "The All Electric BHA: Recent Developments Toward An Intelligent Coiled-Tubing Drilling System," SPE 54469, presented at the 1999 SPE/ICoTA Coiled Tubing Roundtable held in Houston, Texas, May 25-26.

135. Urayama, T.,Yonezawa, T., Hamada, M., Sugino, M., Takabe, H. and Ikeda, A., 2000: "Research and Development of Advanced Coiled Tubing," IADC/SPE 59164, presented at the 2000 IADC/SPE Drilling Conference held in New Orleans, Louisiana, February 23-25.

136. Vikane, E., Samsonsen, B. and Lorentzen, K.E., 1998: "Through Tubing Infill Drilling as a Method for Increased Oil Recovery," IADC/SPE 39358, presented at the 1998 IADC/SPE Drilling Conference held in Dallas, Texas, March 3-6. 
137. Villarroel, Nelson, Almanza, Edgar A., Scott, Martin, Vera, Isidro, Fernandez, Diego, Salazar, Arquimedez and Gomez, Luis, 1999: "Underbalanced Coiled-Tubing-Conveyed Perforating in a Deviated Well," a synopsis of SPE 54509, originally presented at the 1999 SPE/ICoTA Coiled Tubing Roundtable, Houston, Texas, May 25-26, Journal of Petroleum Technology, July.

138. Walton, Ian C. and Gu, Hongren, 1996: "Hydraulics Design in Coiled Tubing Drilling," SPE 36349, presented at SPE/ICoTA Roundtable held in Montgomery, Texas, February 26-28.

139. Weighill, G., Thoreby, H. and Myrholt, L., 1996: "Underbalanced Coiled Tubing Drilling Experience on the Ula Field," SPE 35544, presented at the European Production Operations Conference and Exhibition held in Stavanger, Norway, April 16-17.

140. Weighill, Geoffrey, Thoreby, Helge and Myrholt, Lars, 1997: "Underbalanced CoiledTubing Drilling Experience on the Ula Field," SPE Production \& Facilities, May.

141. Wodka, Philip, Tirsgaard, Adamsen, Carsten J., and Damgaard, Anders P., 1996: "Underbalanced Coiled-Tubing-Drilled Horizontal Well in the North Sea," Journal of Petroleum Technology, May. 


\section{Attachment 1 \\ Example CTD Check Lists}

Attachment 1 is a series of example check lists for planning and executing a CTD project. 


\section{Drilling Operations Check List}

1) $\quad \square \quad$ Was a pre-spud meeting held prior to start-up?

2) $\square \quad$ Are daily briefings held to discuss daily work program/ problems?

3) $\square \quad$ Is the drilling program discussed frequently in these meetings?

4) $\square \quad$ Are appropriate personnel certified in well-control training?

5) $\square$ Is the prescribed method of shutting in the well fully understood by the appropriate personnel?

6) $\square$ Have these personnel been instructed/trained in operating the wellhead/BOP equipment to shut in the well?

7) $\square \quad$ Are adequate materials available to increase mud weight as specified?

8) $\square \quad$ Do crews communicate at crew change?

9) $\square \quad$ Is a supervisor present at all crew changes?

10) $\square \quad$ Are there adequate means of communication between the CT operator and crew?

11) $\square$ Are changes to the approved drilling program communicated to the field personnel in writing?

\section{Safety Meetings/Drills Check List}

It is essential that all personnel be aware of the actions to be taken in an emergency situation.

1) $\square \quad$ Are weekly safety meetings held and attended by all personnel at the well site?

2) $\square \quad$ Are safety "time-out" meetings held prior to all non-routine operations or tasks?

3) $\square \quad$ Are safety drills held frequently?

4) $\square \quad$ Do all personnel understand their respective roles/duties during emergencies? 


\section{Written Instructions/Procedures Check List}

1) $\square \quad$ Are written instructions provided in the cabin concerning diverter drilling or other special problems?

2) $\square \quad$ Are written instructions provided daily and "as-needed" for special operations?

3) $\square \quad$ Is a detailed BOP test procedure in place?

4) Are written instructions/contingency plans provided for:

$\square \quad \mathrm{H}_{2} \mathrm{~S}$

$\square \quad$ Fire and evacuation

$\square \quad$ Major emergency involving underbalanced drilling

$\square \quad$ Emergency killing of well using kill fluids

$\square \quad$ Fishing operations

$\square \quad$ Pressure deployment

$\square \quad$ CT leak/failure

$\square \quad$ Wellhead/BOP leak

$\square \quad$ Well control

$\square \quad$ Severe fluid loss

$\square \quad$ Medical emergency

$\square \quad$ Drills

$\square \quad$ Safety meetings

$\square \quad$ Well-site security

$\square \quad$ Temporary suspension of operations/leaving well site

5) $\square \quad$ Are all of the above instructions discussed in safety meetings?

6) $\square \quad$ Are all personnel aware of these instructions and emergency procedures?

7) $\square \quad$ Is a plan posted showing escape routes, muster areas, and individual responsibilities in case of emergency?

8) $\square \quad$ Is a copy of the CT Contractor's Standards of Operation available at the site?

9) $\square \quad$ Is a copy of the Well-Control Manual available at the well site?

10) $\square \quad$ Are schematics of the wellhead/BOP/downhole tools maintained in the CT cabin? 


\section{Equipment Check List}

1) $\square \quad$ Is the equipment layout/setup safe and efficient?

2) $\square \quad$ Are all wellhead/BOP components in place, of the correct pressure rating, and functioning correctly?

3) $\square \quad$ Are weekly BOP tests conducted? At what frequency?

4) $\square \quad$ Are the BOP controls in a safe area? Is a secondary set required?

5) $\square \quad$ Is the mud system correctly sized for the well being drilled?

6) $\square \quad$ Is all equipment for solids removal correctly sized and working properly?

7) $\square \quad$ Is the choke manifold correctly sized and lined up properly?

8) $\square \quad$ Is the equipment for making up the BHA being used properly?

9) $\square \quad$ Are the necessary gas sensors in place and functioning?

10) $\square \quad$ Are these sensors frequently tested and calibrated?

11) $\square \quad$ Are crews trained and proficient in the use of the make-up equipment?

12) $\square \quad$ Has the fatigue life of the CT been checked and documented? 


\section{General Safety Check List}

The general safety aspects of a CTD operation have an impact in four main areas: well security, equipment, personnel, and the environment.

1) $\square \quad$ Are hazardous areas clearly marked?

2) $\square \quad$ Are handrails in place around the rig floor, mud pits and stairways?

3) $\square \quad$ Are any hazardous chemicals being used or present on location?

4) $\square \quad$ Are adequate instructions/precautions/first aid provided as per the MSDS sheet for these chemicals?

5) Is PPE being used as specified?
$\square \quad$ Boots
$\square$ Hardhats
घ Gloves
$\square \quad$ Hearing protectors
$\square \quad$ Nomex
D Safety glasses
$\square \quad$ Other as required

6) $\square \quad$ Are all ignition sources located in safe zones, or otherwise rated for the zone it is in?

7) $\square \quad$ Are first aid kits and eye-wash stations located as needed?

8) $\square \quad$ Does layout allow for escape routes from all areas occupied by personnel?

9) $\square \quad$ Is medical treatment readily available?

10) $\square \quad$ Is the overall well-site area neat and conducive to safe and efficient operations? 


\section{Documentation Check List}

1) $\square \quad$ Are all changes to the approved drilling program documented?

2) $\square \quad$ Are all written procedures in a readily available file for review?

3) $\square \quad$ Is a medical/first-aid log maintained?

4) $\square \quad$ Are all medical incidents reported and logged?

5) $\square \quad$ Are all drilling activities being logged on the prescribed IADC drilling report?

6) $\square \quad$ Are all well-control incidents recorded and reported?

7) $\square \quad$ Is there an accurate list of all personnel at the rig site?

8) $\square \quad$ Are all relevant operating/technical manuals readily available at the well site?

9) $\square$ Has a "look-back/follow-up" been completed with a review of the overall operation and any major problems or factors discussed and documented? 


\section{Attachment 2 \\ Example CTD Sidetrack Well Summary}

Following is an example of some of the data that should be documented following the CTD operations. This example uses one form to capture several aspects of the overall drilling project. The information may be reviewed quickly and simply, and future references can be completed efficiently. Supporting data for this information should be attached and entered into the database as appropriate. 


\section{Coiled Tubing Drilling}

Sidetrack Well Summary

\begin{tabular}{|c|c|c|c|c|c|c|}
\hline Well:[ & CTD Ex & \multicolumn{3}{|c|}{ Date Completed: } & $03 / 01 / 01$ & \\
\hline TD: & 8800 & Top & Window & 7000 & & Open Hole: \\
\hline
\end{tabular}

\section{Liner Summary}

\begin{tabular}{|c|c|c|c|c|c|c|c|}
\hline OD:[ & Weight: & 9.3 & Grade: & Threads: & STL & ID: & 2.992 \\
\hline Top of Liner: & 6,800 & & Bottom of Liner & 8,800 & & Cemented & $(\mathrm{Yes} / \mathrm{No})$ \\
\hline & & & & & & & no \\
\hline & & & PBTD & 8,800 & & & \\
\hline
\end{tabular}

\section{Logging Summary}

\begin{tabular}{|l|l|l|l|}
\hline \multicolumn{1}{|c|}{ Log Type } & Company & Top Log Interval & Bottom Log Interval \\
\hline NO LOGS & & & \\
\hline & & & \\
\hline & & & \\
\hline & & & \\
\hline & & & \\
\hline
\end{tabular}

\section{Perforating Summary}

Gun Specification: NO NEW PERFORATIONS

\begin{tabular}{|l|l|l|l|l|l|}
\hline Guns OD & Top & Bottom & Length & SPF & Comments \\
\hline & & & & & \\
\hline & & & & & \\
\hline & & & & & \\
\hline & & & & & \\
\hline & & & & & \\
\hline & & & & & \\
\hline & & & & & \\
\hline
\end{tabular}

Totals:

Fluid Summary

Type of Fluid in the Liner SEAWATER

Type of Fluid

Left in the Tubing

SEAWATER

\section{COMMENTS:}

Freeze Protect the Tubing

no yes/no

Flowline

Freeze Protected

NA

BP VALVE IN PLACE, FLOWLINE IS CONNECTED, WELL KILLED AND LEFT WITH KWF (SEAWATER) IN TUBING FLOWLINE WAS SHUT IN BEFORE RIG MOVED ON WELL. 


\section{Attachment 3 \\ Example CTD Wellbore Diagram}

A critically important element of the data set following CTD operations is the updated wellbore diagram. This diagram (see next page) provides a schematic and detailed data on the existing wellbore configuration and all equipment including depths and dimensions in the wellbore. All pertinent data for use in future workovers or service work on the well should be included here and noted. This is one piece of data that is utilized to determine mechanical integrity the well and feasibility of future work. The database should include this diagram and any associated tubing tallies and perforation data. Accuracy and continual updating of the wellbore diagram is of the utmost importance for all work being performed on a well. This is also typically required by the governing regulatory agency following completion of the well. 


\section{CTD Example Wellbore Diagram}

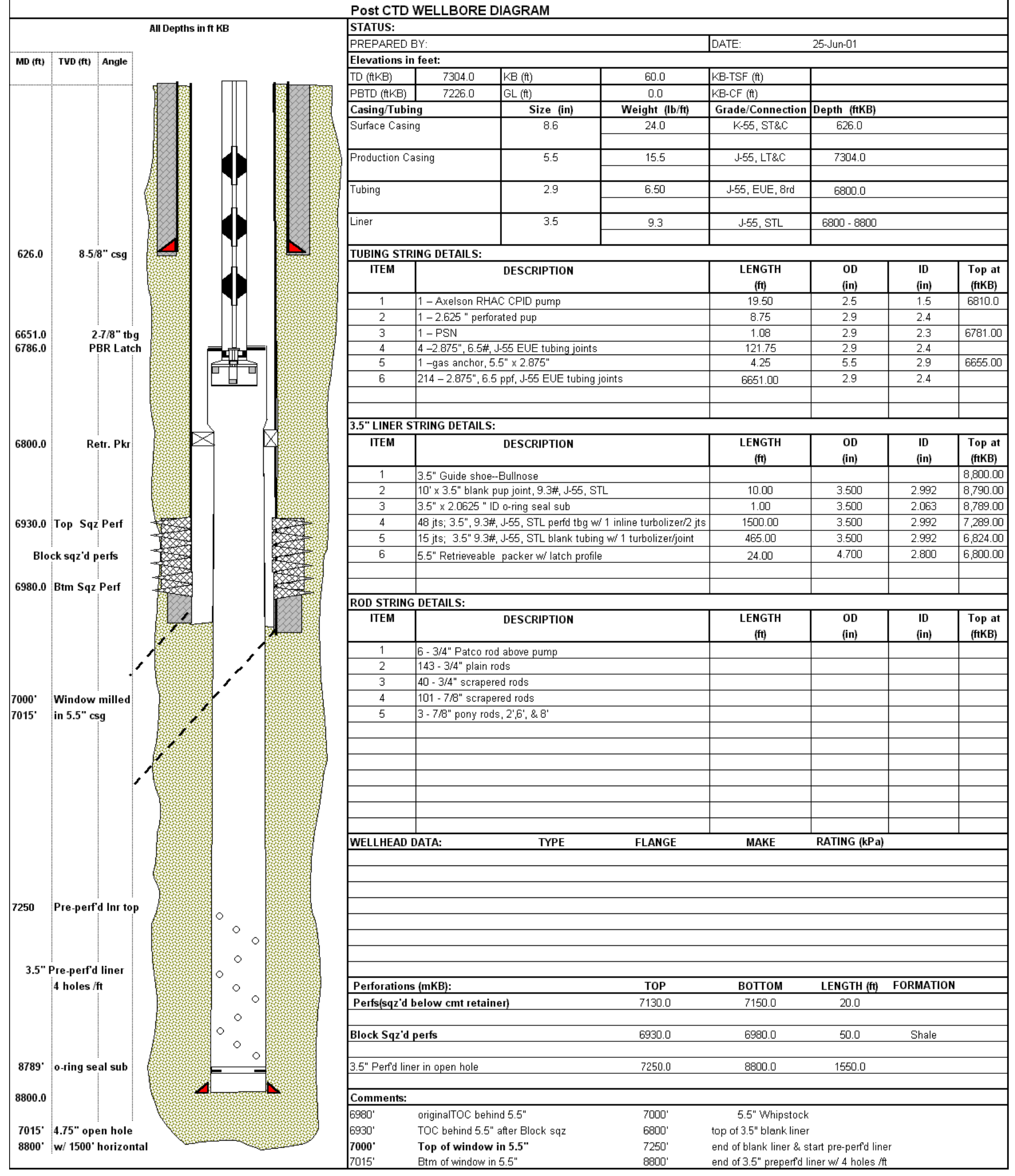




\section{Attachment 4 \\ Example CTD BOP Design}

The BOP configuration is required data to obtain approval from the regulatory agency of the CTD project. The BOP stack should have a pressure rating that is greater than the maximum anticipated surface pressure (MASP) plus the maximum expected surface pump pressure to which the stack will be exposed. MASP, as stated in API RP 5C7, is the highest pressure that may be encountered at the surface for the given operation. Typically MASP is calculated by subtracting the hydrostatic pressure exerted by a column of gas at the TVD of the formation open to the wellbore from the static bottom-hole pressure (SBHP) of the formation. The example diagram on the next page shows a typical BOP that, as required, accommodates the $\mathrm{CT}$ and the BHA/liner to be run. 


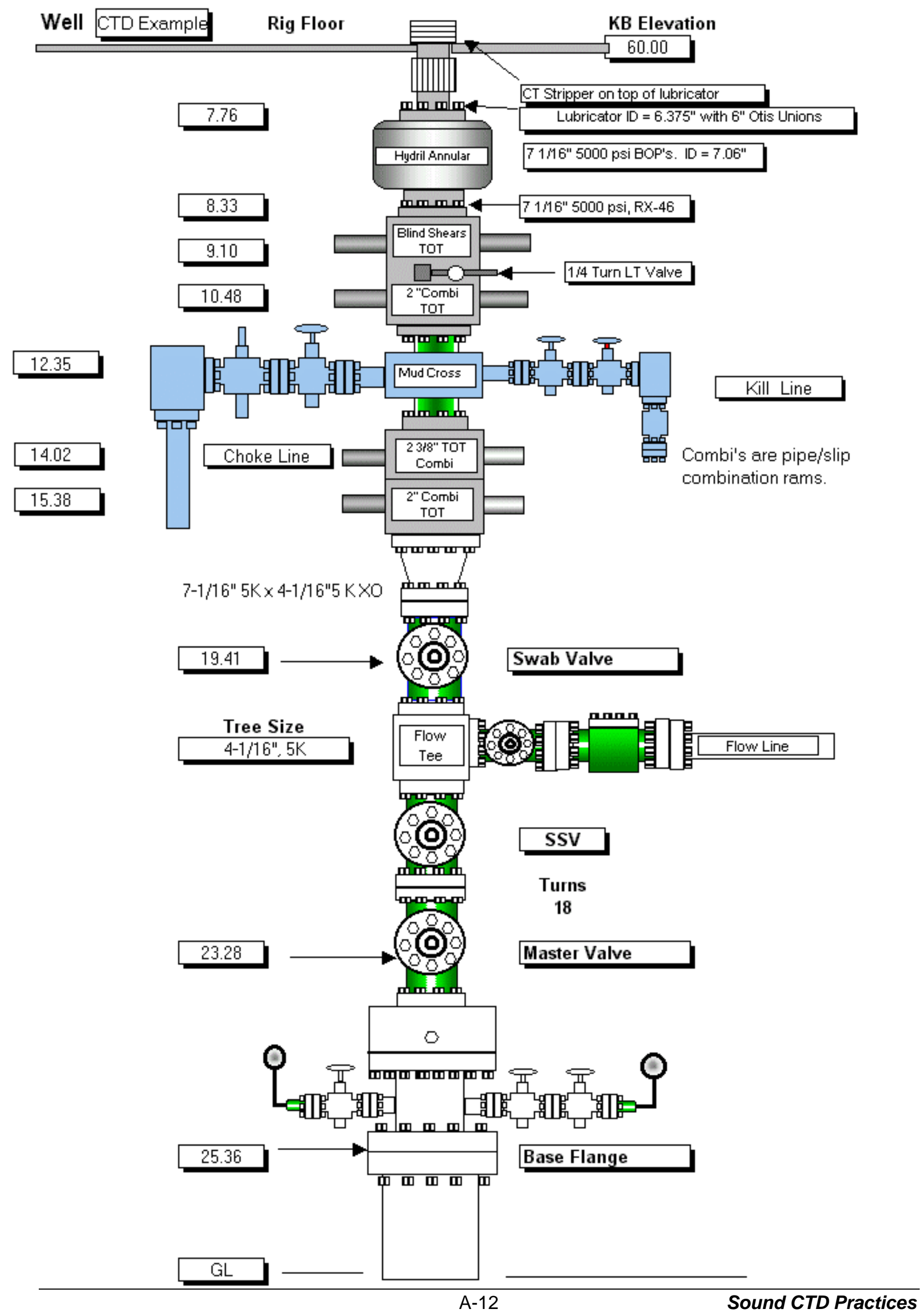




\section{Contact Points}

Brad Tomer, Product Manager

Gas Exploration, Production and Storage

(304) 285-4692, (304) 285-4469 fax

brad.tomer@netl.doe.gov

Albert B. Yost, Division Director

Gas Exploration, Production and Storage (304) 285-4479, (304) 285-4469 fax

albert.yost@netl.doe.gov

John D. Rogers, PhD., P.E., Project Manager

Gas Exploration, Production and Storage

(304) 285-4880, (304) 285-4469 fax

john.rogers@netl.doe.gov
Roy Long, Product Manager

Petroleum Exploration and Production (918) 699-2017, (918) 699-2005 fax

roy.long@npto.doe.gov

Gary L. Covatch, Project Manager Gas Exploration, Production and Storage (304) 285-4589, (304) 285-4469 fax gary.covatch@netl.doe.gov

\section{National Energy Technology Laboratory}

\section{Eastern Offices}

3610 Collins Ferry Road

P.O. Box 880

Morgantown, WV 26507-0880
626 Cochrans Mill Road

P.O. Box 10940

Pittsburgh, PA 15236-0940
National Petroleum Technology Office

One West Third Street

Suite 1400

Tulsa, OK 74103-3519

\section{Strategic Center for Natural Gas Website \\ www.netl.doe.gov/scng}

Bill Hauser, Petroleum Engineer

Engineering and Research Branch

(703) 787-1613, (703) 787-1093 fax

william.hauser@mms.gov

\section{Mineral Management Service}

381 Elden St.

Herndon, VA 20170 


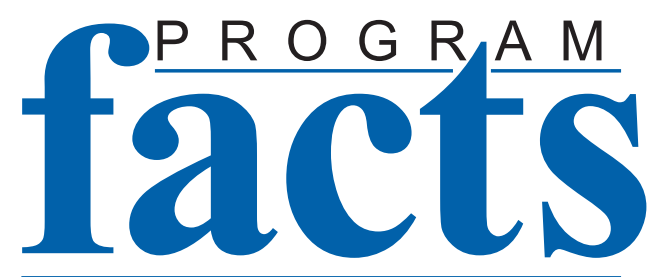

U.S. DEPARTMENT OF ENERGY

NATIONAL ENERGY TECHNOLOGY LABORATORY

\section{CONTACT POINTS}

Joseph P. Strakey

Director, SCNG

(412) 386-6124

joseph.strakey@netl.doe.gov

Leonard E. Graham

Deputy Director, SCNG

(304) 285-4714

leonard.graham@netl.doe.gov

\section{CUSTOMER SERVICE}

(800) 553-7681

\section{STRATEGIC CENTER FOR} NATURAL GAS WEBSITE

www.netl.doe.gov/scng

\section{The Strategic Center for Natural Gas Integrating all Elements of DOE's Natural Gas Technology Development from Borehole to Burner Tip}

The Strategic Center for Natural Gas (SCNG) is strategic in that we're looking at the big picture: planning for a future that allows the full potential of natural gas to be achieved.

The SCNG is a center, the focal point for DOE's natural gas technology program. As such, we are the one place anyone can come to for the most up-to-date information about natural gas research and development and analytical support for policy and regulation development.

The SCNG is a center for natural gas because natural gas will be the fuel of choice for the next 10 to 20 years. It is the most eco-friendly fossil fuel and will provide a smooth transition to our future energy economy.

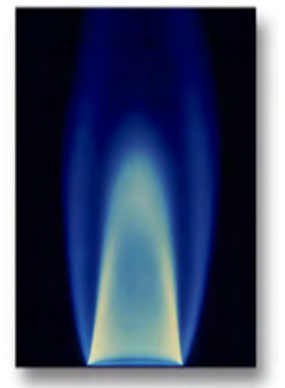

\section{Our Foundation}

The National Energy Technology Laboratory has a 50-year history in natural gas exploration and production, processing, storage, and end use research. We have identified the importance of unconventional natural gas resources by developing techniques to produce natural gas from coalbeds, recognizing the importance of gas hydrates, and sponsoring the first horizontal gas well in the U.S. In the end use area, recent focus has been on developing advanced technologies for fuel cells and advanced turbines.

\section{Our Approach}

National Strategic Planning - Work with industry, other Department of Energy (DOE) offices, and other government agencies to craft a comprehensive, balanced portfolio of research and development activities.

Exploration and Production - Ensure that the technologies needed to economically find and produce future supplies of natural gas are developed.

Infrastructure - Foster the development and deployment of technologies that guarantee the reliability, flexibility, and safety of the nation's gas delivery and storage infrastructure as it adapts to future needs.

End Use Technologies and Markets - Develop competitive, energy efficient, cost-effective means of using natural gas in new and existing markets though cost-shared research and development.

Policies and Regulations - Provide technical data and analytical tools for rational policy development. 


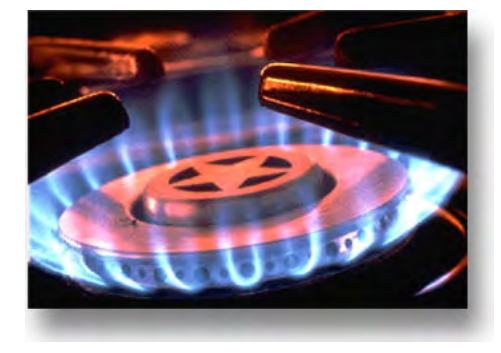

\section{PRODUCT AREA CONTACTS}

Gas Exploration,

Production, and Storage

Brad J. Tomer

(304) 285-4692

brad.tomer@netl.doe.gov

Advanced Turbines AND ENGINES

Abbie W. Layne

(304) 285-4603

abbie.layne@netl.doe.gov

Fuel Cells

Mark C. Williams

(304) 285-4747

mark.williams@netl.doe.gov

INFRASTRUCTURE RELIABILITY

Rodney J. Anderson

(304) 285-4709

rodney.anderson@netl.doe.gov

\section{PROJECT CONTACTS}

Gas Supply Project Division

Albert B. Yost II

(304) 285-4479

albert.yost@netl.doe.gov

Gas Power Projects

Division

Bruce R. Utz

(412) 386-5706

bruce.utz@netl.doe.gov

Combustion \& Engines

Dynamics Division

Daniel J. Maloney

(304) 285-4629

daniel.maloney@netl.doe.gov

\section{The Strategic Center for Natural Gas}

The demand for natural gas is growing. In 2020 the demand is projected to be almost 35 trillion cubic feet, or Tcf -50 percent more than our current consumption (Reference: EIA AEO 2001).

This demand cannot be met without a concerted effort from industry, regulators, landowners and the research community, and the SCNG will engage these communities in this technology challenge.

\section{Vision}

By 2020, U.S. public will be enjoying the benefits from an increase in gas use:

Affordable Supply - To meet our future needs, new and additional resources of natural gas must be made available. Technology innovations will make these new resources affordable.

Reliable Delivery - As demand for natural gas rapidly increases, unprecedented growth in new pipelines, compressor stations, and storage systems will require innovative materials and construction technologies to ensure a reliable and safe infrastructure.

Environmental Protection - Increasing our use of clean-burning natural gas and employing state-of-the-art natural gas technologies will decrease energy-related pollution.

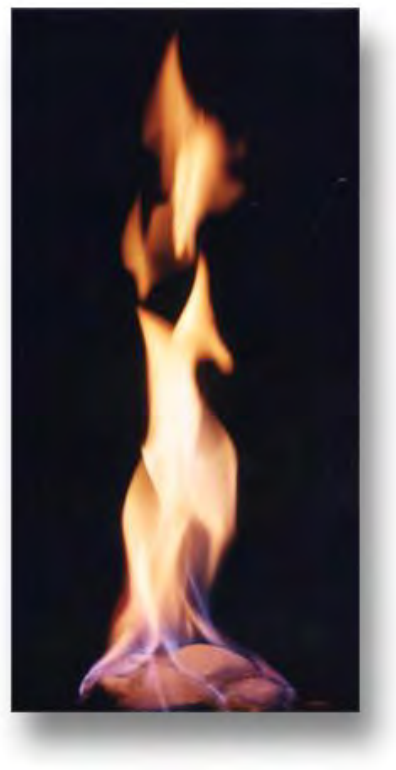

\section{There is a recognized need for coordinated action:}

The President's Committee of Advisors on Science and Technology recommended in 1995 that the Department of Energy develop a strategic research and development plan for natural gas.

The National Petroleum Council's December 1999 Natural Gas Report to the Secretary of Energy recommended that government and industry cooperatively establish a strategy for natural gas as part of the nation's energy portfolio.

The SCNG meets this need by providing a focal point within the Federal Government to coordinate research and development efforts and support policy development. We are ensuring that the United States' future requirements for natural gas will be met.

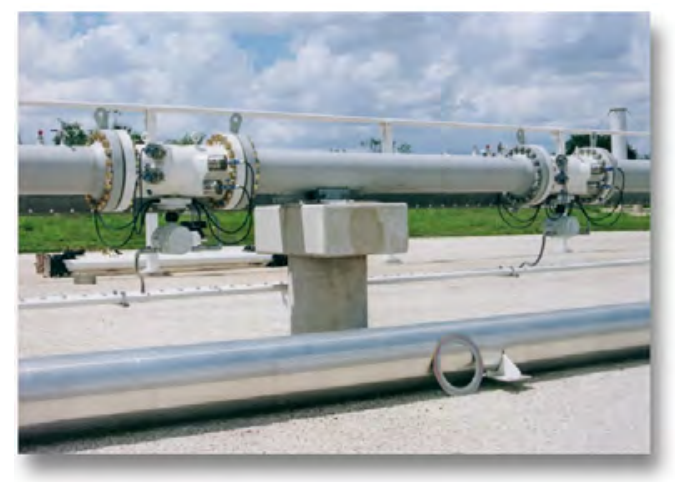




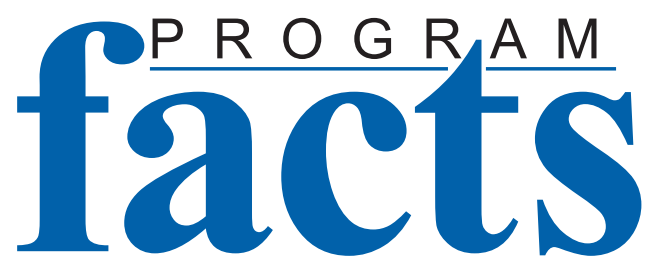

U.S. DEPARTMENT OF ENERGY

NATIONAL ENERGY TECHNOLOGY LABORATORY

\section{CONTACT POINT}

Brad Tomer

Product Manager

Gas Exploration, Production

and Storage

(304) 285-4692

(304) 285-4469 fax

brad.tomer@netl.doe.gov

\section{ADDRESS}

\section{National Energy Technology Laboratory \\ 3610 Collins Ferry Road \\ P.O. Box 880 \\ Morgantown, WV 26507-0880}

\section{STRATEGIC CENTER FOR NATURAL GAS WEBSITE}

www.netl.doe.gov/scng

\section{Gas Exploration, Production, and Storage}

The purpose of the Natural Gas Exploration, Production and Storage (GEPS) program is to partner with industry and others to develop environmentally friendly technologies that will steadily expand the nation's natural gas resource base. This partnership will ensure that adequate supplies of reasonably priced natural gas are available to meet expected demand.

The GEPS Program supports the development and deployment of a steady stream of products and technologies that will progressively expand the nation's recoverable resource base and improve the efficiency of the gas storage system. Program areas include Drilling Completion and Stimulation (DCS), Advanced Diagnostics and Imaging (ADIS), Stripper Well

Revitalization, Secondary Gas Recovery, Methane Hydrates, and Gas Storage Technologies.

The approach of the program is to work with industry, academia, non-profit trade organizations, other government agencies, and national labs to: 1) identify and characterize resources with significant unrealized production potential; 2) define the barriers currently blocking their production and distribution to market; 3 ) develop and test the most promising new approaches to overcoming these barriers; and 4) conduct demonstrations to support the commercialization of the most successful technologies and products.

In the Near Term (to 2005), the challenge is to maintain or reduce gas prices while sustaining high production rates. Therefore, NETL supports R\&D efforts that promise to:

- Enhance the efficiency of production from discovered reservoirs through advanced secondary gas recovery technologies, and effective transfer and application of existing technologies

- Arrest the premature abandonment of the nation's stripper gas wells through technologies developed under the Stripper Well Consortium

- Improve the deliverability of the nation's gas storage system through improved reservoir management practices for conventional storage and the development of advanced storage concepts to support new, high-volume gas demands 


\section{Gas Exploration, Production, and Storage}

The Mid Term (2005-2015) energy supply picture calls for continued rapid expansion of gas use that will depend heavily on full exploitation of the nation's vast store of "unconventional" (marginally-economic and/or high-risk) resource base. Therefore, the GEPS program contains R\&D, which will:

- Reduce drilling costs through technologies to increase rate of penetration, provide long-lasting multi-purpose bits, and lighter drilling rigs

- Provide critical information on unconventional resource volumes and characteristics through assessment of the distribution and potential of the nation's basin-centered and deep (>15,000 ft.) gas

- Deliver advanced exploration technologies for improved "sweet-spot" detection in low-permeability reservoirs featuring a tested, integrate system for natural fracture detection, prediction, simulation and characterization

- Improve the economics of marginal projects through improved completion and stimulation systems and demonstration of the benefits of horizontal drilling in fractured reservoir settings

Long Term (beyond 2015) gas supply is uncerta in. However, it is clear that contributions from new sources for natural gas will be needed. NETL is working on these issues now, with particular focus on:

- Enable dramatic reductions in the costs and risks of deep drilling through improved, real-time, downhole telemetry systems, progressively higher-pressure and higher temperature MWD and LWD equipment, and casing-while-drilling systems

- Enabling the production of gas hydrates by investigating 1 ) the occurrence and nature of gas hydrates, 2) issues of sea-floor stability, 3) the interaction of methane hydrates and global climate, and 4) potential hydrate

\section{Gas Needed to Meet Demand}

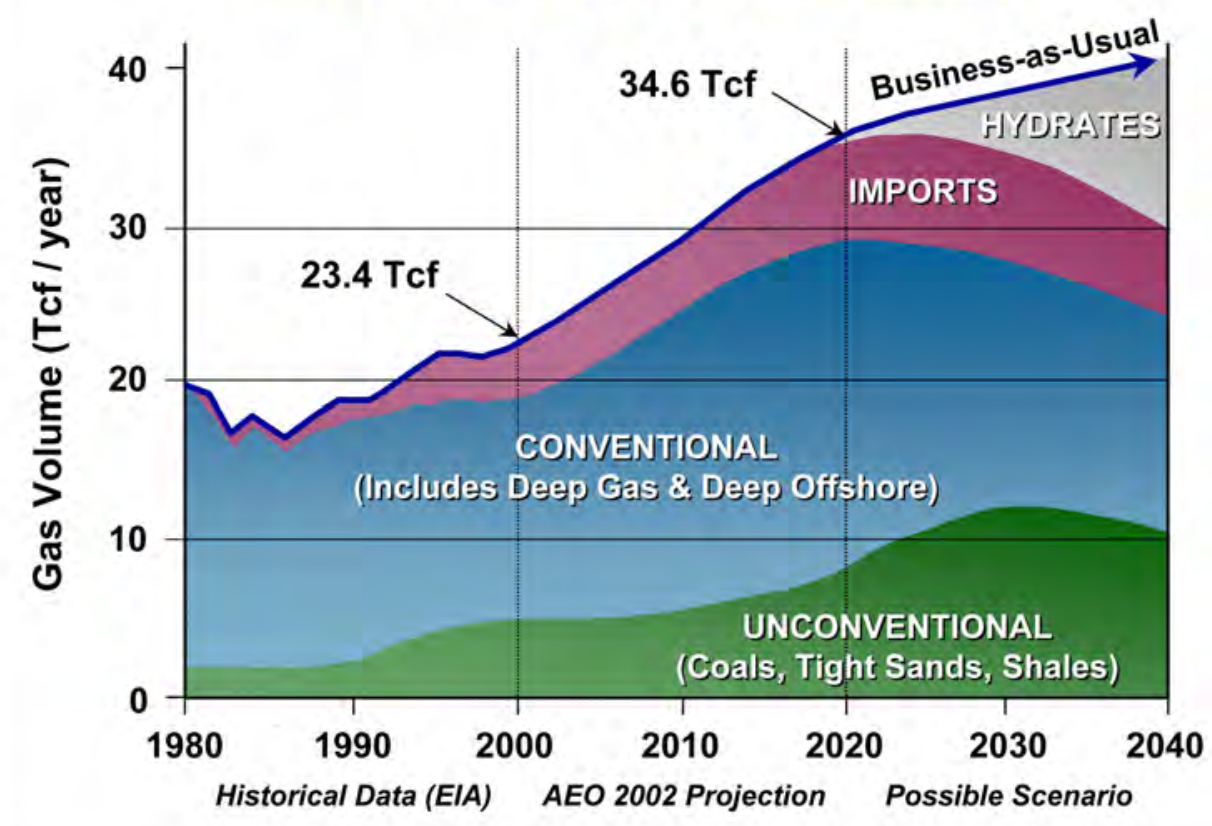




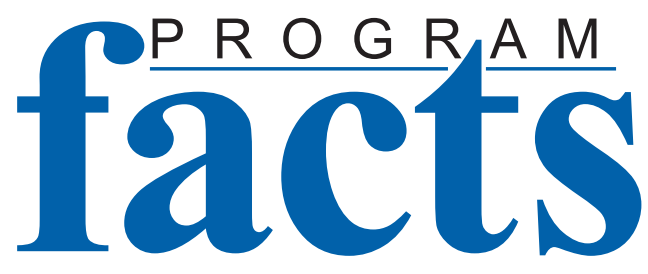

U.S. DEPARTMENT OF ENERGY

NATIONAL ENERGY TECHNOLOGY LABORATORY

\section{CONTACT POINTS}

Brad Tomer

Product Manager

Gas Exploration, Production

and Storage

(304) 285-4692

brad.tomer@netl.doe.gov

Albert Yost

Director

Gas Supply Projects Division

(304) 285-4479

albert.yost@netl.doe.gov

\section{John Rogers}

P roject Manager

(304) 285-4880

john.rogers@netl.doe.gov

\section{Bill Gwilliam}

Project Manager

(304) 285-4401

william.gwilliam@netl.doe.gov

\section{Gary Covatch}

Project Manager

(304) 285-4589

gary.covatch@netl.doe.gov

\section{STRATEGIC CENTER FOR NATURAL GAS WEBSITE}

www.netl.doe.gov/scng

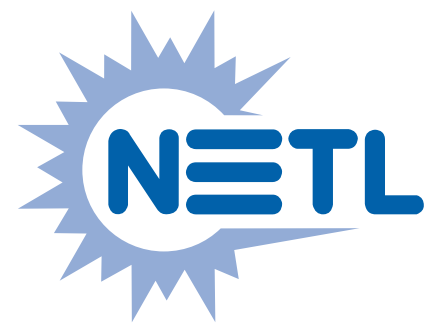

\section{Drilling, Completion, and Stimulation}

This technology area focuses on the development of new and improved technologies that can increase production from existing fields. Technologies under development can increase the value of producing wells in several ways: by increasing the rate of penetration or extending the drill bit life, by developing new methods for drilling faster, by eliminating formation damage, and by more effectively linking the formation to the borehole.

Advanced drilling systems currently being developed and demonstrated are:

- Advanced mud hammer and hammer engine technologies

- Optimization of mud hammer drilling performance

- High-pressure coiled tubing jet assist drilling system

- High temperature MWD/LWD systems

- Advanced designs forTSP bits

- Hydraulic pulse drilling system

- Microwave processing for advanced diamond composites

- High-power slimhole drilling system

- Advanced underbalanced drilling fluids

- Coiled tubing inspection system

- Underbalanced drilling products

- Downhole seismic source for "look ahead of bit"

- Microdrilling system

- Laser drilling system

- Composite drill pipe

- Advanced high baud two-way telemetry system

Advanced completion and stimulation technologies are focused on the following:

- Carbon dioxide/sand fracturing stimulation

- Non-damaging drill-in and completion fluids

- Downhole fluid analyzer

- Improved (high energy/low damage) perforation system

- Improved fracture diagnostics systems

- Real time fracture diagnostics

- Subsea separation system

- Ultra-lightweight cement 


\section{ADDRESS}

National Energy Technology Laboratory

3610 Collins Ferry Road P.O. Box 880

Morgantown, WV 26507-0880

(304) 285-4469 fax

626 Cochrans Mill Road P.O. Box 10940

Pittsburgh, PA 15236-0940

(412) 386-4604 fax

\section{Drilling, Completion, and Stimulation}

\section{Current Activities}

- Conventional Drilling System Efficiency

- Advanced Slim-Hole Motor/TSP BitDrilling System

- Mud Hammer Drilling System

- O ptimization of Mud Hammer Drilling Performance

- High Temperature (195 C) MWD

- High Temperature (175 C) LWD

- Coiled tubing inspection system

\section{- Under Balanced Drilling Systems}

- Risk Analysis Software

- New Concept Drilling System/Components

- Microwave Processed Components and BHA Hardening

- High P ressure Coiled-Tubing Drilling System

- Hydraulic Pulse Drilling System

- Integrated Downhole Hammer Engine

- New Aggressive TSP Cutter Design

- Advanced Microdrilling

- Downhole Seismic Source for Pore P ressure P rediction

- Laser Drilling System

- Composite Drill Pipe

- Advanced High Baud Two-way Telemetry System

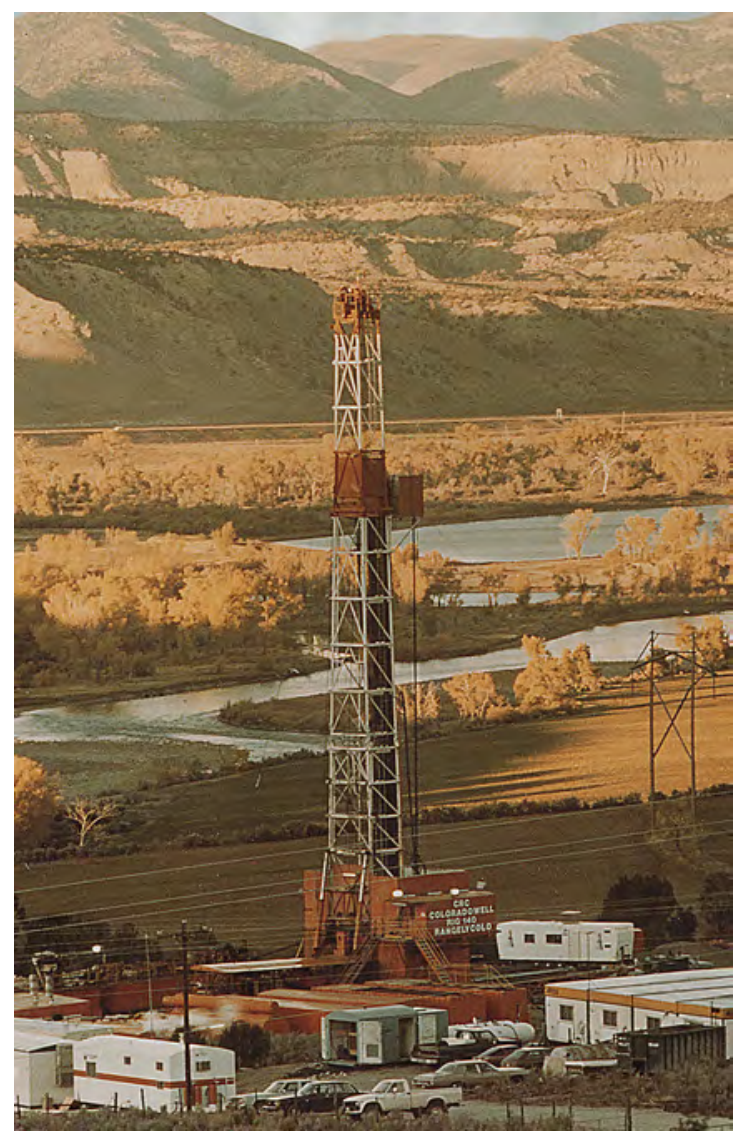

\section{- Advanced Completion and Stimulation Systems}

- $\mathrm{CO}_{2}$ S and F racturing

- New Non-Damaging Drill-In and Completion Fluids

- Downhole Fluid Analyzer

- Subsea Separation System

- Ultra-Lightweight Cement

\section{- Supporting DCS Research}

- Riser Wear S tudy (DEA-137)

- Acoustic Telemetry (SNL)

- Ceramic Borehole Sealants (ANL)

- S mart Proppants for F racturing (INEEL)

- Simulation of Near Wellbore Mechanics (SNL) 